\title{
Factores pronósticos en implantología oral
}

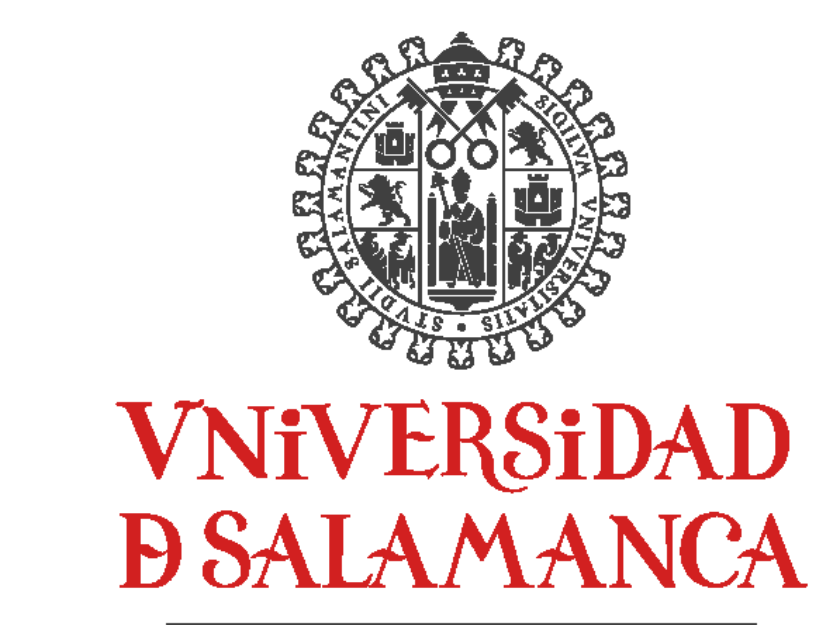

CAMPUS DE EXCELENCIA INTERNACIONAL

Tesis Doctoral.

Departamento de Cirugía Facultad de Medicina

Autor: Guillermo Manzano Martínez

Director: Javier Montero Martín 
DON JAVIER MONTERO MARTÍN,

PROFESOR TITULAR DE PRÓTESIS ESTOMATOLÓGICA DEL DEPARTAMENTO DE CIRUGÍA DE LA UNIVERSIDAD DE SALAMANCA.

\section{CERTIFICA:}

Que la Tesis Doctoral titulada: FACTORES PRONÓSTICO EN IMPLANTOLOGÍA ORAL, de la que es autor D. Guillermo Manzano Martínez ha sido realizada en el Departamento de Cirugía de la Facultad de Medicina bajo mi dirección y supervisión, reuniendo, en mi opinión todos los requisitos para ser presentada y defendida para la obtención del Grado de Doctor por la Universidad de Salamanca.

Lo que firmo en Salamanca a 1 de Mayo de 2016 para que así conste a los efectos oportunos donde convenga.

Fdo: Javier Montero Martín 
PRF. DR. D. FRANCISCO SANTIAGO LOZANO SÁNCHEZ. DIRECTOR DEL DEPARTAMENTO DE CIRUGÍA DE LA FACULTAD DE MEDICINA DE LA UNIVERSIDAD DE SALAMANCA.

\section{CERTIFICA:}

Que el presente Trabajo de Tesis Doctoral, titulado " FACTORES PRONÓSTICO EN IMPLANTOLOGÍA ORAL", ha sido realizado por Don Guillermo Manzano Martínez en el Departamento de Cirugía de la Universidad de Salamanca, cumpliendo los requisitos necesarios para su presentación y defensa ante el tribunal evaluatorio.

Y para que así conste donde convenga y obren los efectos oportunos, expido el presente certificado en Salamanca a 15 de Mayo de 2016.

Fdo: Prof. Dr. D. Francisco Santiago Lozano Sánchez Director del Departamento de Cirugía 


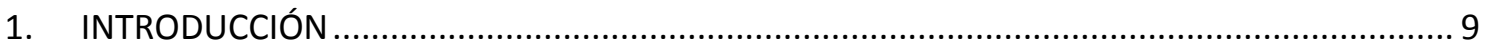

1.1 Antecedentes históricos y situación actual....................................................................... 11

1.2 El Implante dental: características técnicas, evolución e innovación............................... 13

1.2.1 Evolución de las características macroscópicas de los implantes endoóseos ............ 13

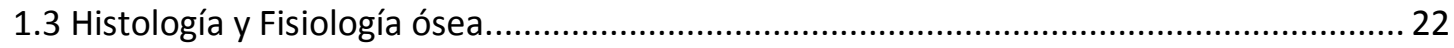

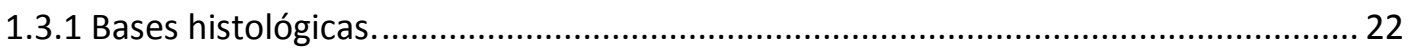

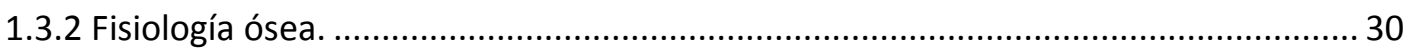

1.3.3 Evolución de los procedimientos de regeneración ósea............................................ 39

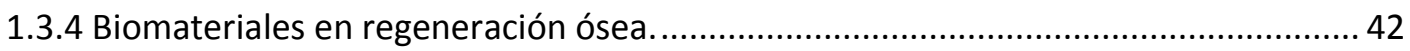

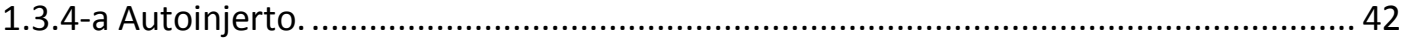

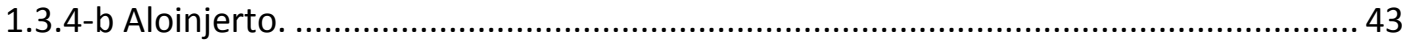

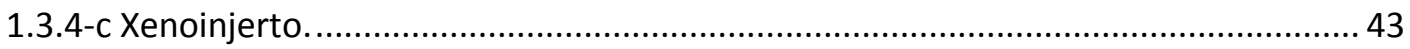

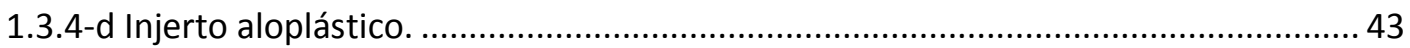

1.4 Determinantes de la osteointegración de los implantes dentales. ....................................4 44

1.5 Complicaciones de la fase protética en rehabilitaciones implantosoportadas. ................ 46

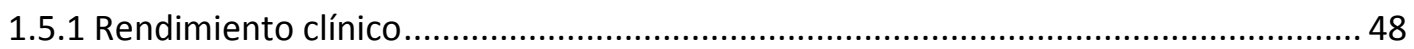

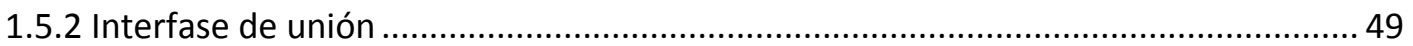

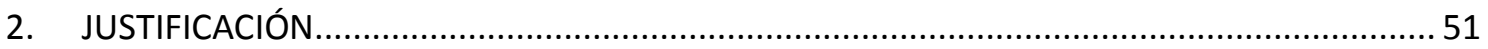

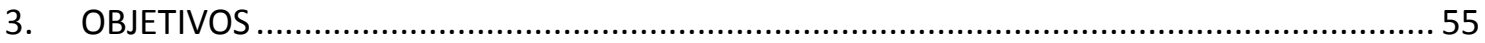

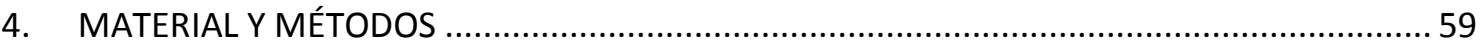

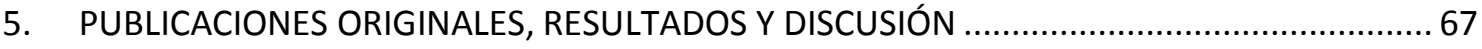

5.1 Comparativa del comportamiento clínico de los implantes de zirconio con los implantes

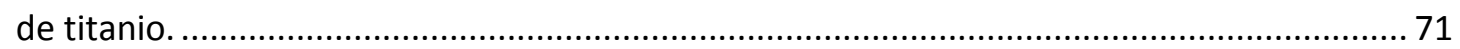

5.2 Efecto de la Simvastatina sobre la regeneración ósea....................................................... 79

5.2.1 Fundamentos bioquímicos de la simvastatina tópica sobre el tejido óseo .................8 80

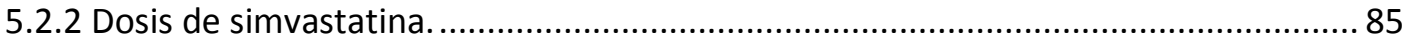

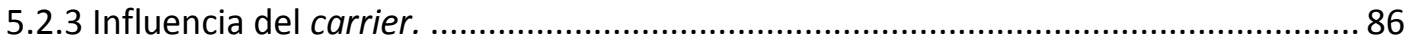

5.3 Factores de riesgo que participan en el fracaso temprano en implantología. .................. 91

5.3.1 Factores de riesgo relacionados con el paciente ........................................................ 95

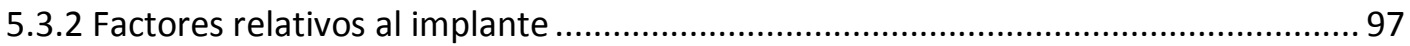

5.4 Evaluación clínica de la incidencia de complicaciones protéticas en coronas implantosoportadas realizadas sobre pilares tipo UCLA. 


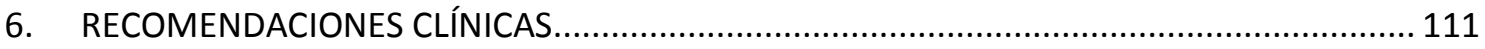

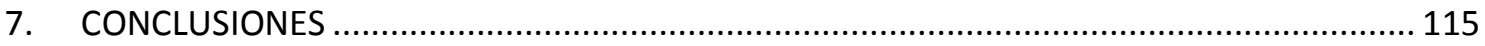

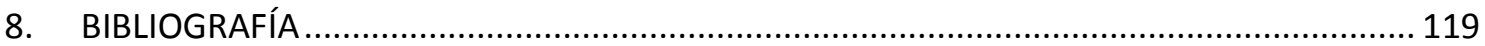

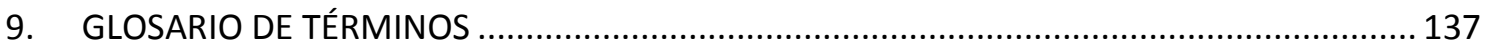




\section{INTRODUCCIÓN}




\subsection{Antecedentes históricos y situación actual.}

La implantología oral ha revolucionado la práctica odontológica y ha tenido un rápido desarrollo en los últimos años. Después de la evidencia científica del éxito de la osteointegración de los implantes y del conocimiento de los fenómenos biológicos de dicho proceso, la tendencia ha sido hacia la simplificación de la técnica quirúrgica y prostodóncica para extenderlas entre la profesión dental. Los protocolos clínicos han ido evolucionando a su vez, casi siempre encaminados a acortar tiempos de espera entre fases del tratamiento de rehabilitación sobre implantes pero sin perder por ello predictibilidad del tratamiento, eficacia y calidad (1). Pero no solo el objetivo ha sido acortar el tiempo de espera en las fases quirúrgicas y prostodónticas del tratamiento, sino que también se ha avanzado mucho en otros aspectos, como puede ser en la posibilidad de colocación de implantes en zonas donde la calidad, cantidad y topografía óseas no son favorables (1)

Los implantes dentales tienen una historia de varios siglos que comienzan con las primeras civilizaciones hace más de 2.000 años en América del Sur y del Norte y las regiones del Asia Central y el Mediterráneo. Los hallazgos arqueológicos han indicado que estas civilizaciones reemplazaban dientes perdidos mediante tallados de piedra, conchas, huesos y oro (2)

Alrededor de 1930, excavaciones arqueológicas en Honduras revelaron que la civilización maya tuvo los primeros ejemplos conocidos de los implantes dentales, que data de alrededor del año 600 dC, cuando se encontró un fragmento de mandíbula con implantes. El espécimen tenía tres conchas talladas en forma de diente colocadas en los alveolos de los incisivos inferiores. Estudios posteriores de este caso confirmaron la existencia de hueso compacto y maduro alrededor de dos de dichos implantes (2)

En la Edad Media, se surgió el uso de aloinjertos y xenoinjertos. Sin embargo, esta práctica no llegó a ser muy popular, ya que este tipo de procedimientos fueron identificados como la causa de las enfermedades infecciosas e incluso muerte.

La historia moderna de la implantología dental comienza durante la Segunda Guerra Mundial, cuando en los años de servicio en el ejército, el Dr. Norman Goldberg pensó en la posibilidad de realizar restauraciones dentales utilizando metales que se 
usaban para reemplazar a otras partes del cuerpo 12. Más tarde, en 1948, en asociación con el Dr. Aaron Gershkoff, produjeron el primer implante subperióstico. (2)

Uno de los acontecimientos más importantes de la implantología dental se produjo en 1957, cuando un cirujano ortopédico sueco llamado Per-Ingvar Brånemark estudiando los procesos de cicatrización y regeneración ósea, descubrió que el hueso crecía en cercanía con el titanio (Ti), y que podía adherirse al metal sin ocasionar ningún tipo de reacción de rechazo. Branemark llamó a este fenómeno "osteointegración", llevando a cabo muchos más estudios animales y ensayos clínicos en seres humanos. En 1965, colocó los primeros implantes dentales Ti en un paciente de 34 años de edad, con dientes perdidos debido a graves deformidades de la barbilla y la mandíbula. Brånemark inserta cuatro fijaciones de Ti en la mandíbula del paciente, y varios meses más tarde utilizó colocó una prótesis fija. Los implantes dentales estuvieron en boca más de $\mathbf{4 0}$ años, hasta el final de la vida del paciente $(3,4)$.

En mayo de 1982, Brånemark presentó los resultados de sus 15 años de investigación en la Conferencia de Toronto el Osteointegración en Odontología Clínica (5). En ese mismo año, la FDA (Food and Drug Administration) de Estados Unidos aprobó el uso de implantes dentales de Ti, y en 1983, el doctor Matts Andersson desarrolló el Procera (Nobel Biocare, Zurich, Suiza), que consistía en el diseño y fabricación asistida por ordenador (CAD / CAM) de coronas dentales. Este método ofrece una alta precisión y la posibilidad de replicar con absoluta exactitud las unidades fabricadas tantas veces como sea necesario (2).

El desarrollo de la cerámica moderna se inició en 1992. A partir de ese momento, se han incorporado tratamientos de superficie de cerámica y elementos de cerámica a los implantes con el fin de mejorar la osteointegración de los mismos, bien sea aumentando la superficie del implante en contacto con el mismo y/o aumentando la velocidad del proceso (6).

Hoy en día, en el mundo se están colocando unos 450.000 implantes dentales osteointegrados, con una expectativa del 95\% de éxito (en el caso de sustitución de un solo diente con una corona con el apoyo del implante), con un mínimo de riesgos y complicaciones asociadas (2). 


\subsection{El Implante dental: características técnicas, evolución e innovación.}

Principalmente, cuatro han sido los diseños de implantes que se han desarrollado y utilizado en la odontología clínica a lo largo de la historia moderna de la implantología: implantes subperiósticos, en forma de hoja o lámina perforada, en forma de rama e implantes endo-óseos. Estos últimos son los utilizados hoy en día y sobre los que nos vamos a centrar en su evolución.

Por lo general, los implantes dentales están hechos de titanio de grado 4 porque es resistente y más fuerte. Sin embargo, se utilizan también aleaciones de Ti, principalmente Ti6Al4V , ya que es más fuerte y más resistente a la fatiga que el Titanio puro (7). Varios parámetros en el diseño de los implantes endo-óseos afectan a las tasas de supervivencia de los implantes, incluyendo: la forma del cuerpo, tamaño, composición química de la superficie, y las características topográficas entre otros factores. $(2,7,8)$. También es conveniente destacar, que nuevos materiales como el zirconio se utilizan cada vez más combinados con diseños y tratamientos de superficie similares a los del titanio (6)

\subsubsection{Evolución de las características macroscópicas de los implantes endoóseos}

Los implantes dentales están diseñados para lograr una estabilidad mecánica primaria y promover una fuerte interacción hueso-implante en el tiempo a través del fenómeno de osteointegración (8). Para los implantes endoóseos, hay tres principales factores a nivel macroscópico: 1) roscas, 2) diseños de ajuste a presión del cuerpo sólido (cilíndricos, cónicos), y / o 3) diseños del recubrimiento. Cada configuración afecta a las propiedades biomecánicas a largo plazo en la interfase hueso-implante y en gran medida va a determinar el éxito o el fracaso del implante, ya que una forma óptima permitirá una distribución equitativa de la tensión a la matriz del hueso circundante que favorecerá el crecimiento del hueso circundante. En caso de que no se den unas 
condiciones favorables, se provocará lo contrario, es decir, la reabsorción ósea entorno al implante (9).

\section{Conexión Implante-pilar}

La función de la conexión es proporcionar una solución para atornillar el cuerpo del implante anclado en el hueso al pilar sobre el cual se colocará la prótesis (10). Hay 2 formas básicas de conexión: interna o externa, con multitud de formas geométricas dependiendo del fabricante, las cuales también han seguido una evolución a lo largo de los años en su diseño. En cualquier caso, con respecto a la conexión ésta debe evitar la rotación del pilar y permitir el recambio del componente protésico en caso de ser necesario (11).

\section{Materiales y diseño macroscópico del cuerpo del implante}

La biocompatibilidad no sólo implica la compatibilidad del material con el tejido, sino también la acuidad de dicho material para realizar la función para la que ha sido diseñado. En el caso de los implantes dentales, la biocompatibilidad de los materiales se evalúa mediante el estudio del Bone to Implant Contact (BIC), que consiste en medir la cantidad de superficie ósea en contacto con la superficie implantaría, permitiendo de esta forma evaluar la osteointegración de los mismos $(7,8,12)$. Por lo tanto, las siguientes variables son fundamentales y deben ser consideradas en el diseño de los implantes: composición del material, ancho y longitud del implante, geometría, características de la superficie, etc. Variables como el estado médico del paciente, calidad y anatomía ósea del sitio a implantar y la técnica quirúrgica empleada van a influenciar en el diseño de implantes dentales específicos para situaciones concretas (13).

\section{Biomateriales}

Los biomateriales utilizados para la fabricación de implantes dentales incluyen metales, cerámicas, carbonos, polímeros, y combinaciones de éstos.

El titanio, incluyendo aleación Ti-6Al-4V (Ti-6 de aluminio-vanadio 4), es el primer material moderno usado para los implantes dentales, y sigue siendo uno de los más utilizados en los implantes dentales contemporáneos. El titanio comercialmente puro es un metal ligero con excelente biocompatibilidad, rigidez relativamente alta y alta 
resistencia a corrosión. Sin embargo, cuando se expone al aire, se forma un óxido superficial y esta capa de óxido determina la Respuesta biológica. Esta capa de óxido es una interfaz dinámica que actúa como plataforma para la aposición de hueso (12).

Otros metales se han utilizado para la osteointegración, incluyendo circonio, oro y aleaciones de titanio-aluminio-vanadio .

Biocerámicas como hidroxiapatita también se han utilizado como recubrimientos de plasma pulverizado sobre una estructura metálica porque, a pesar de su baja resistencia, han demostrado una excelente biocompatibilidad y capacidad para integrarse con los tejidos duros (12).

\section{Diseño macroscópico.}

Una amplia variedad de diferentes tamaños y formas de los implantes han evolucionado para adaptarse a los conceptos quirúrgicos actuales y mejorar el tratamiento del paciente. La investigación ha revelado que los cambios sutiles en la forma, longitud y anchura de los implantes podrían influir en las tasas de éxito (13).

\section{Longitud}

La longitud del implante y el diámetro tienen una influencia en la distribución de tensiones en la interfase hueso-implante, así como en las tasas de éxito (13-17). La longitud del implante es la dimensión desde la plataforma hasta el ápice de implante. Clásicamente se acepta que los implantes más largos garantizan mejores tasas de éxito y el pronóstico; y que los implantes más cortos tienen tasas de éxito estadísticamente más bajos debido a la estabilidad reducida, lo cual puede explicarse en términos de menos hueso al contacto implante $(13,16,17)$. Sin embargo, se prefieren los implantes cortos o estrechos para la solución protésica del áreas hueso alveolar extremadamente reabsorbido $(14,15)$.

\section{Diámetro}

El diámetro del implante se mide desde el punto de un hilo hasta el punto opuesto en la zona del implante más ancha y típicamente oscila entre 3 y $7 \mathrm{~mm}$; aunque los implantes de diámetro más estrecho se pueden utilizar en espacios limitadas, los clínicos seleccionan el diámetro del implante mayor que permitan las características del caso para obtener la mayor tasa de contacto hueso - implante (Bone Implant Contact = BIC) (13-17). 


\section{Geometría}

Una de las principales preocupaciones en cuanto al diseño es la forma del implante, ya que la geometría afecta a la interacción entre el hueso y el implante, el área superficial, la distribución de fuerzas en el hueso y la estabilidad de la implante. Por lo tanto, los implantes dentales se clasifican en diferentes grupos de acuerdo con su forma. Los principales tipos de implantes son cilíndricos, cónicos, escalonada, en forma de tornillo, y cilíndrico hueco. Varios estudios revelaron que las superficies de implantes cónicos o superficies con discontinuidades geométricas resultaron en tensiones más altas que las formas más suaves tales como cilíndrica o la cónica, por ello son las formas más extendidas $(8,12)$.

Roscas

Como se mencionó anteriormente, las roscas se incorporan en los implantes con el fin de mejorar la estabilidad inicial, ampliar el área de superficie del implante, distribuir favorablemente el estrés y reducir al mínimo la cantidad de tensiones adversas en la interfaz hueso-implante. El perfil de la rosca se caracteriza por la profundidad, tono (número de hilos por unidad de longitud), ángulo de flanco, el radio superior de curvatura, y la parte recta en la parte inferior de la rosca. Diferentes modificaciones en los patrones de rosca tales como micro-hilos cerca del cuello del implante, se han empleado macro-roscas en la mitad del cuerpo, y la variedad de roscas de paso alterados para acentuar el efecto de hilos e inducir un comportamiento biomecánico deseado (18).

\section{Características de la superficie}

Cuando un material se coloca en el cuerpo, se desencadena una respuesta biológica que es mediada por la interacción del implante a través de su superficie con el hueso circundante. Las características a nivel microscópico de la superficie influyen en el nivel de osteointegración, medido en términos de BIC (Bone Implant Contact). Dos de los factores más importantes que afectan a la calidad y la velocidad de osteointegración son la naturaleza física y química de la superficie del implante. Estas propiedades también tienen un efecto sobre el mantenimiento de los tejidos blandos y hueso circundante alrededor de la implante $(8,9)$.

A fin de aumentar la tasa de éxito de los implantes dentales, la investigación se ha centrado en el control de las propiedades de superficie tales como la morfología, la 
topografía, la rugosidad, la composición química, energía de superficie, la tensión residual, la existencia de impurezas, espesor de película de óxido de Ti, y la presencia de compuestos metálicos y no metálicos en la superficie. Estas propiedades influyen profundamente en la respuesta ósea y el tejido respecto al implante, ya sea aumentando o disminuyendo los tiempos de curación y osteointegración. La investigación ha demostrado que las células osteoblásticas se adhieren más rápidamente a las superficies rugosas que a superficies lisas y pulidas. Esta propiedad también puede producir la llamada y el posicionamiento de estirpes celulares específicas, llegando a plantearse la posibilidad de poder afectar directamente a la forma celular y a su función (8).

Hay dos grandes tipos de tratamiento de superficie desde el punto de vista químico: 1) Adicción de una fase inorgánica a la superficie implantaria (por ejemplo, hidroxiapatita de calcio o fosfatos) y 2) adicción de fases orgánicas (como por ejemplo factores de crecimiento) $(9,12)$. La adicción de fases inorgánicas tales como fosfatos de calcio aporta propiedades osteoconductivas al implante. El recubrimiento de los implantes de titanio con fosfatos de calcio aumenta la velocidad a la que se produce la formación de hueso (7). Los implantes de titanio también pueden ser revestidos con hidroxiapatita, pulverizando la superficie del implante mediante un plasma de hidroxiapatita formando una película inorgánica(9). Aunque este recubrimiento sirve para aumentar la osteoinducción, el enlace entre la película inorgánica y la superficie del implante es un factor limitante en la eficacia de los revestimientos inorgánicos: si las partículas se desprenden de la superficie implantaria o sufren algún tipo de alteración pueden causar el fracaso en la osteointegración del implante, es decir, el efecto contrario para el que fueron concebidas $(2,7,9,12)$. Por ello las técnicas de modificación de superficie del implante dental mediante adición de partículas inorgánicas han caído en desuso, imponiéndose técnicas tales como el arenado o el grabado ácido para crear dichas micro-rugosidades en la superficie del implante que le aporten una superficie con unas características que favorezcan y agilicen el proceso de osteointegración del mismo $(2,7,9,12)$.

Para aumentar la rugosidad de la superficie, se han descrito los siguientes métodos. 


\section{Mecanizado}

Una vez fabricada la estructura del implante, éste se somete a procedimientos de limpieza, descontaminación, pasivación y esterilización; pero no existe un procedimiento en el cual se modifique la superficie de forma específica de forma adicional al procedimiento puramente físico de fabricación del mismo. La superficie obtenida es la resultante de las características propias del material utilizado para la fabricación del implante (9).

\section{Pulverización de plasma}

Consiste en utilizar diferentes sustancias en forma de polvo (por ejemplo, Ti o fosfatos de calcio) los cuales se calientan a altas temperaturas y se proyectan sobre la superficie de implantaria formando recubrimientos de entre 30 a 50 micras de espesor. Esta técnica confiere a la superficie del implante una rugosidad media de $7 \mu \mathrm{m}(2)$, aumentando el área de superficie del implante hasta 6 veces si la comparamos con la misma superficie sin tratar $(9,12)$. Cabe destacar que el espesor del recubrimiento va a depender de diversos factores tales como el tamaño de partícula, la velocidad y momento del impacto, la temperatura y la distancia desde la punta de la boquilla a la superficie del implante a pulverizar. Este espesor del recubrimiento normalmente oscila entre 10 y 40 micras en el caso de pulverizado con partículas de titanio y entre 50 y 70 micras para la hidroxiapatita. Sin embargo, los estudios han demostrado que estos recubrimientos pueden ser parcialmente disueltos o reabsorbidos después de largos períodos de función. La delaminación o reabsorción del recubrimiento pueden causar una pérdida de la integridad mecánica y reacciones biológicas adversas, pudiendo provocar fenómenos clínicos como la periimplantitis $(7-9,12)$.

\section{Granallado}

Este es uno de los métodos más frecuentemente utilizados para el tratamiento de las superficies de los implantes dentales, que consiste en aumentar la rugosidad de la misma mediante la proyección de partículas duras (habitualmente partículas de alúmina o de óxido de titanio) sobre la superficie implantaria (9). La rugosidad obtenida mediante este método va a depender del tamaño de la partícula proyectada, el tiempo durante el cual dicha superficie implantaria ha estado sometida al procedimiento de granallado, de la presión con la que las partículas son proyectadas y de la distancia de la fuente de emisión de partículas a la superficie sobre la que impactan. Mediante esta 
técnica es que se mejora la adhesión, proliferación y diferenciación de los osteoblastos debido a las microrrugosidades creadas, y a su vez se aumenta la superficie expuesta al contacto con el tejido óseo. Por otro lado, uno de los principales inconvenientes es que pueden quedar restos de partículas adheridas en mayor o menor medida a la superficie del implante tras el procedimiento, pudiendo constituir una interferencia durante el proceso de osteointegración del implante $(9,12)$.

\section{Grabado ácido}

Esta técnica consiste en aumentar el espesor de la capa de óxido y la rugosidad de la superficie del implante sumergiendo el implante en una solución ácida (habitualmente de ácido clorhídrico o ácido fluorhídrico), la cual erosiona la superficie implantaria dando lugar a microporos con tamaños que van desde 0,5 hasta $2 \mu \mathrm{m}$ de diámetro. Los factores que van a determinar el resultado del ataque químico son la concentración de la solución ácida, el tiempo de exposición y temperatura del proceso. La principal ventaja de los tratamientos con ácido es que proporcionan una rugosidad homogénea, aumentan de forma significativa el área de superficie activa y mejorar la adhesión celular, y por lo tanto hacen que el proceso de osteointegración se acelere $(2,8,9,12)$.

Las modificaciones implementadas sobre estas técnicas han demostrado una mejora en la inducción en la adhesión celular y un aumento en la expresión de los genes implicados en la promoción del proceso de osteointegración. Entre estas técnicas modificadas a partir de la técnica original básica, nos encontramos con la técnica de doble grabado ácido más arenado en la cual se combinan procesos químicos y físicos para obtener superficies que mejoran exponencialmente sus propiedades (2).

\section{Anodización}

Es un proceso electroquímico en el que el implante se sumerge en un electrolito, mientras que se aplica una corriente, lo cual provoca microporos de diámetro variable y un aumento de la capa de óxido de titanio $(9,12)$. Las principales ventajas de la técnica de anodización incluyen un aumento en la biocompatibilidad (debido al ya comentado aumento de la capa de óxido de titanio en la superficie) y un aumento de la adhesión y proliferación celular entorno al implante (8). 


\section{El tratamiento con láser}

Aunque la periimplantitis ha sido tratada comúnmente con la administración sistémica de antibióticos, el éxito ha sido limitado debido a la participación en este proceso de cepas resistentes de bacterias (19). Diversos tipos de láseres dentales se han hecho populares para la limpieza, desinfección y esterilización de las superficies de los implantes dentales. Se cree que la descontaminación clínica del implante mediante láser es causada por las propiedades físicas de la energía de la luz láser y su interacción con los tejidos, debido a la reflexión, dispersión, transmisión, absorción y ligera elevación de la temperatura que se produce (2).

\section{Recubrimiento}

Los implantes dentales se pueden recubrir con una gran variedad de materiales y / o moléculas dependiendo de la aplicación y las características específicas que se quieran conseguir. Por ejemplo, el recubrimiento de la superficie con fosfatos de calcio produce superficies bioactivas que mejoran el coeficiente de contacto hueso-implante (BIC). También se sabe que los iones fluoruro pueden conducir a un aumento de los niveles de calcificación del hueso, y por esta razón, los implantes dentales también se han recubierto con iones fluoruro. Además, dado que los osteoblastos reconocen moléculas específicas, es posible recubrir superficies de implantes con moléculas ancladas a la misma para mejorar la unión celular, la deposición de proteínas y la mineralización a su alrededor. Estas moléculas inmovilizadas incluyen secuencias de aminoácidos (como el tripéptido arginina-glicina-aspártico, también conocida como secuencia RDG), vitronectina, colágeno, grupos funcionales, sustancias farmacológicas (bifosfonatos) y agentes antimicrobianos (por ejemplo, tetraciclina) $(7-9,12)$.

\section{Nanotecnología.}

La irrupción de la Nanotecnología en el diseño y fabricación de los implantes ha abierto un gran campo de investigación sobre las técnicas para producir implantes basados en la nanotecnología así como de sus beneficios e inconvenientes. Estas nuevas técnicas consisten en la modificación de la rugosidad de la superficie implantaria a nivel de molecular e incluso atómico para promover la absorción de proteínas y facilitar la adherencia celular, incorporación a la superficie de recubrimientos de fosfato de calcio biomiméticos o la adicción de factores de crecimiento para acelerar el proceso de cicatrización ósea alrededor del implante (2). 
La mayoría de los intentos para conseguir nano-rugosidad en la superficie implantaria han utilizado métodos de procesamiento como la litografía y el marcado por láser, pero muy pocos estudios han analizado las modificaciones provocadas por dichas técnicas en la superficie, así como las modificaciones producidas por tratamientos químicos a escala nanométrica. Otra técnica es la deposición de nanopartículas biomiméticas de fosfato de calcio, alúmina, titanio o zirconio $(7,9,20,21)$. La superficie de los implantes dentales TI también se puede recubrir con agentes estimulantes de hueso, tales como factores de crecimiento (factor de crecimiento transformante- $\beta$, proteínas morfogenéticas de hueso [BMP], factores de crecimiento derivados de plaquetas como la insulina y el factor de crecimiento [IGF] 1 y 2) y fármacos antirresortivos (bifosfonatos) con el fin de mejorar localmente el proceso de curación del hueso $(2,7,8)$. En el estudio realizado por Schliephake et al. se comparó la tasa de formación de hueso periimplantaria entre un implante de titanio sin recubrimiento y ese mismo implante con recubrimiento de Colágeno tipo 1 y con otro recubierto de Colágeno tipo 1 más BMP-2 (Bone Morphogenetic protein 2) (22). Los resultados de este estudio en animales mostraron una mayor formación de hueso alrededor del implante para el implante recubierto de colágeno-BMP en comparación con el implante de revestido con colágeno o con el no revestido. De este estudio se desprende que tanto el colágeno como la BMP-2 actúan como moléculas bioactivas. Además de añadir biomoléculas que promueven el crecimiento óseo, también se pueden añadir moléculas tales como bifosfonatos que pueden disminuir la tasa de reabsorción ósea (7).

En cuanto a la modificación de la superficie a nivel nanométrico, hay estudios que describen un método físico de compactación de nanopartículas de TiO2 frente a la compactación de partículas a nivel de micrométrico para producir superficies de rugosidad nanométrica. Otro enfoque interesante es el proceso de monocapas autoensambladas moleculares que se forman por el posicionamiento espontáneo de moléculas en la superficie, dejando al descubierto sólo los grupos de cadena final que pueden tener moléculas osteoinductoras o adhesivas para las células tales como los dominios $\operatorname{RGD}(2,7,9,12)$.

Materiales con función de gradiente

Según lo descrito por Mehrali et al. en 2013 (23), la capacidad de adaptación biológica ósea es la responsable de la correcta formación de una zona densa externa, 
rígida denominada hueso cortical la cual en su interior alberga una capa porosa, menos densa y de mayor elasticidad denominada hueso esponjoso, entre las cuales se establece un grado adecuado de interconectividad que exhibe gradación funcional en su transición. Por lo tanto, los materiales con función de gradiente (MGF) están ganando protagonismo por sus aplicaciones potenciales en el campo de la implantología dental. Un MGF es un material compuesto, heterogéneo, que incluye un número de componentes que exhiben un gradiente de composición entre una superficie del material a la siguiente, resultando en un material con propiedades que varían continuamente dependiendo de la zona y sus características. Este diseño crea un comportamiento mecánico optimizado y mejora la biocompatibilidad y osteointegración de los mismos, ya que su comportamiento se asemeja a la biología (23).

\subsection{Histología y Fisiología ósea.}

Para poder comprender y actuar sobre los procesos de regeneración ósea, mejorándolos tanto en calidad como en velocidad con diferentes técnicas y diferentes agentes, debemos antes ser conocedores de las bases histológicas y fisiológicas de un tejido tan complejo como el hueso.

\subsubsection{Bases histológicas.}

Desde un punto de vista histológico, el hueso es un tejido conjuntivo mineralizado muy vascularizado e inervado, estructurado en laminillas de matriz osteoide calcificada. La disposición de estas laminillas es la que determina que el hueso sea cortical o esponjoso (Figura 1). Ambos están constituidos por osteonas. El hueso cortical o compacto se estructura en conductos de Havers recubiertos de laminillas en disposición concéntrica donde se sitúan los osteocitos. El hueso esponjoso o trabecular lo constituyen laminillas óseas en forma de red que delimitan cavidades en cuyo interior se encuentra medula ósea (24). 
Tanto el hueso cortical como el esponjoso contienen células especializadas, matriz orgánica y fase mineral.

\section{Células óseas.}

Las células óseas se

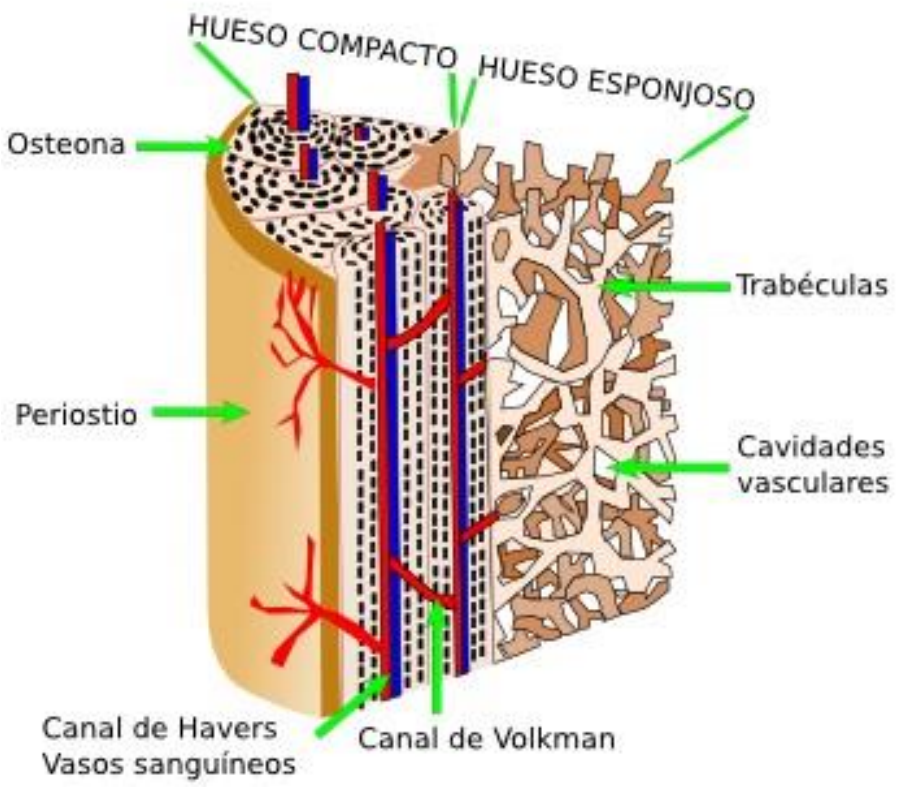
indiferenciadas (mesenchymal stem cells). Desde los trabajos de Friedenstein (25) en 1976 se conoce que estas células mesenquimales pueden dar

Figura 1. Esquema hueso trabecular y cortical.

Atlas de histología vegetal y animal. Departamento de Biología Funcional y Ciencias de la Salud. Facultad de Biología. Universidad de Vigo.

origen a cinco estirpes celulares distintas: fibroblastos, osteoblastos, condroblastos, adipocitos y mioblastos, en respuesta a diferentes señales moleculares que inician la cascada de activación de diferentes genes.

\section{- El osteoblasto.}

Los osteoblastos son células grandes $(20-30 \mu \mathrm{m})$, poliédricas, con citoplasma basófilo y con un aparato de Golgi y un retículo endoplasmático rugoso de tamaño grande (Figura 2). Proceden de las células mesenquimales pluripotenciales de la medula ósea, endostio, periostio y pericitos perivasculares (26). Existen diversos factores que inducen la diferenciación osteoblástica a partir de las células mesenquimales pluripotenciales indiferenciadas:

- Genética y factores de crecimiento: la diferenciación hacia la estirpe osteoblástica está controlada por genes pertenecientes a la familia Hedgehog, de los cuales los más conocidos son: Ihh (Indian hedgehog) y Shh (Sonic hedgehog) $(26,27)$. Son indispensables el factor de transcripción Cbfa1 (corebinding factor $a-1$, también llamado Runx2) (28-31) y las proteínas 
morfogenéticas óseas (BMPs: Bone Morphogenetic Proteins), que constituyen los principales reguladores de la diferenciación osteoblástica desde las células mesenquimales pluripotenciales (27).

- Marcadores de diferenciación: A medida que las células precursoras se van diferenciando expresan en su membrana celular proteínas específicas de su función o marcadores celulares. La expresión de Cbfa1 es la primera evidencia de la diferenciación osteogénica (27), cuyo máximo nivel se alcanza en los preosteoblastos. El colágeno I y la osteopontina (OPN: Osteopontin) se expresan de forma temprana en células osteoprogenitoras. Igualmente la fosfatasa alcalina (ALP: Alkaline Phosphatase) es una proteína de superficie que podría participar en la regulación de la proliferación, migración y diferenciación de las células osteoblásticas. La sialoproteína ósea (BSP: Bone Sialoprotein) y la osteocalcina (OCN: Osteocalcin), son marcadores de diferenciación del pre-osteoblasto al osteoblasto y aparecen cuando se inicia la mineralización. La expresión de estas proteínas resulta especialmente útil como marcadores osteogénicos en los estadíos finales de la diferenciación osteoblástica (32).

Los osteoblastos emiten prolongaciones citoplasmáticas hacia la matriz, que comunican con la red de osteocitos y con osteoblastos vecinos. Los osteoblastos y osteocitos se comunican entre sí por proteínas transmembrana o integrinas, que actúan de enlace entre células o entre una célula y la matriz extracelular, permitiendo el paso de agentes mensajeros como calcio, citoquinas o prostaglandinas. En estas células la conexión intercelular se realiza mediante la Conexina 43 (33).

Los osteoblastos sintetizan la matriz orgánica o sustancia osteoide a un ritmo de 2 a $3 \mu \mathrm{m}$ por día, expresando además la enzima fosfatasa alcalina (ALP), que permite la mineralización a un ritmo de 1-2 $\mu$ m por día (34). Otras funciones de los osteoblastos son sintetizar las proteínas colágenas y no colágenas de la matriz orgánica del hueso, dirigir la disposición de las fibrillas de la matriz extracelular, contribuir a la mineralización de la sustancia osteoide, gracias a la fosfatasa alcalina, mediar en la reabsorción llevada 
a cabo por los osteoclastos a través de la síntesis de citoquinas específicas y sintetizar factores de crecimiento (34).

La vida media un osteoblasto humano oscila entre 1 a 10 semanas, al término de las cuales un 15\% se convertirán en osteocitos y el resto pueden o bien desaparecer por mecanismos de apoptosis 0 transformarse en células limitantes 0 de revestimiento (bone lining cells) (32). Tanto los osteocitos como las células limitantes representan

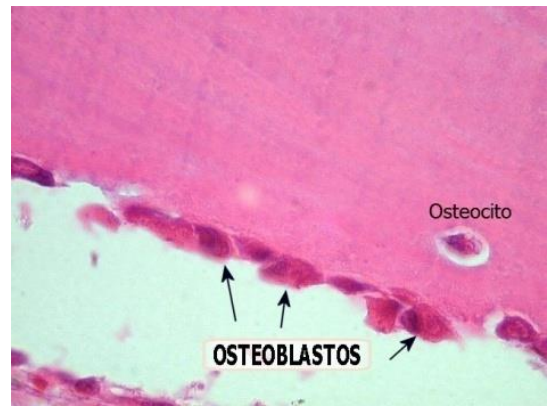

Figura 2. Osteoblastos y osteocito. estadíos más avanzados de maduración que el osteoblasto. Las células limitantes son células elongadas y planas, con un núcleo en forma de huso, sin apenas organelas. Pueden expresar marcadores osteoblásticos como la sialoproteína ósea, osteopontina, osteonectina, y fosfatasa alcalina así como el receptor de parato-hormona (PTH: Parathormone). Permanecen a lo largo de la superficie del endostio, constituyendo ambas estructuras una capa protectora de la superficie ósea, que juega un papel importante en la activación del remodelado óseo (35).

\section{- El osteocito.}

Una vez mineralizada la matriz, algunos osteoblastos quedan atrapados dentro, transformándose en osteocitos (Figura 2). Los osteoblastos, osteoclastos y células limitantes se hallan en la superficie ósea, mientras que los osteocitos están en el interior. El número de osteocitos es 10 veces mayor que el de osteoblastos en hueso maduro (36). Poseen forma estrellada y su cuerpo se sitúa en el interior de lagunas u osteoplasmas y los procesos citoplasmáticos se comunican entre sí a través de los conductos calcóforos que están llenos de fluido óseo extracelular. De esta forma, los osteocitos se organizan formando una red de células interconectadas que representa una única estructura, con la ventaja de que existe una gran superficie de contacto en el interior y hacia la superficie ósea, para asegurarse oxígeno y nutrientes (36).

Los osteocitos también participan en la síntesis y mineralización de la matriz osteoide, pero se cree que su función principal es la de controlar el remodelado óseo, 
detectando las variaciones mecánicas de las cargas, fenómeno denominado mecanotransducción (37).

Los osteocitos constituyen el estadío final de la línea osteoblástica y son incapaces de renovarse. Poseen los mismos marcadores que los osteoblastos, pero tienen como marcador especifico el CD-44, receptor de membrana que se expresa fuertemente en osteocitos y es negativo en osteoblastos y células limitantes (35).

\section{- El osteoclasto.}

Es la célula encargada de la reabsorción. Son células grandes $(100 \mu \mathrm{m})$, multinucleadas, ricas en mitocondrias y vacuolas (Figura 3). Los osteoclastos contienen fosfatasa ácida tartrato resistente (TRAP: Tartrate-Resistant Acid Phosphatase), que permite la desfosforilación de las proteínas, cuya actividad es aprovechada para su identificación. Además tienen receptores para calcitonina (35).

Los osteoclastos proceden de células madre hematopoyéticas medulares denominadas "Unidades Formadoras de Colonias de Granulocitos y Macrófagos"

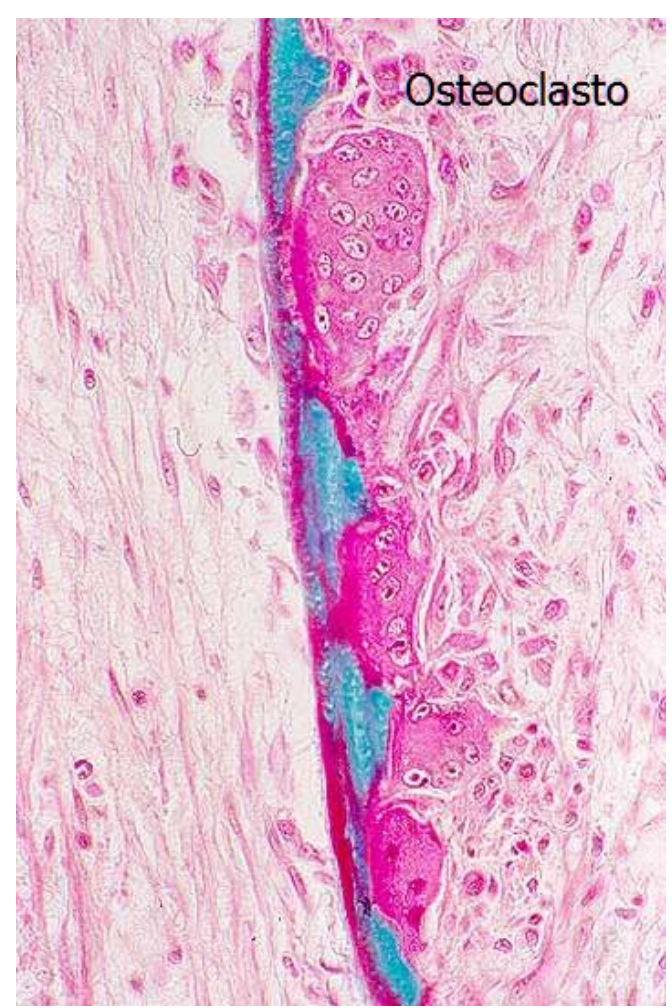

Figura 3. Imagen histológica de Osteoclastos. (CFU-GM: Colony Forming Units for Granulocytes and Magrophages), precursoras de macrófagos y monocitos (38).

Los osteoclastos tienen dos especializaciones en la membrana: un borde en cepillo donde tiene lugar la reabsorción y una zona clara, rica en microfilamentos, con integrinas que sirven de anclaje a la matriz. Los osteoclastos se movilizan hacia la zona a reabsorber $y$, seguidamente, se adhieren a la superficie ósea mineralizada por el ribete en cepillo mediante las integrinas. La integrina del osteoclasto, particularmente av $\beta 3$, reconoce la secuencia Arg-Gly-Asp (RGD) existente en el colágeno y otras proteínas de la matriz osteoide. A este nivel el $\mathrm{pH}$ es acido, ya que secretan ácidos $\left(\mathrm{H}^{+}\right)$producidos 
por la anhidrasa carbónica II y enzimas proteolíticas como colagenasas, metaloproteasas, catepsina K y glucuronidasa, entre otras (38), provocando la reabsorción del hueso mediante la solubilización de la matriz orgánica en primer lugar y a continuación la reabsorción de la matriz mineral.

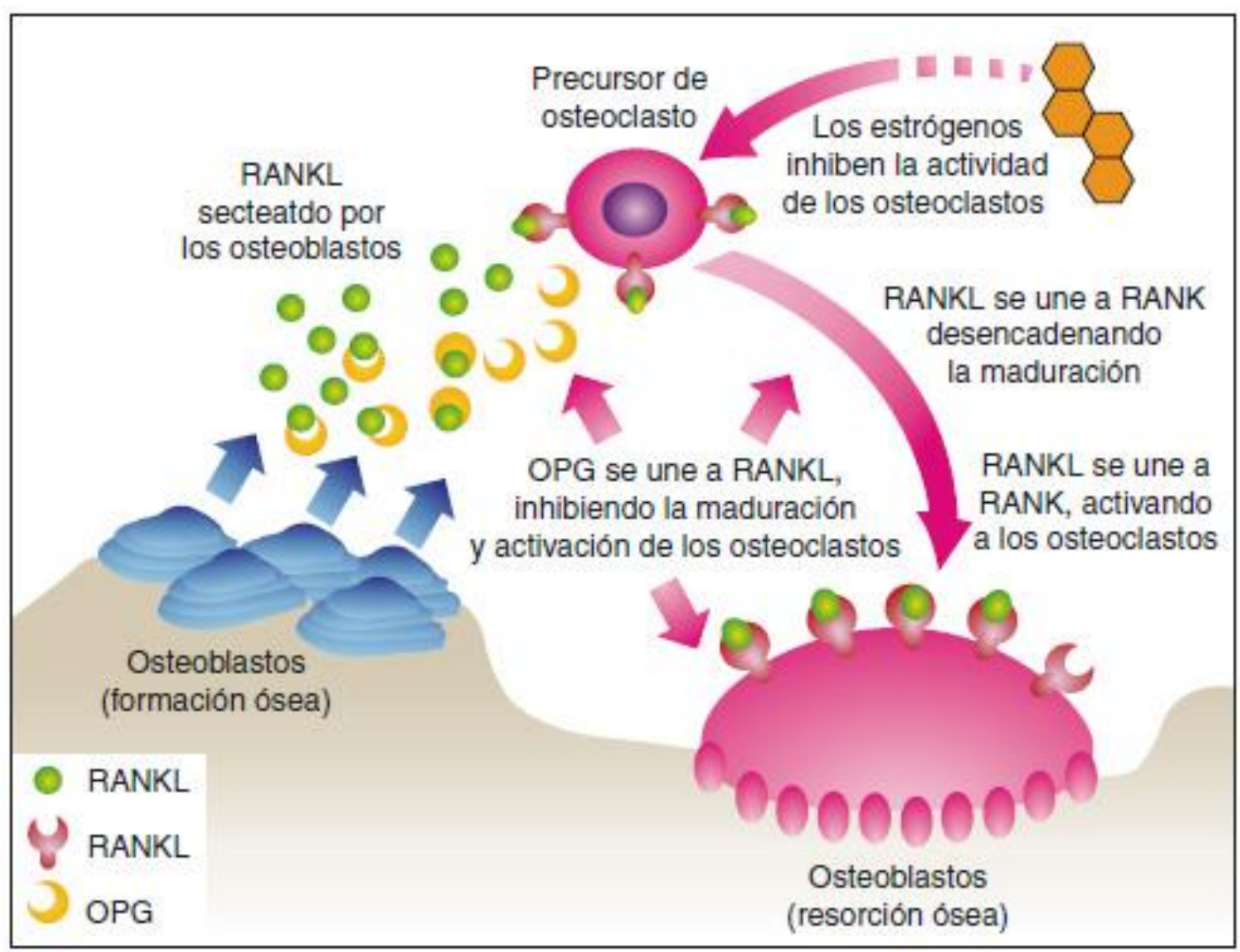

Figura 4. Esquema de la regulación de la Osteoclastogénesis.

En el proceso de osteoclastogénesis (Figura 4, (39)) los osteoblastos son fundamentales: el factor estimulante de las colonias de macrófagos (M-CSF: Macrophage Colony Stimulating Factor) producido por los osteoblastos es requerido en las primeras fases de la osteoclastogénesis para la formación de células gigantes multinucleadas. La regulación de la osteoclastogénesis se basa en la existencia de 3 moléculas clave (35):

- Osteoprotegerina (OPG: Osteoprotegerin), proteína circulante sintetizada por osteoblastos y pre-osteoblastos perteneciente a la superfamilia de los receptores de TNF (Tumor Necrosis Factor). 
- RANKL (receptor activator of NFkB ligand), ligando situado en la superficie de osteoblastos y pre-osteoblastos.

- RANK (receptor activator of NFkB), receptor del anterior situado en la membrana de osteoclastos y pre-osteoclastos.

EI RANKL es una citoquina transmembrana perteneciente a la familia del factor de necrosis tumoral (TNF) (40). La interacción entre RANKL y su receptor RANK produce una activación de la diferenciación y de la actividad osteoclástica, aumentando la reabsorción. Asimismo, los efectos del RANKL son inhibidos por la osteoprotegerina (OPG) (34).

Cuando se unen OPG y RANKL se inhibe la unión de RANKL a RANK y se inhibe la diferenciación osteoclástica. Por ello OPG, RANK y RANKL son importantes reguladores de la osteoclastogénesis (35).

\section{Matriz orgánica.}

La matriz orgánica o sustancia osteoide representa un tercio del peso óseo. Está formada en un $90 \%$ por colágeno. La matriz mineralizada extracelular debe ser considerada como algo más que un reservorio de calcio y fósforo, ya que constituye una reserva de proteínas importantes en la regulación de la diferenciación celular y en la integridad y función del tejido óseo (41).

Además del colágeno existen otras proteínas no colágenas con funciones importantes como son:

- Proteoglicanos: Constituyen el $10 \%$ de las proteínas no colágenas. Son moléculas de gran tamaño que intervienen en las etapas iniciales de la morfogénesis ósea (41).

- Proteínas con ácido y-carboxi-glutámico: Son la osteocalcina (OCN) y la proteína de la matriz con ácido $\gamma$-carboxiglutámico. Este acido es un aminoácido que liga calcio y necesita vitamina K para su síntesis. La osteocalcina es una pequeña proteína de la matriz sintetizada por los osteoblastos y plaquetas, dependiente de las vitaminas D y K. Sus niveles plasmáticos se han 
considerado como uno de los marcadores bioquímicos de la osteogénesis, relacionándose con el número y actividad de los osteoblastos (41).

- Glicoproteínas: Son la osteonectina, la fosfatasa alcalina y las proteínas con el tripéptido RGD (Arg-Gly-Asp) (41).

- La osteonectina es una glicoproteína con gran afinidad por el colágeno tipo I, por el calcio y por la hidroxiapatita. Se cree que interviene en la regulación de la adhesión celular entre la matriz y las células. En el hueso es necesaria para la mineralización normal (41).

- La fosfatasa alcalina es una enzima que libera fosfato inorgánico a partir de ésteres fosfóricos, necesarios para la mineralización. Se considera un buen marcador de la actividad osteoblástica (41).

- Proteínas con el tripéptido RGD, también llamadas SIBLINGS (Small Integrin-Binding Ligand, N-linked Glycoprotein) son cinco: osteopontina, sialoproteínas óseas, fibronectina, trombospondina y vitronectina. Son fundamentales en los procesos de remodelado y regeneración óseos, con una secuencia Arg-Gly-Asp (RGD) que es reconocida por las integrinas de los osteoblastos y los osteoclastos (av $\beta 3$ entre otras). Además actúan como receptores de superficie de las células óseas permitiendo la adhesión de las células a la matriz extracelular y activando cascadas de señalización (41).

- Proteínas procedentes del plasma: Se encuentran en la matriz orgánica ósea en mayor proporción que en el plasma. Son la albumina y la a2-SH-glicoproteina que están relacionadas con la incorporación del calcio a la matriz osteoide (41).

- Factores de Crecimiento: Son polipéptidos sintetizados en el propio hueso o procedentes de otros lugares (hígado, plaquetas, etc.), que intervienen en la diferenciación, crecimiento y proliferación celulares (42). 


\section{Fase mineral.}

Finalmente, el componente mineral del hueso representa el 65\% del peso óseo. Está formado por calcio, fosfato y carbonato (en proporciones de 10:6:1) en forma de pequeños cristales de hidroxiapatita $\mathrm{Ca} 10(\mathrm{PO} 4) 6(\mathrm{OH}) 2$ y, en menor proporción magnesio, sodio, potasio, manganeso y flúor (35).

\subsubsection{Fisiología ósea.}

La regeneración tisular es la respuesta que consigue el restitutio ad integrum del tejido tras un trauma, a diferencia de la reparación, donde el tejido que se forma es un tejido cicatricial, con características diferentes al original. En este sentido el hueso es el único tejido del organismo, a excepción del tejido embrionario, que se restituye totalmente tras una lesión (26). La regeneración ósea origina una respuesta en la que están involucrados los vasos sanguíneos, las células y la matriz extracelular. Tras un trauma, se produce una respuesta inflamatoria y un hematoma inicial, con hematíes, plaquetas y fibrina. Las células del coagulo liberan interleuquinas y factores de crecimiento, originando la migración de linfocitos, macrófagos, precursores de osteoclastos y células mesenquimales pluripotenciales (26). Estas moléculas promueven la diferenciación hacia células endoteliales, fibroblastos, condroblastos y osteoblastos, dando origen a un nuevo tejido fibrovascular, que reemplazara al coagulo inicial. Todo ello está regido por una serie de complejas interacciones entre factores de crecimiento, hormonas y citoquinas. En este proceso va a ser fundamental el aporte vascular, la síntesis proteica y la mineralización $(26,35)$.

El hueso es un tejido dinámico en constante formación y reabsorción, que permite el mantenimiento del volumen óseo, la reparación del daño tisular y la homeostasis del metabolismo fosfocálcico (26). Este fenómeno equilibrado denominado proceso de remodelado permite la renovación de un 5\% del hueso cortical y un $20 \%$ del trabecular al año. Aunque el hueso cortical constituye un $75 \%$ del total, la actividad metabólica es 10 veces mayor en el trabecular, ya que la relación entre superficie y volumen es mayor (la superficie del hueso trabecular representa un $60 \%$ del total). Por esto la renovación es de un 5-10\% del hueso total al año (35). 
El remodelado óseo existe toda la vida, pero sólo hasta la tercera década el balance es positivo. Es precisamente en la treintena cuando existe la máxima masa ósea, que se mantiene con pequeñas variaciones hasta los 50 años. A partir de aquí, existe un predominio de la reabsorción y la masa ósea empieza a disminuir (32).

A nivel microscópico el remodelado óseo se produce en pequeñas áreas de la cortical o de la superficie trabecular, llamadas unidades básicas multicelulares o BMU (Basic Multicellular Units) (43). La reabsorción siempre precede a la formación y en el esqueleto joven las cantidades de hueso reabsorbidas son similares a las neoformadas. Por esto se dice que es un proceso balanceado, acoplado en condiciones normales, tanto en el espacio como en el tiempo (43). La vida media de cada unidad de remodelado en humanos es de 2 a 8 meses y la mayor parte de este período está ocupado por la formación ósea. Existen en el esqueleto humano 35 millones de unidades básicas multicelulares y cada año se activan 3-4 millones, por lo que el esqueleto se renueva totalmente cada 10 años (35).

\section{Fases del remodelado.}

El remodelado óseo puede ser dividido en las siguientes fases:

- Fase quiescente: Se dice del hueso en condiciones de reposo. Los factores que inician el proceso de remodelado aún no son conocidos (44).

- Fase de activación: El primer fenómeno que tiene lugar es la activación de la superficie ósea previa a la reabsorción, mediante la retracción de las células limitantes (osteoblastos maduros elongados existentes en la superficie endóstica) y la digestión de la membrana endóstica por la acción de las colagenasas. Al quedar expuesta la superficie mineralizada se produce la atracción de osteoclastos circulantes procedentes de los vasos próximos (44).

- Fase de reabsorción: Seguidamente, los osteoclastos comienzan a disolver la matriz mineral y a descomponer la matriz osteoide. Este proceso es acabado por los macrófagos y permite la liberación de los factores de crecimiento contenidos en la matriz, fundamentalmente TGF- $\beta$ (factor transformante del crecimiento $\beta$ ), PDGF (factor de crecimiento derivado de las plaquetas), IGF-I e IGF-II (factor análogo a la insulina I y II) (44). 
- Fase de formación: Simultáneamente en las zonas reabsorbidas se produce el fenómeno de agrupamiento de preosteoblastos, atraídos por los factores de crecimiento que se liberaron de la matriz que actúan como quimiotácticos y además estimulan su proliferación. Los preosteoblastos sintetizan una sustancia cementante sobre la que se va a adherir el nuevo tejido y expresan BMPs (proteínas morfogenéticas óseas), responsables de la diferenciación. A los pocos días, los osteoblastos ya diferenciados van a sintetizar la sustancia osteoide que rellenará las zonas horadadas (45).

- Fase de mineralización: A los 30 días del depósito de osteoide comienza la mineralización, que finalizará a los 130 días en el hueso cortical y a 90 días en el trabecular (44).

Y de nuevo empieza fase quiescente o de descanso.

\section{Factores reguladores del remodelado óseo.}

El balance entre la reabsorción y la formación óseas está influido por una serie de factores, interrelacionados entre sí, como son factores locales, hormonales, genéticos, mecánicos, vasculares y nutricionales (43).

\section{Factores locales.}

El remodelado óseo también está regulado por factores locales, entre los que destacan los factores de crecimiento, las citoquinas y recientemente se han implicado las proteínas de la matriz ósea, como moduladoras de la acción de otros factores locales. Las células del hueso también juegan un papel importante por la producción de prostaglandinas y óxido nítrico, así como de citoquinas y factores de crecimiento (35).

- Factores de crecimiento: Son polipéptidos producidos por las propias células óseas o en tejidos extra-óseos, que actúan como moduladores de las funciones celulares, fundamentalmente sobre el crecimiento, diferenciación y proliferación celular (46).

- IGF-I y II (Insulin-like Growth Factor I y II): Los factores de crecimiento análogos a la insulina son polipéptidos similares a esta hormona sintetizados por el hígado y los osteoblastos. Se hallan en gran concentración en la matriz 
osteoide (47). Incrementan el número y función de los osteoblastos, favoreciendo la síntesis de colágeno. Circulan unidos a proteínas de unión (IGFBP: IGF-binding proteins) que a su vez pueden ejercer efectos estimulatorios o inhibitorios sobre el hueso. Las IGFs están reguladas por hormonas y factores de crecimiento locales: la $\mathrm{GH}$, los estrógenos y la progesterona aumentan su producción, mientras que los glucocorticoides la inhiben (48). Asimismo, median en la interacción osteoblasto-osteoclasto e intervienen de forma activa en el remodelado óseo (48). El IGF-II es el factor de crecimiento más abundante de la matriz ósea, siendo importante durante la embriogénesis (49).

- TGF- $\boldsymbol{\beta}$ (Transforming Growth Factor-6): Los factores de crecimiento transformantes $\beta$ son una superfamilia de proteínas muy abundantes en el tejido óseo (los segundos, tras los IGF). Están presentes en la matriz en forma latente y se activan durante la reabsorción osteoclástica $(42,50,51)$.

TGF- $\beta$ es un potente estimulador de la formación ósea, potenciando la diferenciación osteoblástica y la síntesis de la matriz osteoide e inhibiendo la síntesis de proteasas (entre las que destacan la metaloproteasa de la matriz (MMP), enzima que degrada la misma). Asimismo, inhibe la reabsorción al reducir la formación y diferenciación de los osteoclastos, así como la actividad de los osteoclastos maduros y estimular su apoptosis (50).

Pero además de estas funciones, se ha descubierto que inhibe la proliferación epitelial y media en el efecto anabolizante de los andrógenos (51).

- BMPs (Bone Morphogenetic Proteins): Las proteínas morfogenéticas óseas están incluidas dentro de la familia de los TGF- $\beta$. Constituyen un grupo de 15 proteínas capaces de conseguir la transformación de tejido conjuntivo en tejido óseo, por lo que se consideran osteoinductivas. Asimismo, son capaces de estimular la diferenciación de células pluripotenciales hacia diferentes líneas celulares (tejido adiposo, cartílago y hueso). Son muy abundantes en el tejido óseo y durante la embriogénesis participan en la formación de hueso y cartílago (52).

Actualmente se las considera como los factores más potentes de la diferenciación osteoblástica (27). Canalis et al (52) creen que además de estimular la osteogénesis inhiben la osteoclastogénesis. 
- PDGF (Platelet-Derived Growth Factor): El factor de crecimiento derivado de las plaquetas por un lado estimula la síntesis protéica llevada a cabo por los osteoblastos y por otro, favorece la reabsorción ósea. Otros efectos son la proliferación de fibroblastos, de células musculares lisas, la neovascularización y la síntesis de colágeno, por lo que favorece la cicatrización (53).

- FGF (Fibroblastic Growth Factor): El factor de crecimiento fibroblástico es anabolizante óseo, ya que es mitógeno de los osteoblastos y de las células endoteliales vasculares, así como de los fibroblastos (54).

- EGF (Epidermal Growth Factor): El factor de crecimiento epidérmico es un potente mitógeno de las células de origen mesodérmico y ectodérmico. Se sintetiza en múltiples tejidos del organismo. Respecto al hueso podría tener una doble acción formadora y destructora, si bien ésta última es la más conocida (46).

- VEGF (Vascular Endothelial Growth Factor): El factor de crecimiento vascular endotelial induce la angiogénesis y la proliferación endotelial vascular. Produce vasodilatación y un incremento de la permeabilidad vascular. Se produce en situaciones de hipoxia y actualmente se está considerando como uno de los factores claves en el desarrollo de las primeras fases del proceso de reparación de fracturas y regeneración ósea, así como en el desarrollo tumoral (46).

- GM-CSF (Granulocyte/Macrophage-Colony Stimulating Factor): El factor estimulador de colonias de granulocitos y macrófagos es importante para la osteoclastogénesis y puede intervenir en la patogenia de la osteopetrosis (46).

- M-CSF (Macrophage-Colony Stimulating Factor): El factor estimulador de colonias de macrófagos es producido por los osteoblastos y células del estroma medular y es requerido como factor esencial en las primeras fases de la osteoclastogénesis para la formación de células gigantes multinucleadas, pero no tiene efecto sobre la actividad osteoclástica (46).

- TNF (Tumor Necrosis Factor): El factor de necrosis tumoral in vitro estimula la reabsorción y se le ha relacionado con la pérdida ósea de la artritis y de la enfermedad periodontal (46). 
- Proteínas de la matriz: Recientemente se ha descubierto que las proteínas de la matriz actúan como moduladores de los factores de crecimiento (41). Hay que tener en cuenta que las proteínas de la matriz se hallan a una concentración mil veces mayor que los factores de crecimiento, por lo que podrían jugar un papel más importante en la regulación de las diferentes funciones celulares (51).

Por otro lado, estas proteínas de la matriz también participan en la regulación de la diferenciación de las células contenidas en la matriz. Por ejemplo el colágeno I es uno de los marcadores más tempranos que regulan las células osteoprogenitoras y la fosfatasa alcalina es una proteína de superficie que podría participar en la regulación de la proliferación, migración y diferenciación de las células osteoblásticas (46).

- Citoquinas: Son polipéptidos sintetizados en células linfocíticas y monocíticas que juegan un papel importante en múltiples funciones celulares, como en la respuesta inmunológica, la inflamación y la hematopoyesis, con un efecto autocrino y paracrino. En el hueso son importantes las siguientes:

- Interleuquina 1 (IL-1: Interleukin-1): Estimula directamente la reabsorción osteoclástica, incrementando la proliferación y diferenciación de los preosteoclastos así como la actividad osteoclástica e inhibiendo la apoptosis de los osteoclastos (44). En realidad son 3 moléculas diferentes relacionadas: IL-1 $\alpha$, IL$1 \beta$ y el antagonista del receptor de IL-1, siendo esta última inhibidora del efecto de las dos primeras. Su acción sobre la reabsorción es directa e indirecta, a través de la síntesis de prostaglandinas.

- Interleuquina 6 (IL-6): Estimula la reabsorción ósea y parece implicada en la patogenia de la enfermedad de Paget (55). Se cree que juega un papel importante en las etapas iniciales de la osteoclastogénesis. Se produce en respuesta a PTH, IL-1 y $1,25(\mathrm{OH}) 2 \mathrm{D} 3$.

- Interleuquina 11 (IL-11): De reciente descubrimiento, se produce en la médula ósea e induce la osteoclastogénesis.

- Prostaglandinas (PG: Prostaglandins): In vitro favorecen la reabsorción ósea, fundamentalmente la PGE2, pero también la PGE1, PGG2, PGI2 y PGH2 (56). Estudios in vivo que miden los niveles de prostaglandinas en el líquido crevicular, han demostrado su participación en la destrucción ósea que tiene lugar en la enfermedad periodontal (57). 


\section{Factores hormonales.}

El desarrollo normal del esqueleto está condicionado por el correcto funcionamiento del sistema endocrino, fundamentalmente de la somatotropina (GH: Growth Hormone) y las hormonas calcitrópicas (parathormona, calcitonina y metabolitos de la vitamina D). Las hormonas son mensajeros sistémicos que actúan a distancia de su lugar de producción (efecto endocrino), pero también regulan la síntesis y acción de los factores locales, que intervienen directamente en el metabolismo celular (efectos autocrino y paracrino) (24).

Las hormonas más importantes que intervienen en la fisiología ósea son:

- Hormonas tiroideas: Las hormonas tiroideas, tiroxina $\left(T_{4}\right)$ y triyodotironina $\left(T_{3}\right)$, son hormonas basadas en la tirosina producidas por la glándula tiroides. Poseen dos acciones contrapuestas sobre el hueso. En primer lugar, estimulan la síntesis de la matriz osteoide por los osteoblastos y su mineralización, favoreciendo la síntesis de IGF-I. En segundo lugar, se produce un efecto contrario, estimulando la reabsorción al aumentar el número y función de los osteoclastos.(58)

- PTH (parathormona): Es la hormona que controla la homeostasis del calcio a través de la acción directa sobre el hueso y el riñón e indirecta en el intestino. Producida en las glándulas paratiroideas que responden al descenso de la calcemia, es la hormona hipercalcemiante por excelencia, al favorecer la reabsorción. No obstante, en los últimos años se ha descubierto un papel estimulador en la formación ósea, a través de la síntesis de IGF-I (Insuline-like Growth Factor I) y TGF-B (Transforming Growth Factor B) (42). Este doble efecto de reabsorción y formación se explicaría porque la PTH en administración continua estimularía la reabsorción ósea a través de la síntesis de un factor favorecedor de la osteoclastogénesis (RANKL) por parte de las células osteoblásticas, mientras que a dosis intermitentes estimularía la formación de hueso, asociado a un incremento de los factores de crecimiento mencionados anteriormente y a una disminución de la apoptosis de los osteoblastos (42).

- Calcitonina: Producida en las células C o parafoliculares del tiroides, es inhibidora de la reabsorción ósea, al reducir el número y la actividad de los osteoclastos. Sin embargo, esta acción es transitoria, ya que los osteoclastos parecen volverse “impermeables" a la calcitonina en pocos días (46). 
- Calcitriol ó 1,25(OH)2 vitamina D3: Hormona esteroidea que favorece la absorción intestinal de calcio y fosfato y, por tanto, la mineralización ósea. Es necesaria para el crecimiento normal del esqueleto. Algunos autores piensan que puede ser producida por células linfocíticas o monocíticas del hueso, ejerciendo un papel importante como regulador local de la diferenciación de los osteoclastos (59).

- Andrógenos: Tienen un efecto anabolizante sobre el hueso, a través del estímulo de los receptores de los osteoblastos. Asimismo, actúan de mediadores en el pico de GH existente en la pubertad. Mientras que la deficiencia androgénica se asocia a una menor densidad ósea, la administración de testosterona en jóvenes antes del cierre epifisario incrementa la masa ósea. Igualmente, las mujeres con exceso de andrógenos presentan densidades óseas más altas (44).

- Estrógenos: Son esenciales para el cierre de los cartílagos de conjunción y se ha descubierto que juegan un papel importante en el desarrollo esquelético tanto femenino como masculino durante la adolescencia (44). (60)(59)(58)(57)(56)(54)(53)Los estrógenos tienen un doble efecto sobre el metabolismo óseo: por un lado favorecen la formación ósea al aumentar el número y función de los osteoblastos y por otro lado, disminuyen la reabsorción. Se han descrito receptores de estrógenos en osteoblastos, osteocitos y osteoclastos humanos. Investigaciones recientes han comprobado que los estrógenos pueden aumentar los niveles de osteoprotegerina (OPG), proteína producida por los osteoblastos que inhibe la reabsorción (60), por lo que podrían jugar un papel importante en la regulación de la osteoclastogénesis. Es por esto que la deficiencia de estrógenos durante la menopausia constituye el factor patogénico más importante de la pérdida ósea asociada a la osteoporosis.

- Progesterona: Es igualmente anabolizante sobre el hueso, bien directamente, a través de los osteoblastos, que poseen receptores para la hormona o bien de forma indirecta, mediante la competición por los receptores osteoblásticos de los glucocorticoides (44).

- Insulina: Estimula la síntesis de la matriz directa e indirectamente, a través del aumento de la síntesis hepática de IGF-I (factor de crecimiento análogo a la insulina-I) (47).

- Glucocorticoides: A dosis altas tienen efectos catabólicos sobre el hueso, ya que inhiben la síntesis de IGF-I por los osteoblastos, y suprimen directamente la BMP-2 
y el Cbfa1, factores críticos para la osteoblastogénesis (61). Sin embargo, se ha demostrado que a dosis fisiológicas tienen capacidad osteogénica favoreciendo la diferenciación osteoblástica (37).

- Hormona de crecimiento (GH: Growth Hormone): Tiene dos acciones sobre el hueso, directa e indirecta. La GH actúa directamente sobre los osteoblastos, con receptores para la hormona, estimulando su actividad, lo que produce un aumento en la síntesis de colágeno, osteocalcina y fosfatasa alcalina. La acción indirecta se produce a través del aumento de la síntesis de IGF-I y II por los osteoblastos. Estos factores favorecen la proliferación y diferenciación de los osteoblastos, aumentando su número y función (62).

Desde hace unos años se viene considerando a la GH como un factor de crecimiento local, ya que no sólo se sintetiza en la adenohipófisis, sino en casi todas las células del organismo, incluidos los osteoblastos (62).

\section{Factores genéticos.}

Son determinantes muy importantes en el pico de masa ósea, ya que entre el 60 y el $80 \%$ de ésta se encuentra determinada genéticamente (63). Así los sujetos de raza negra poseen una masa ósea mayor que los de raza blanca y éstos mayor que la amarilla. La masa ósea se transmite de padres a hijos, por ello la predisposición a padecer osteoporosis es mayor en hijas de madres que la padecen (64).

\section{Factores mecánicos.}

La actividad física es imprescindible para el correcto desarrollo del hueso. Se cree que la acción muscular transmite al hueso una tensión que es detectada por la red de osteocitos incluida en el interior del fluido óseo. Estos osteocitos producen mediadores como prostaglandinas, óxido nítrico e IGF-I, que estimulan tanto su actividad como la de los osteoblastos y originan una mayor formación ósea. Y por el contrario, la falta de actividad muscular, el reposo o la ingravidez tienen un efecto deletéreo sobre el hueso, acelerando la reabsorción (65).

\section{Factores vásculo-nerviosos.}

La vascularización es fundamental para el normal desarrollo óseo, permitiendo el aporte de células sanguíneas, oxígeno, minerales, iones, glucosa, hormonas y factores 
de crecimiento. La vascularización constituye el primer paso para la osificación: los vasos sanguíneos invaden el cartílago y posteriormente se produce la reabsorción ósea por los osteoclastos, procedentes de los vasos próximos. Igualmente, la neoformación vascular es el primer hecho en el fenómeno de la reparación de fracturas o de la regeneración ósea, ya que la existencia de oxígeno es fundamental para que se produzca el restitutio ad integrum y no tejido fibroso (35).

El hueso es inervado por el sistema nervioso autónomo y por fibras nerviosas sensoriales. Se han encontrado fibras autónomas en periostio, endostio, hueso cortical y asociadas a los vasos sanguíneos de los conductos de Volkmann, así como neuropéptidos y sus receptores en el hueso. Como ejemplos de la importancia de la inervación en la fisiología ósea son la osteopenia y la fragilidad ósea presentes en pacientes con desórdenes neurológicos, así como la menor densidad mineral ósea existente en mandíbulas denervadas (24).

\section{Factores nutricionales.}

Este factor cobra importancia debido a que puede ser modificado. Se necesita un mínimo de calcio para permitir la mineralización que la mayoría de los autores cifran en unos $1.200 \mathrm{mg}$. diarios hasta los 25 años; después y hasta los 45 no debe ser inferior a 1 gramo y tras la menopausia debe ser por lo menos $1.500 \mathrm{mg}$ al día (24). Asimismo, se conoce que hábitos tóxicos como tabaco, cafeína, alcohol y exceso de sal constituyen factores de riesgo para la aparición de osteopenia (58).

\subsubsection{Evolución de los procedimientos de regeneración ósea.}

Los principales objetivos que debe procurar un material a la hora de rellenar una cavidad ósea son restaurar la función y la forma de la zona de hueso donde se ha producido el defecto, y tener estabilidad en el tiempo. La tasa de reabsorción del biomaterial debe ser idealmente igual que la de formación de hueso por los osteoblastos $(66,67)$. Actualmente, se buscan biomateriales que cada vez tengan un menor periodo fisiológico de osificación, que sean técnicamente simples de manipular y que cuenten con una amplia experiencia clínica (1). 
El material que cumple con la mayoría de estas características es el injerto de hueso autólogo, por lo que es considerado el "gold standard" y además posee propiedades imprescindibles para la regeneración ósea como son (68):

- Osteoinducción: se inicia por medio de la transformación de células mesenquimales indiferenciadas perivasculares de la zona receptora, a células osteoformadoras en presencia de moléculas reguladoras del metabolismo óseo. Dentro de estas moléculas cabe destacar el grupo de las proteínas morfogenéticas, pero también se encuentran otra serie de proteínas implicadas en el metabolismo óseo. La fuente de estas proteínas son los injertos autólogos, el plasma rico en factores de crecimiento y las proteínas morfogenéticas obtenidas mediante técnicas de ingeniería genética. La proteína morfogenética, que se deriva de la matriz mineral del injerto, es reabsorbida por los osteoclastos y actúa como mediador de la osteoinducción. Esta fase comienza 2 semanas después de la cirugía y alcanza un pico entre las 6 semanas y los 6 meses, para decrecer progresivamente después.

- Osteogénesis: depende exclusivamente de la supervivencia de las células trasplantadas (en el caso de hueso autógeno), principalmente de los preosteoblastos y osteoblastos. Se origina principalmente en hueso esponjoso, debido a su rápida revascularización, que puede ser completa a las 2 semanas, mientras que en el cortical puede llevar varios meses.

- Osteoconducción: es un proceso lento y prolongado, donde el injerto tiene la función de esqueleto. Este tipo de propiedad predomina sobre todo en los injertos corticales, donde el injerto es progresivamente colonizado por vasos sanguíneos y células osteoprogenitoras de la zona receptora, que van lentamente reabsorbiéndolo y depositando nuevo hueso.

Las 3 fases (osteogénesis, osteoinducción y osteoconducción), ocurren simultáneamente siempre y cuando se trate de un injerto autólogo trabecular, corticotrabecular o cortical. $(68-70)$.

Sin embargo, la demanda de biomateriales efectivos para el aumento de hueso está sufriendo un incremento debido a las desventajas del injerto óseo autógeno, como pueden ser la limitada disponibilidad ósea, la morbilidad adicional en el área donante, 
la imposibilidad de almacenamiento y la necesidad de anestesia general si la zona donante es extraoral (68-70).

Con el fin de satisfacer esta necesidad planteada, el objetivo es desarrollar un injerto óseo con propiedades osteogénicas mejoradas, que posea las ventajas del injerto de hueso autólogo (osteogéneis, osteoinducción y osteoconducción) pero sin sus inconvenientes (sin morbilidad de la zona donante, sin dificultad de almacenamiento y conservación, sin limitación de disponibilidad, etc) (68).

Los sustitutos aloplásticos óseos han sido combinados con diferentes moléculas con el objetivo de inducir la neoformación ósea de una forma más eficiente. Virchow en 1853 fue el primero en describir la matriz orgánica no mineralizada del hueso (sustancia osteoide) constituida mayoritariamente (90\%) por colágeno (35)]. Unos años más tarde, en 1889, algunos cirujanos como Senn, documentaron el empleo de hueso xenogénico desmineralizado como injerto óseo en defectos craneales de perro (35)]. Sin embargo, las verdaderas propiedades que estos injertos podrían proporcionar pasaron desapercibidas debido a la utilización por parte de estos pioneros de la investigación en regeneración ósea del ácido etilen-diamino-tetra-ácetico (EDTA) como medio para la desmineralización ósea, que produce la inactivación irreversible de las proteínas de la matriz, disminuyendo su efectividad (71). No fue hasta 1965 cuando Urist (71), al sustituir el EDTA por el ácido hidroclórico como medio desmineralización, observó la formación de hueso ectópico tras la implantación de matriz ósea desmineralizada entre los tejidos blandos de ratones de fragmentos acuñando el concepto de autoinducción ósea (71). Lo que Urist había descubierto fue el inesperado comportamiento de las células huésped vecinas al injerto que concluía en su diferenciación osteoprogenitora (71). Unos años más tarde Urist de nuevo divulgó la identificación en la matriz orgánica de una proteína insoluble de bajo peso molecular a la que denominó bone morphogenetic protein (72). Poco tiempo después otros autores aislarían del hueso bovino diferentes polipéptidos de 16-18 y $30 \mathrm{KDa}$ de peso molecular que pasaron a formar la familia de las denominadas BMPs (68). Sin embargo las BMPs según algunos autores $(73,74)$ presentan algunos problemas como por ejemplo su corta vida, dificultad de almacenamiento y manipulación, ineficacia en cuanto al reconocimiento de células 
diana y su alto coste, por lo que de momento no se puede plantear su utilización en los tratamientos habituales de regeneración ósea.

Buscando alternativas a la aplicación exógena de estas proteínas obtenidas por ingeniería genética, surgen trabajos que sugieren el uso tópico de compuestos farmacológicos que regulan dichos factores de crecimiento óseo intrínsecos. La estrategia consiste en combinar dichos compuestos con un sustituto osteoconductivo pudiendo mejorarse las características de los materiales de regeneración ósea con un equilibrio coste-beneficio muy aceptable (75-78). En esta línea en 1999, Mundy y colaboradores en la revista Science (79) son los primeros en plantear el uso de la simvastatina como agente estimulante del proceso de formación ósea. La aplicación tópica de simvastatina, un inhibidor del colesterol comúnmente utilizado para el tratamiento la hipercolesterolemia, ha demostrado que aplicado de forma tópica en un defecto óseo estimula la expresión de BMP-2 $(1,66)$ y el factor de crecimiento endotelial vascular (VEGF) (80) en los osteoblastos promoviendo el crecimiento de hueso en defectos óseos, alveolos post-extracción y líneas de fractura mandibular (1,66,79-86).

\subsubsection{Biomateriales en regeneración ósea.}

El objetivo de los procedimientos de regeneración ósea es estimular o al menos facilitar el crecimiento de nuevo hueso en el lugar donde existe un déficit óseo (87).

Existen diferentes tipos de material de injerto en función de su origen: autoinjerto, aloinjerto, xenoinjerto e injerto aloplástico.

\subsection{4-a Autoinjerto.}

El hueso autólogo está considerado el gold stándard debido a que posee como hemos dicho anteriormente propiedades osteogénicas, osteoinductivas y osteoconductivas. Durante muchos años el gold standard ha sido el injerto autólogo obtenido de zonas intraorales o extraorales (88). Sin embargo, la demanda de biomateriales efectivos para el aumento de hueso está sufriendo un incremento debido a las desventajas del injerto óseo autógeno, como pueden ser la limitada disponibilidad 
ósea, la morbilidad adicional en el área donante, la imposibilidad de almacenamiento y la necesidad de anestesia general si la zona donante es extraoral (68-70).

\subsection{4-b Aloinjerto.}

Se trata de un injerto óseo procedente de un individuo de la misma especie que el individuo receptor. El principal problema que presentan este tipo de materiales es la posibilidad de transferir infecciones al paciente receptor o producir reacciones inmunes (87). Estos inconvenientes prácticamente desaparecen ya que estos injertos sufren complejos procesos para su preparación y conservación como irradiación, tratamientos de temperatura (criopreservación, liofilización), etc, que disminuyen el riesgo eliminando todo componente orgánico presente en el hueso, pero que a su vez afectan negativamente sus características físicas, bioquímicas y mecánicas (87). Un ejemplo de este tipo de injerto es Grafton ${ }^{\circledR}$ de Osteotech ${ }^{\circledR}$.

\subsection{4-c Xenoinjerto.}

Se denomina xenoinjerto óseo aquel hueso que procede de un individuo de diferente especie al individuo receptor (89). El principal representante de este tipo de injertos es el hueso bovino desproteinizado (Bio-Oss ${ }^{\circledR}$ ), del cual se ha eliminado toda la materia orgánica evitando la respuesta inmune del receptor. Su configuración estructural es similar a la del hueso humano, al igual que su módulo de elasticidad y la fuerza compresiva que es capaz de soportar (89). Es osteoconductivo pero no hay evidencias de que sea osteoinductivo. Su tiempo de sustitución oscila entre 6 y 8 meses (87). También entraría dentro de este grupo otro de los biomateriales que serán estudiados en este trabajo como es la hidroxiapatita porcina.

\subsection{4-d Injerto aloplástico.}

Son materiales sintéticos que hasta el momento han demostrado que poseen propiedades osteoconductivas, actuando como andamios para el proceso de regeneración ósea. Dentro de este grupo se encuentran el $\alpha$-TCP ( $\alpha$-tricalcium phosphate) y el $\beta$-TCP (6-tricalcium phosphate) (76). Los biomateriales de origen 
sintético poseen un gran biocompatibilidad, mostrando una reacción fibrótica mínima. Constituyen un buen soporte para la neoformación ósea y desde el punto de vista biomecánico tienen una adecuada resistencia y un módulo de elasticidad similar al hueso natural, lo cual es necesario para prevenir fracturas cuando el hueso sea sometido a cargas $(76,87)$.

Tanto el fosfato tricálcico como la hidroxiapatita (HA: Hidroxiapatite) son altamente biocompatibles presentando estructura y composición química similar, pero difieren en el proceso de reabsorción. La HA en forma densa una vez incorporada al hueso, presenta una reabsorción mínima mientras que el TCP se reabsorbe más rápidamente (88).

\subsection{Determinantes de la osteointegración de los implantes}

\section{dentales.}

El fracaso en el tratamiento de implantes puede ser caracterizado por la mobilidad del implante, seguida por una radiolucidez alrededor del mismo, periimplantitis con supuración o por quejas subjetivas del paciente (90). Sin embargo, no existen unos criterios específicos para definir con claridad el concepto de fracaso en implantología (91). La imposibilidad de los tejidos de establecer y/o mantener la osteointegración del implante es una de las causas que lleva al fracaso del implante (92). El fracaso en implantología se ve asociado frecuentemente a factores tales como calidad y cantidad ósea pobres, insuficiente estabilidad primaria del implante y sobrecargas (93). Muchos autores han intentado establecer unos criterios claros para definir el éxito del tratamiento con implantes osteointegrados siendo los criterios de Albrektsson et al. (94) unos de los que más ampliamente han sido aceptados: Implante clínicamente inmóvil, ausencia de radiolúcidez radiográfica alrededor del implante, pérdida ósea vertical inferior a 0,2 mm/año después del primer año de función, ausencia de sintomatología dolorosa en la zona que pueda estar relacionada con el implante, el implante tanto en su diseño como en su posición permite la colocación de una prótesis funcional y estéticamente aceptable tanto para el paciente como para el profesional. Mediante la evaluación de estos criterios, un implante será exitoso si se cumplen en un $85 \%$ a los 5 años y del $80 \%$ a los 10 años (94). En 2007, durante el Congreso Internacional 
de Implantología Oral de Pisa, se establecen 4 niveles para evaluar el éxito de los implantes: éxito, supervivencia satisfactoria, supervivencia comprometida y fracaso de los implantes. Éste último término se aplica cuando los implantes que deben ser retirados o que ya se han perdido (95).

El fracaso en implantología puede subdividirse en fracaso temprano o tardío, dependiendo del momento en el que se produzca. En este aspecto tampoco la subdivisión es clara, pero podría ser lógico denominar el fracaso temprano a todo aquel fracaso implantológico que se produzca anteriormente a la conexión protésica, y fracaso tardío a aquel producido tras la carga protésica del implante. Esta subdivisión es necesaria ya que la etiología de estos dos tipos de fracaso es diferente (96). El fracaso temprano de un implante es el resultado de la incapacidad de establecer un contacto íntimo hueso-implante (Bone Implant Contact: BIC) (97-99). Esto significa que la cicatrización ósea tras la inserción del implante se ha alterado. Los mecanismos que normalmente guían la cicatrización mediante aposición ósea fallan, produciéndose una cicatrización de la zona mediante tejido fibroso, y no óseo, alrededor del implante (99). Todo ello conllevará a tener mobilidad en el implante o a su pérdida. Los fracasos tempranos están caracterizados por una pérdida ósea mínima, y la mayoría de ellos ocurren muy pronto tras la cirugía, por lo que conocer los factores de riesgo potenciales del fracaso temprano es de gran importancia para los clínicos (100). Diversos estudios clínicos han identificado los siguientes factores de riesgo para la aparición del fracaso temprano en implantología: características del implante, calidad y cantidad ósea de la zona implantaria, procedimientos quirúrgicos adicionales tales como injertos óseos, factores sistémicos como síndromes de origen genético, desórdenes metabólicos y hábitos tabáquicos $(13,98,101,102)$

Por otro lado, el fracaso tardío en implantología ha sido asociado con el acúmulo de placa bacteriana y/o sobrecargas, provocando dichos factores periimplantitis (102). Aunque numerosos estudios se centran en el papel que juegan factores sistémicos y locales en el mantenimiento a largo plazo de la osteointegración de los implantes, poco se sabe de los factores que pueden afectar a la aposición ósea inicial, hasta la conexión del aditamento protésico $(93,103)$. En los datos que arroja la literatura al respecto, la incidencia del fracaso temprano se mueve en un rango entre 0.76 y el $7.47 \%$, siendo la 
incidencia de fracasos tardíos (5-10 años posterior a la carga protésica) entre el 2.1 y el 11.3\%. De estos datos se desprende la importancia de que los clínicos conozcan el rol que juegan diferentes factores de riesgo en el fracaso temprano de implantes, para poder minimizarlo.

Por último cabe destacar que son escasos los estudios clínicos aleatorizados y los metaánálisis que la literatura ofrece al respecto al día de hoy (13).

\subsection{Complicaciones de la fase protética en rehabilitaciones}

\section{implantosoportadas.}

El rango de indicaciones de la implantología dental se ha aumentado de forma exponencial en les últimas décadas, y una terapia que en un principio estaba indicada para rehabilitar arcadas completas ha pasado a ser ampliamente indicada para rehabilitar todo tipo de situaciones clínicas utilizando diferentes estrategias y técnicas: desde coronas unitarias implantosoportadas, puentes parciales sobre implantes hasta rehabilitaciones completas y bien sea retenidos mediantes técnicas de cementado así como atornillados (104). Múltiples variables clínicas, anatómicas y técnicas van a influenciar la aplicación de unos recursos terapéuticos $u$ otros. $Y$ entre todas ellas también juegan un papel importante a la hora de elegir el tipo de restauración a colocar, las posibles complicaciones biológicas y técnicas que se pueden presentar durante el tratamiento, tasas de supervivencia de las diferentes restauraciones y no solo de los implantes que las soportan.

Las restauraciones unitarias mediante coronas implantosoportadas constituyen una situación clínico-terapéutica que cada vez se presenta con una mayor asiduidad ante el clínico. La complicación más común de este tratamiento es el aflojamiento del tornillo que ancla y retiene la restauración al implante subyacente (105).

Las restauraciones implantosoportadas unitarias se pueden clasificar en (106):

- Atornillada: la restauración es fijada y retenida mediante un tornillo que une directamente la corona al implante. Este tornillo atraviesa la restauración a través de una abertura cilíndrica o chimenea creada a tal efecto. Una vez apretado el tornillo, la 
chimenea se recubre generalmente con una resina compuesta para sellar el acceso al tornillo.

- Cementada: en esta modalidad la retención se obtiene mediante un cemento que une la restauración a un pilar intermedio o muñón artificial, que a su vez se retiene mediante un tornillo directamente al implante al igual que las prótesis atornilladas. En este tipo de restauración no hay chimenea de acceso al tornillo.

Asimismo, la fabricación de las restauraciones puede tener sus variantes. Estas pueden $\operatorname{ser}(105)$ :

- Coronas ceramometálicas, si se componen de un núcleo metálico recubierto de porcelana. A su vez se pueden diferenciar 3 tipos de fabricación de la estructura metálica:

- Pilar mecanizado: son pilares estandarizados o prefabricados mediante el mecanizado de bloques de la aleación que los compone, sobre los que el protésico añade el metal de la corona mediante el colado (la transformación de un patrón de cera en metal).

o UCLA (Universal Castable Long Abutment) (107): este pilar fue desarrollado por Lewis en la Universidad de California de Los Ángeles a mediados de la década de los 80 (107). Son pilares hechos de plástico sobre los que el técnico protésico elabora un patrón de cera que mediante la técnica de colado será sustituido por una aleación metálica que forma el núcleo de la restauración sobre la que ira la cerámica. Estos pilares pueden ser a su vez de dos tipos diferentes:

- Pilar sobrecolable: cuando el pilar plástico lleva una base de una aleación metálica, que normalmente suele ser de oro. Esta base metálica es la que asienta sobre la conexión del implante.

- Pilar totalmente calcinable: cuando el pilar está hecho completamente de plástico.

- Coronas totalmente cerámicas, cuando la totalidad de la restauración se compone de cerámica. La mayoría de estas restauraciones están fabricadas con cerámicas a base de zirconio. 


\subsubsection{Rendimiento clínico}

Debido al alto porcentaje de supervivencia que queda reflejado en la literatura (108112), los clínicos, pero sobre todo los pacientes, cada vez solicitan más la rehabilitación mediante implantes. Bianco et al. (108) en un estudio retrospectivo multicéntrico donde revisaban restauraciones unitarias implantosoportadas durante un periodo de observación de 8 años, obtuvieron una tasa de supervivencia acumulada del 96\%. Simon (113) en un estudio clínico retrospectivo de diez años de premolares y molares restaurados mediante implantes unitarios observó igualmente un porcentaje del 96\% de 8 supervivencia de los implantes. Krennmair et al. (114) en un estudio retrospectivo obtuvieron una supervivencia acumulada a los 5 años del 98.3\%. Más recientemente, una revisión sistemática sobre la supervivencia y complicaciones a 5 años de coronas unitarias implantosoportadas realizada por Jung et al. (111) obtuvieron una tasa de supervivencia del $96.8 \%$.

Otra razón que ha provocado el incremento del uso de implantes son las indiscutibles ventajas tanto biológicas como funcionales de las restauraciones implantosoportadas respecto a las prótesis removibles convencionales y las prótesis fijas dentosoportadas. Un estudio llevado a cabo por Brägger et al. (115) comparando los parámetros económicos para la reposición de una pérdida unitaria mediante coronas individuales implantosoportadas o puentes fijos de 3 piezas dentosoportados, demuestra una mejor relación coste/efectividad para las restauraciones implantosoportadas. Dado que la efectividad es un factor clave en el complejo proceso de decisión y afecta a la preferencia del paciente hacia cierto tratamiento, es necesaria una información del éxito y supervivencia de las supraestructuras implantosoportadas.

Aunque la mayoría de estas investigaciones tienen un alto rango de éxito y el aflojamiento del tornillo se da con relativa poca frecuencia, el aflojamiento del tornillo es la complicación técnica más frecuentemente encontrada $(105,109,111,112,116$ 118), con unas tasas de aflojamiento que oscilan entre un 4.5 y un $12.7 \%$. Y aunque el aflojamiento del tornillo no es un problema serio en sí mismo, sí que es un gran inconveniente para el paciente y el dentista, requiriendo tiempo de trabajo extra en el sillón dental. 
Además, el movimiento de la restauración debido al aflojamiento del tornillo puede provocar irritación y dolor en los tejidos periimplantarios. Otro aspecto muy a tener en cuenta acerca de las consecuencias del aflojamiento del tornillo, es que puede poner en riesgo la integridad del sistema debido a que las cargas oclusales sobre una restauración con un tornillo aflojado pueden provocar la deformación e incluso la fractura del tornillo, así como daños en la conexión del implante. Y esto es aún más importante si la restauración es cementada, ya que estas pueden ser dañadas o destruidas para lograr acceder al tornillo aflojado $(104,119)$.

Para Simon (113) el porcentaje del aflojamiento de tornillos fue del $7 \%$ tras un periodo de observación de 10 años. Kreissl et al. (112) obtuvieron tras un periodo de observación de 5 años una incidencia acumulada de aflojamiento del 6.7\%. Krennmair et al. (114) obtuvieron en un periodo de 5 años una incidencia de aflojamiento del tornillo del $4.5 \%$. Jung et al. (111) en su revisión sistemática obtuvieron una incidencia acumulada de aflojamiento del tornillo tras 5 años del 12.7\%, duplicando la incidencia de aflojamiento en prótesis parciales fija implantosoportadas. Aunque enfatizan en sus conclusiones que un estudio que utilizaba un antiguo diseño de tornillos de oro fue principalmente el responsable del alto porcentaje de aflojamiento en coronas unitarias. Excluyendo este estudio del análisis, la incidencia acumulada desciende a 5.8\%, muy similar a la incidencia para las prótesis parciales fijas implantosoportadas (112).

\subsubsection{Interfase de unión}

Para saber qué debemos hacer para evitar el aflojamiento de los tornillos de nuestras restauraciones, primero debemos entender el mecanismo por el cual se aflojan estos tornillos. Cuando dos componentes son apretados entre sí mediante un tornillo, a esta unidad se le llama junta de tornillo. El tornillo se afloja solamente si las fuerzas externas que tratan de separar las partes, llamadas fuerzas de separación, son mayores que las fuerzas que las mantienen juntas, Ilamadas fuerzas de cierre. Estas fuerzas de separación no tienen por qué ser eliminadas para prevenir el aflojamiento del tornillo, tan sólo deben mantenerse por debajo del umbral de la fuerza de cierre establecida. Para conseguir una unión segura, el tornillo debe tensarse de modo que la fuerza interna de cierre sea mayor que la fuerza externa que trata de separar la unión. La carga de sujeción 
suele ser proporcional al torque o par de apriete aplicado en el tornillo. El torque es una forma práctica para medir la tensión desarrollada. Un torque demasiado pequeño podría permitir la separación de la junta teniendo como resultado el aflojamiento del tornillo, y un torque demasiado grande puede causar el fracaso del tornillo o la liquidación de los hilos de rosca (120).

El torque aplicado desarrolla una fuerza en el tornillo llamada precarga, que es la carga inicial en el tornillo. La precarga sujeta el paso de rosca del tornillo firmemente a la parte reciproca del implante y mantiene unidas las partes produciendo una fuerza de cierre entre la cabeza del tornillo y su asiento. Al ser apretado el tornillo se alarga, produciendo una tensión ente el vástago y las espiras del implante. La recuperación elástica del tornillo crea un fuerza de cierre que tira de la prótesis y el implante de uno hacia el otro. Son principalmente dos los mecanismos por los que se aflojan los tornillos: un exceso de flexión en la unión y el efecto de asentamiento. Si una fuerza de flexión en una restauración unitaria provoca una carga superior a la resistencia del tornillo, se da una deformación plástica permanente, con una pérdida de fuerzas de tensión en el núcleo del tornillo. Esto resulta en una reducción en las fuerzas de contacto, y consecuentemente, el tornillo se afloja más fácilmente (120-122).

El proceso de asentamiento se basa en que las superficies no son completamente lisas, lo que provoca que las superficies no estén completamente en contacto la una con la otra. Cuando la interfase del tornillo es sometida a cargas externas pueden ocurrir micromovimientos entre las superficies que desgasten las áreas de contacto. Cuando el asentamiento es mayor a la elongación elástica del tornillo, el tornillo se afloja porque no hay fuerzas de contacto para mantener el tornillo (120-122).

El principal factor del inicio del aflojamiento es la carga oclusal. En la cavidad oral, estos procesos ocurren gradualmente con la vibración del tornillo y el desgaste de las superficies, resultando en un estiramiento y distorsión del tornillo y sus roscas. La consecuencia final son movimientos en la interfase implante/aditamento e inevitablemente el aflojamiento de las prótesis (118). 
2. JUSTIFICACIÓN 


\section{Justificación}

Dado que existen dos periodos de interés pronóstico en implantología (precarga y postcarga) y que siguen existiendo falta de evidencias para el clínico acerca de los principales factores pronóstico que inciden en dichas fases, se plantean varios estudios para dar respuesta a las siguientes preguntas:

Durante el periodo precarga las preguntas que nos hacemos son:

1. ¿Es posible mejorar la osteointegración de los implantes mediante el uso tópico de sustancias osteoestimuladoras? Mucho se ha estudiado y publicado sobre la forma de mejorar y acelerar el proceso de osteointegración de los implantes dentales (123). Se han propuesto aplicación de sustancias de forma tópica que van desde el alendronato hasta los factores de crecimiento y las células madre con el objetivo fundamental de acortar el tiempo de tratamiento (123). Una de esta sustancias es la Simvastatina, que ha sido elegida para su estudio debido a los prometedores resultados obtenidos por otros autores, por lo fácil que resulta su síntesis y conservación y lo sencilla que sería su aplicación clínica (124).

2. Teniendo en consideración los nuevos materiales de fabricación de implantes, alternativos al titanio, entre los que destaca el zirconio, ¿qué impacto tienen en cuanto al pronóstico clínico? Debido a la irrupción en el mercado de implantes fabricados en zirconio, buscamos conocer la evidencia existente que tienen detrás.

3. ¿Qué factores atribuibles al paciente (locales, generales y hábitos) y factores relacionados con el implante pueden influir en el resultado terapéutico de los implantes y en qué medida? El fracaso tardío en implantología ha sido asociado con el acúmulo de placa bacteriana y/o sobrecargas, provocando dichos factores periimplantitis (102). Aunque numerosos estudios se centran en el papel que juegan factores sistémicos y locales en el mantenimiento a largo plazo de la osteointegración de los implantes, poco se sabe de los factores que pueden afectar a la aposición ósea inicial, hasta la conexión del aditamento protésico $(93,103)$. En los datos que arroja la literatura al respecto, la incidencia del fracaso temprano se mueve en un rango entre 0.76 y el $7.47 \%$, siendo la incidencia de 
fracasos tardíos (5-10 años posterior a la carga protésica) entre el 2.1 y el $11.3 \%$. De estos datos se desprende la importancia de que los clínicos conozcan el rol que juegan diferentes factores de riesgo en el fracaso temprano de implantes, para poder minimizarlo. Por ello decidimos llevar a cabo un estudio de metanálisis sobre esta temática, para poder analizar la literatura existente en este aspecto y poder aportar luz sobre qué factores influyen de forma significativa en el proceso de fracaso temprano en implantología, ya que es sobre el que menos literatura existe y por tanto menor evidencia (13).

Durante el periodo postcarga el período postcarga.

Las restauraciones unitarias mediante coronas implantosoportadas es una situación clínico-terapéutica que cada vez se presenta con una mayor asiduidad ante el clínico. La complicación más común de este tratamiento es el aflojamiento del tornillo que ancla y retiene la restauración al implante subyacente (105). Aunque el aflojamiento del tornillo se da con relativa poca frecuencia constituye la complicación técnica más frecuentemente encontrada con unas tasas de aflojamiento que oscilan entre un $4.5 \mathrm{y}$ un $12.7 \%(105,111,112)$. Aunque el aflojamiento del tornillo no es un problema serio en sí mismo, sí que es un gran inconveniente para el paciente y el dentista requiriendo tiempo de trabajo extra en el sillón dental. Además, el movimiento de la restauración debido al aflojamiento del tornillo puede provocar irritación y dolor en los tejidos periimplantarios (115). Otro aspecto muy a tener en cuenta acerca de las consecuencias del aflojamiento del tornillo, es que puede poner en riesgo la integridad del sistema debido a que las cargas oclusales sobre una restauración con un tornillo aflojado pueden provocar la deformación e incluso la fractura del tornillo, así como daños en la conexión del implante, siendo aún más importante si la restauración es cementada, ya que la restauración pueden tener que ser dañadas o destruidas para lograr acceder al tornillo aflojado (119). Por todo ello decidimos estudiar esta situación concreta para tratar de establecer unos criterios y así poder evitarla en la medida de lo posible dentro de la práctica diaria clínica y de esta forma mejorar el pronóstico de este tipo de restauraciones implantosoportadas. 
3. OBJETIVOS 


\section{Objetivos.}

El objetivo principal de esta tesis doctoral ha sido identificar y posteriormente analizar algunos temas que se creen de interés para el clínico dentro del tratamiento integral que supone una rehabilitación oral implantosoportada, los cuales influyen y pueden determinar el pronóstico del tratamiento y sobre los cuales no hay respuestas evidentes en la bibliografía. Para ello se marcan estos objetivos iniciales, sobre los cuales se desarrollará un Material y Métodos individual para intentar alcanzarlos:

- Descubrir qué existe en la literatura sobre materiales de fabricación de implantes alternativos al titanio, y si lo superan en cuanto a características físicas, químicas y estéticas.

- Poner de manifiesto qué posibilidades existen para poder acelerar los procesos de regeneración ósea mediante la combinación de sustancias químicas junto con los actuales materiales de regeneración ósea, qué sean sostenibles y de fácil aplicación clínica.

- Conocer la evidencia científica existente en la literatura de los factores de riesgo existentes de forma previa a la carga protésica que pueden llevar al fracaso de la osteintegración de un implante dental y su grado de influencia sobre este proceso.

- Conocer las complicaciones protésicas más habituales, su incidencia y cómo prevenirlas. 
4. MATERIAL

\author{
Y \\ MÉTODOS
}


El presente trabajo se basa en la realización de estudios de diferente diseño (revisión bibliográfica, revisión sistemática, estudio analítico retrospectivo y metanálisis) en áreas de especial interés y controversia en las diferentes fases por las que pasa el tratamiento implanto-protésico. Por lo tanto, para analizar cada uno de los objetivos propuestos se plantea una metodología diferente que se detalla a continuación:

\section{- Análisis de materiales alternativos al Titanio para la fabricación de implantes:} una vez identificado el Zirconio como el principal material que actualmente se postula como alternativa al titanio en cuanto a materiales de fabricación de los implantes dentales, se decide realizar una revisión sistemática basada en una búsqueda bibliográfica en la base de datos Pubmed utilizando la siguiente estrategia de búsqueda: ((("Zirconium"[Mesh] AND "Titanium"[Mesh]) AND "Dental Implants"[Majr]) AND "Osseointegration"[Mesh] NOT "Abutments"). Se limita la búsqueda a estudios animales publicados en inglés. Analizando los abstract se seleccionan aquellos artículos en los cuales se analizan cuantitativamente el grado de osteointegración de los implantes de ambos materiales mediante medidas de BIC (Bone to Implant Contact) y RTQ (Removal Torque). Después de esta preselección se analizaran en profundidad los artículos seleccionados, tanto en contenido como sus referencias. Si alguna de las referencias existente en los artículos seleccionados se considera relevante, se añadirá manualmente a la selección derivada de la estrategia de búsqueda.

- Mejoras en el proceso de regeneración ósea: Realizamos una búsqueda bibliográfica preliminar para identificar el "state of the art" en cuanto a técnicas de aceleración y mejora del proceso fisiológico de regeneración ósea. Encontramos que la mayoría de las investigaciones más recientes se centran en el potencial de la utilización de "Stem cells" (Células madre) y de proteína morfogenética ósea (BMP). Este tipo de técnicas tienen unas barreras, que se desarrollan más adelante en el apartado de discusión, que hacen que a día de hoy no sea ni siquiera planteable el utilizarlas en el día a día de la profesión. 
Por tanto nos centramos en opciones alternativas, cuya implementación, a priori, pensamos que pudieran ser más asequibles para el clínico. Por ello decidimos profundizar en el uso de la Simvastatina combinada con biomateriales para regeneración ósea y estudiar la evidencia científica existente sobre su potencial de mejora del proceso de regeneración ósea. Se realiza una primera búsqueda en la base de datos Pubmed, utilizando como palabras clave "simvastatin" y "bone regeneration", obteniendo 75 resultados. Para acotar el número de resultados, realizamos otra búsqueda con la siguiente estrategia: "Simvastatin" [Mesh] and "Bone Regeneration" [Mesh], limitándonos a los artículos publicados en inglés durante los últimos 10 años, obteniendo 37 resultados relevantes. Posteriormente se completó la lista de artículos mediante una selección manual de 4 artículos relevantes obtenidos de los artículos previamente seleccionados. Los 41 artículos fueron analizados en profundidad y los principales hallazgos resumidos y analizados en función de su nivel de evidencia.

- Fracaso temprano en implantología: Para analizar este aspecto se decide realizar un estudio de meta-análisis debido principalmente a tres razones: la relevancia clínica del proceso, la controversia existente entre autores sobre los factores de riesgo predisponentes a que ocurran fracaso temprano del implante unida a la gran cantidad de estudios presentes en la literatura que siguen alimentando dicha controversia.

- Estrategia de búsqueda: Se realizan 2 búsquedas bibliográficas en la base de datos Pubmed para hacer un análisis comprensivo de la literatura publicada en inglés durante los últimos 10 años. La primera búsqueda se llevó a cabo mediante la siguiente ecuación: "dental implants"[Mesh] AND (early [all fields] AND failure [all fields], obteniendo 53 resultados. Esta búsqueda fue amplia para poder obtener un número grande de resultados. Para acotar la búsqueda se realizó la siguiente estrategia más restrictiva: ("early failure" AND "dental implants") obteniendo 29 resultados. Después de añadir el filtro "randomized 
controlled trial" a las 2 ecuaciones anteriormente mencionadas, no obtuvimos ningún resultado de algún estudio que reportara los factores de riesgo para fracaso temprano en implantología testado con este tipo de diseño experimental. Al no obtener resultados con el diseño anteriormente citado, incluimos en el análisis estudios clínicos tanto prospectivos como retrospectivos. Además se realizó una búsqueda manual sobre la bibliografía de los artículos seleccionados en busca de estudios relevantes adicionales y posibles falsas exclusiones.

- Selección de los artículos: 2 lectores (GM y JM) seleccionaron independientemente los artículos basándose en los títulos y el abstract utilizando los criterios de exclusión previamente definidos. Los artículos excluidos fueron case reports, revisiones bibliográficas (narrativas), estudios invitro o animales, estudios sobre implantes que no fueran dentales (cadera, rodilla), artículos en los que exclusivamente se trataba carga inmediata o temprana, y grupos de pacientes médicamente comprometidos (por ejemplo pacientes irradiados o con enfermedades sistémicas como la diabetes). Los desacuerdos entre los lectores en cuanto a la selección de artículos fueron resueltos mediante sesiones de discusión y si se mantenían ambos en desacuerdo un tercer lector (MB) revisó el estudio independientemente. En caso de duda, la referencia fue incluida. Después de la selección de los artículos basada en el abstract, se obtuvo el texto completo de las referencias seleccionadas. Posteriormente, tres expertos procedentes de diferentes instituciones (MP, MB y FJM) evaluaron de forma independiente los artículos a texto completo mediante un formulario de evaluación. Cada juez cuantificó mediante una escala tipo Likert con 5 niveles o mediante una escala de 0 a 10 diferentes parámetros de calidad de los estudios (tamaño de la muestra, 
método de selección de la muestra, diseño del estudio, periodo de seguimiento, calidad de los resultados expuestos, calidad del tratamiento estadístico de los datos, etc) emitiendo una puntuación final para cada artículo en una escala de 0 a 10

De los 20 artículos seleccionados para el análisis de los expertos, solamente 9 fueron incluidos en el metanálisis. Los 11 artículos restantes fueron excluidos por diferentes razones como por ejemplo: reporte incompleto de los datos obtenidos, definición de fracaso temprano incorrecto, no diferenciación entre fracaso temprano y tardío en sus resultados, etc) (Tabla 1).

\begin{tabular}{|c|c|c|}
\hline Autor, año (Ref) & Status & Razón de exclusión \\
\hline Alsaadi et al, 2007(8) & Incluido & \\
\hline Alsaadi et al, 2008(20) & Incluido & \\
\hline Anitua et al, 2008(21) & Incluido & \\
\hline Baqain et al, 2012(2) & Incluido & \\
\hline Roos-Jansåker et al, 2006(33) & Incluido & \\
\hline Shibuya et al, 2012(3) & Incluido & \\
\hline Urban et al. (47) & Excluido & Diferentes criterios para considerar fracaso temprano \\
\hline Van Steenberghe et al, 2002(5) & Incluido & \\
\hline Vehemente et al. (48) & Excluido & No diferencia entre fracaso temprano y tardío \\
\hline Zembic et al. (49) & Excluido & Implantes evaluados tras la carga protésica \\
\hline Bornstein et al, 2008(22) & Incluido & \\
\hline Gianserra et al. (50) & Excluido & Descripción de resultados insuficiente \\
\hline Huynh-Ba et al. (51) & Excluido & $\begin{array}{l}\text { Ausencia de relación entre fracaso temprano y } \\
\text { variables estudiadas }\end{array}$ \\
\hline
\end{tabular}




\begin{tabular}{|l|l|l|}
\hline Kinsel et al. (52) & Excluido & Implantes evaluados tras la carga protésica \\
\hline Koldsland et al. (9) & Excluido & No diferencia entre fracaso temprano y tardío \\
\hline Kronström et al, 2001(4) & Incluido & \\
\hline McDermott et al. (53) & Excluido & No diferencia entre fracaso temprano y tardío \\
\hline Susarla et al. (54) & Excluido & No diferencia entre fracaso temprano y tardío \\
\hline Sverzut et al. (32) & Excluido & Diferentes criterios para considerar fracaso temprano \\
\hline
\end{tabular}

Tabla 1. Relación de artículos aceptados y rechazados en la selección bibliográfica válida para el estudio metaanalítico.

- Análisis estadístico: para realizar la comparación meta-analítica de los datos agregados, el tamaño del efecto elegido fue el odds ratio (OR). El odds ratio puede definirse de forma sencilla como una medida de asociación entre una exposición y un resultado (en nuestro caso el fracaso temprano del implante). Por tanto el OR representa la posibilidad de que ocurra el fracaso temprano de un implante debido a una exposición concreta, comparado con la probabilidad de que el fracaso temprano ocurra en ausencia de dicha exposición. Esto significa que un factor de riesgo con un OR con valor mayor que 1 implica un mayor riesgo de fracaso temprano comparado con los implantes no expuestos a dicho factor. El método de Mantel-Haenzsel fue utilizado para integrar los OR asumiendo el modelo de efectos fijos. El test de homogeneidad Q fue llevado a cabo con el objetivo de validar la hipótesis de que estamos ante un modelo de efectos fijos y que por tanto el tamaño del efecto es el mismo en todos los estudios analizados. Puesto que la potencia del test de homogeneidad es robusta y que el test $Q$ solo deberían encontrar resultados significativos cuando la discrepancia entre OR es grande, decidimos explorar la heterogeneidad entre estudios mediante las contribuciones al test $Q$ para validar los resultados de $Q$ cuando el $p$-valor sea inferior a 0.15 . El estadístico $l^{2}$ fue utilizado también para 
valorar la heterogeneidad (125-127). El meta-análisis fue realizado utilizando el programa MIX 2.0 (Biostat XL, 2011).

- Complicaciones de la fase protésica: Aflojamiento de tornillo. Elegimos el aflojamiento de tornillo como temática de nuestro estudio para esta fase del tratamiento implantológico ya que, según la literatura, es la complicación más común del tratamiento protésico implantosoportado. El objetivo fue mediante un estudio retrospectivo evaluar la incidencia de complicaciones protéticas en coronas implantosoportadas fabricadas sobre aditamentos tipo UCLA, así como identificar los factores de riesgo con el objetivo de establecer una serie de recomendaciones para ayudar al clínico a disminuir dicha complicación. Para ello se diseñó un estudio retrospectivo, con un periodo de duración de 5 años, llevado a cabo en 71 pacientes parcialmente edéntulos, rehabilitados mediante 93 coronas unitarias implantoretenidas. Se analizaron aspectos sociodemográficos, factores anatómicos, variables relativas a los implantes y otras relacionadas con la prótesis. Para establecer los posibles factores de riesgo se utilizaron coeficientes como el Odds Ratio (OR), Tasa de Incidencia (\%) y el Riesgo Relativo (RR). Para comparar variables cuantitativas se utilizaron los test ANOVA y T de Student, el Test Chi-cuadrado se utilizó para comparar proporciones y también se realizó un análisis de regresión logística. Se estableció un nivel de significación de $\alpha=0.05$. 


\section{Publicaciones}

\section{Originales, Resultados y Discusión}




\section{Comparison of Clinical Performance of}

\section{Zirconia Implants and Titanium Implants in Animal Models: A Systematic Review}

Gullermo Manzeno, uUS $1 / L$ t Huben Harrero. DDS $1 /$ /avier Montero, DDS, PhD 2

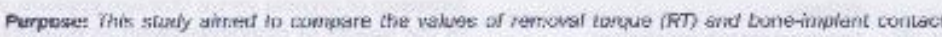

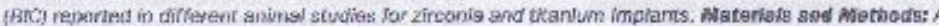

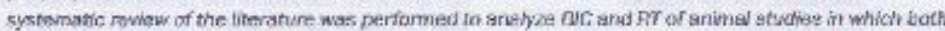

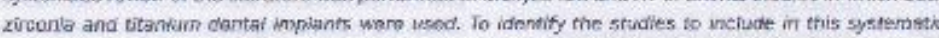

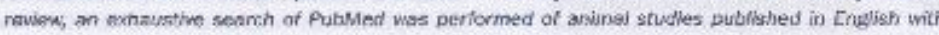

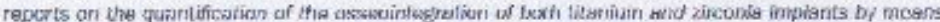

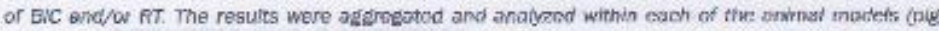

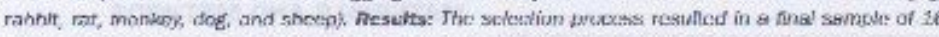

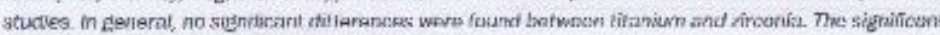

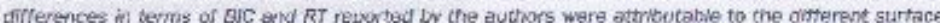

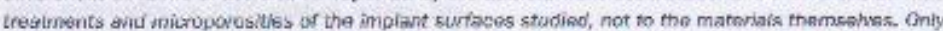

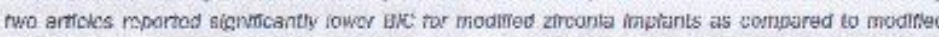

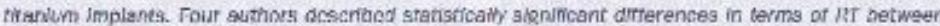

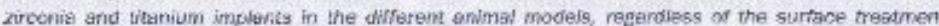
received by the implants. Conclusions: Whathin the firmitetions or this study, the vefues for the GWC and

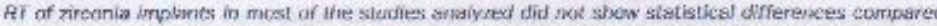
with tilawium implents. Modihlod surtaco zlrconla may nave potential as a candidate for a successful

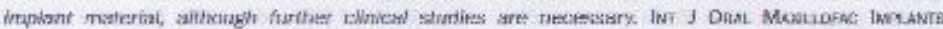

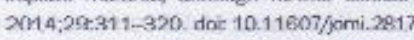

Key words: dentaf implants, tiankith, zirconte

The replacement of tenth with dental implents in partially or completely edentulous patients is o widely accepred and documented treatment modality' 15 The materials most commonty used for this purpose are commerisilly pure titanium and titanium alloys because of their biocompatibility and excellent mechanical properties ${ }^{l-7}$ Commercially pure titanium has different degrees of purity (grades 1 to 4 ), as char acterized by cxygen, iron, and carbon content. 6 Most

2 Dertal Postgratuate Student, Departmont of Surgery, Faciaty of Medicine. Unwereity of Saliamanca, Campue Migust de Unemurno, Spain.

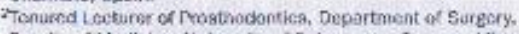
Faciulty of Medicine. Unibersity of Salemarnea, Campus Migue de Linzenunst. Snain.

Conrespondense tue Janier Montero. Clinica Otiontologgeca.

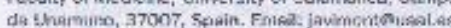

Q2014 by Quintessenos Pubirhong co ins. implants are macie of grade $\mathbf{4}$ titarium, since it is stron. ger than the other grades." Titanium alloys are typical ly titanium-aluminum-vanadlum (II-6Al-ry) (grade 5 titanium alloy), which has greater strength and fatigue tesistarce than pute titanium ${ }^{\circ}$

Since the introduction by Branemark et al $\left.\right|^{1,2}$ of the biwolrogir connrepst of ensersinterpation, defincd as a direct structural and functional connection between ordered living bone and the surface of a load-carrying implant, titanium has been considered the gold stardard moie titanium has been considered the gold stardard moie-
rial used for dental implants. riel used for dental implants ${ }^{-5}$ Ten-year survival matos been reporteef 7, , ? for marhinew titanium implants

Zirconia has been proposed as an alterrative to titanium as an implant material primarily for esthetic reasons. ${ }^{B}$ When titanium implants are used, esperially reasons ${ }^{k}$ When titanium implants are thed, esperisily
in anterlor sites in the mourh, they can produce poon In anterlor sites in the mouth, they can produce poor
osthetics: the groyish color of the implant body is $v x$. osthetics: the groyish color of the impliant body is ox
posed after soft tissue recession or if a thin gingival biotype is present. The material of zirconis implants is yttria-stabilized zirconia ceramic (Y-TZP), which

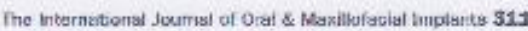

Q 2014 BY QUNTESSENCE PUBLLSHING CO, INC. PRINTING OF THIS DOCUMENT IS RESTRICTED TO PERBOAAL USE OALY

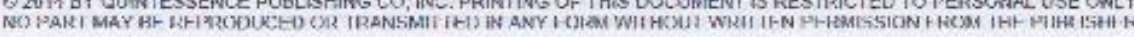




\subsection{Comparativa del comportamiento clínico de los implantes de zirconio con los implantes de titanio.}

En esta revisión sistemática se buscó analizar en la literatura existente el rendimiento clínico de los implantes de zirconio frente a los de titanio. Encontramos que la mayoría de los estudios se basaban para analizar dicho rendimiento o comportamiento clínico en el análisis de la osteointegración de los implantes de diferentes materiales, utilizando como medidas el BIC (Bone Implant Contact) y / o RTQ (Removal Torque). La metodología aplicada para esta revisión siguió las recomendaciones de la guía QUÓRUM recomendada por el Comité Internacional de Editores de Revistas Médicas (www.icmje.org). En suma, en la mayoría de los estudios incluidos se observó que el período de curación para la evaluación de los implantes de titanio y óxido de circonio osciló entre 14 días y 6 meses (Tabla 2)Tabla 2. Torque de remoción obtenido en los diferentes estudios analizados. (6). Los implantes se colocaron en diferentes modelos animales (de las ratas a los monos), en diferentes lugares anatómicos, y bajo diferentes condiciones de carga protésica (en su mayoría no cargados). Además, la mayoría de ellos se realizaron en conejos (por lo general en el fémur o la tibia) y mini cerdos (en el maxilar). En estos estudios, el hueso reacciona con implantes de zirconio como lo hizo con los implantes de titanio $(20,128-$ 132) o aún mejor en el período inicial de curación (133-135). Sin embargo, otros autores han encontrado una tendencia hacia una mejor BIC para los implantes de titanio (136-138). Debe tenerse en cuenta que la mayoría de los estudios se realizaron con una pequeña muestra de los animales ( $n \leq 15$ individuos), e incluso evaluaron diferentes períodos de seguimiento, lo que reduce considerablemente la potencia estadística para la detección de diferencias significativas. Un parámetro que puede mejorar el proceso de formación ósea temprana es la modificación de la superficie del implante $(139,140)$. Varios estudios han demostrado que una mayor rugosidad de la superficie del implante logra un contacto mayor entre hueso e implante (141-145). En la presente revisión, 3 estudios $(131,133,146)$ compararon los implantes mecanizados de óxido de 
circonio e implantes de óxido de circonio con una superficie modificada mediante chorreado de arena en el mismo animal de experimentación encontrando un mayor BIC en los implantes con una superficie modificada $(131,133)$. Sin embargo, estos resultados no fueron significativos, mientras que el RTQ sí que se mostró significativamente mayor en los implantes con superficie modificada $(131,133,146)$. Otra técnica para intentar mejorar la osteointegración consiste en el recubrimiento del implante con diferentes compuestos, lo cual se ha aplicado también en los implantes de óxido de circonio: CaP (20)(147), hidroxiapatita (135), y Ca (132). Sin embargo, en los estudios de Lee et al. (20) y Rocchietta et al. (135) estos procedimientos de revestimiento no proporcionaron ningún beneficio con respecto a los implantes de óxido de zirconio modificados con chorro de arena. Koch et al. (132) encontraron que los implantes de óxido de circonio revestidos con calcio conservan una mayor cantidad de cresta ósea, pero esta mejora no fue significativa en comparación con los implantes de óxido de circonio sin recubrir. Sin embargo, los autores concluyeron que la conservación del hueso crestal podría haber sido debida a dicho recubrimiento de calcio.

Otro factor que debe ser abordado en futuros estudios es el efecto de la carga del implante. De los artículos revisados, sólo uno evaluó el nivel de osteointegración de los implantes de circonio en comparación con los implantes de titanio bajo condiciones de carga (136). Después de un período de carga de 5 meses, no hubo diferencias significativas en el BIC de los implantes de titanio (arenado y grabado ácido) y los implantes de óxido de zirconio (tratamiento de superficie mediante chorreado de arena), obteniendo los implantes de titanio un BIC mayor en términos absolutos (136). No se observaron diferencias entre los dos tipos de implante en el análisis de los tejidos blandos periimplantarios. En la comparación de los implantes de Zr y Ti, ambos deben tener un tratamiento de superficie equivalente porque el RTQ y los parámetros de BIC pueden ser modificados por la diferencia en la rugosidad de la superficie y no por el material. Cabe señalar que en el diseño macroscópico de los implantes (de tipo rosca, implantes cónicos o cilíndricos, etc.) también debe ser similar para poder obtener resultados 
equivalentes. En los estudios revisados, el RTQ fue significativamente mayor en los implantes de óxido de circonio con una superficie modificada, en comparación con los implantes de óxido de zirconio mecanizado $(131,133,146)$. Sin embargo, en la comparación de los implantes de titanio modificados con los implantes de óxido de zirconio modificados los valores RTQ son similares (Tabla 2). De todos los artículos estudiados, sólo 6 de ellos $(129,130,132,136,138,146)$ se llevaron a cabo en la cavidad oral de los animales. Serían necesarios más estudios con un diseño "split mouth" para, entre otros parámetros, analizar la degradación de los implantes de óxido de zirconio en bajo condiciones orales. Además, los estudios que evalúan el rendimiento clínico después de la carga funcional de los implantes de circonio son escasos.

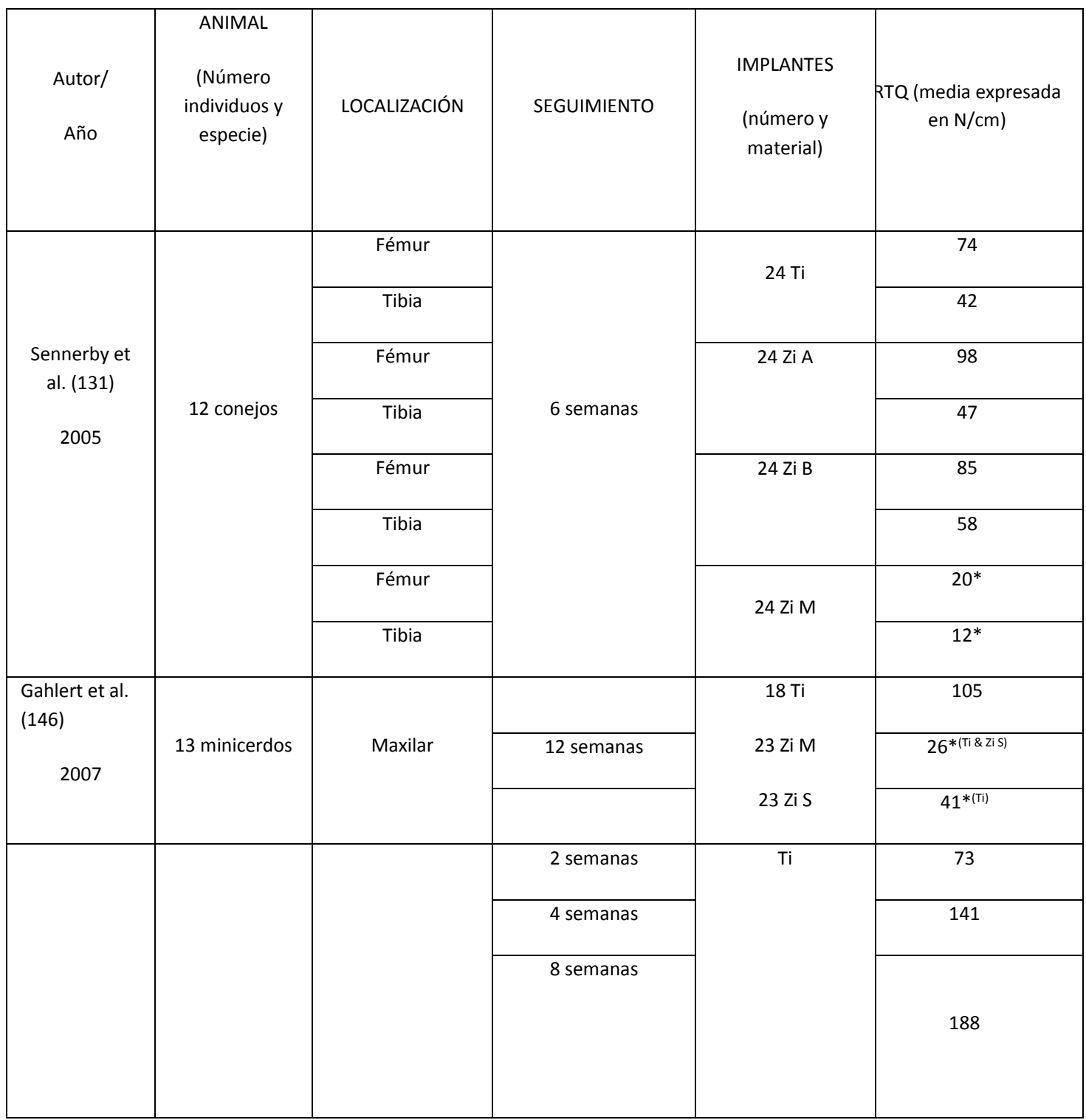


Factores pronósticos en implantología oral

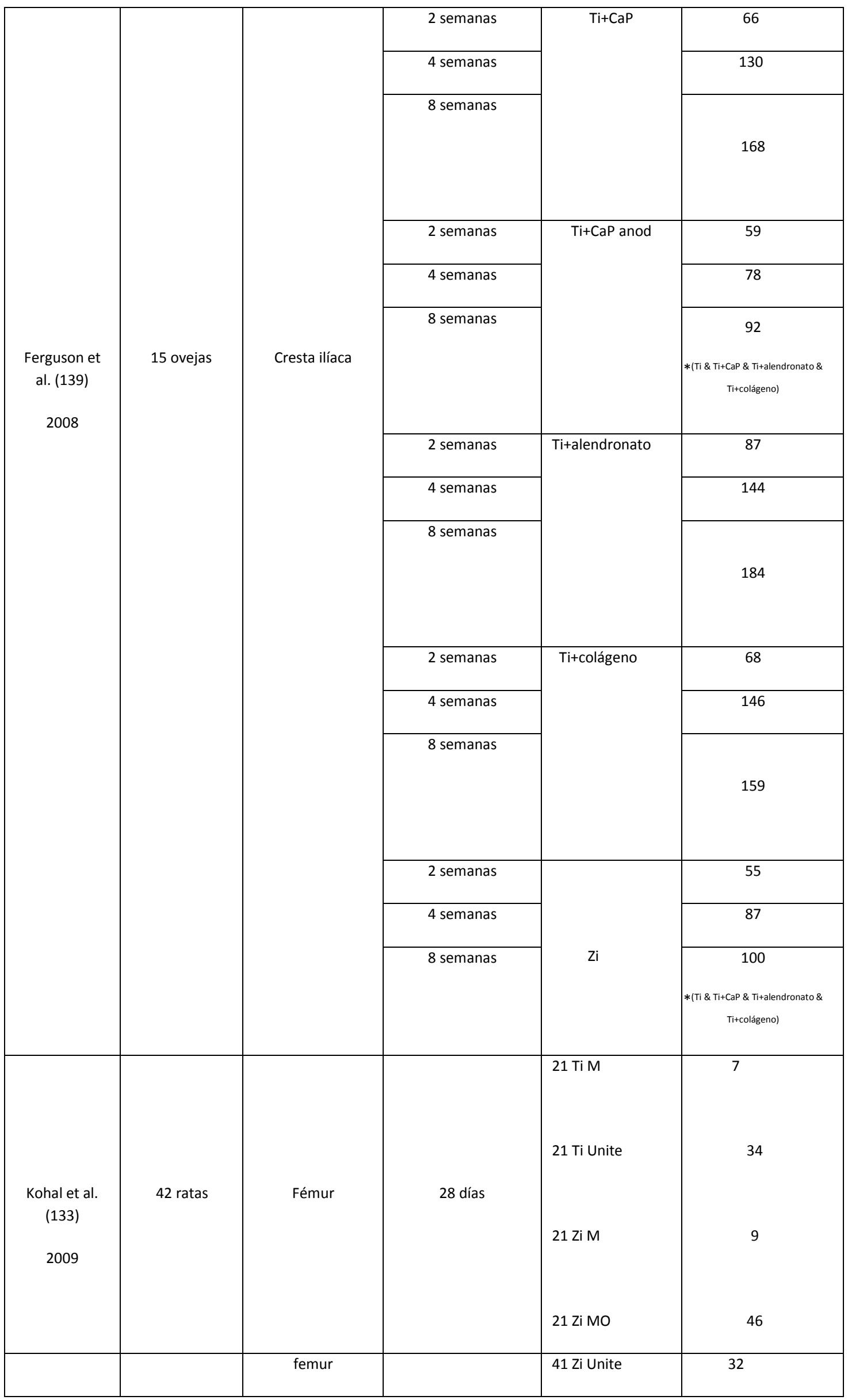




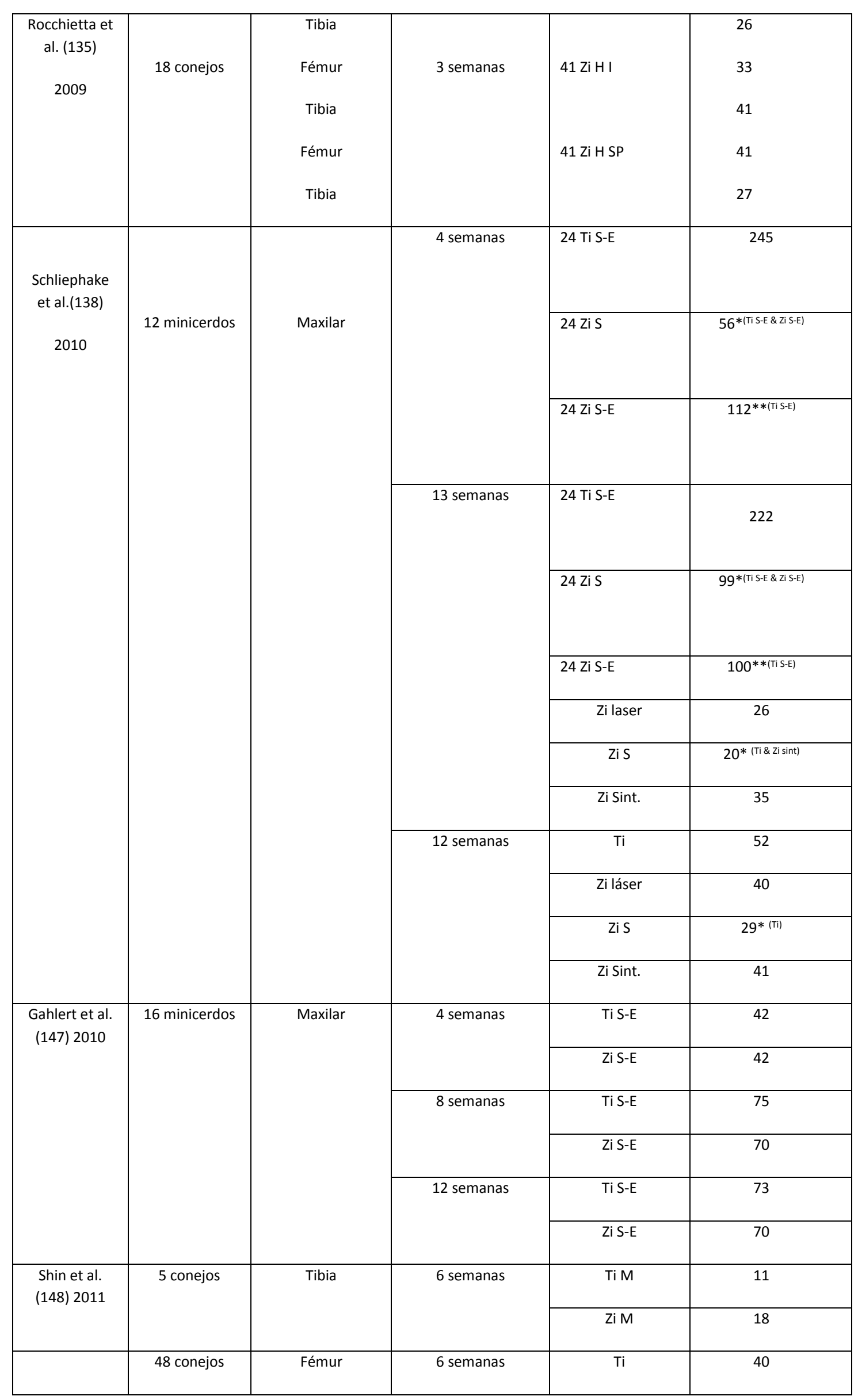




\begin{tabular}{|c|c|c|c|}
\hline \multirow{7}{*}{$\begin{array}{l}\text { Hoffmann et } \\
\text { al. (149) } 2012\end{array}$} & & Zi laser & 26 \\
\hline & & ZiS & $20 *$ (Ti \& Zi sint) \\
\hline & & Zi Sint. & 35 \\
\hline & 12 semanas & $\mathrm{Ti}$ & 52 \\
\hline & & Zi laser & 40 \\
\hline & & ZiS & $29 *(\mathrm{Ti})$ \\
\hline & & Zi Sint. & 41 \\
\hline
\end{tabular}

Tabla 2. Torque de remoción obtenido en los diferentes estudios analizados.

$\begin{array}{llll}\text { Ti: titanium } & \text { Zi: zirconia } & \text { S: sandblasted } & \text { Sub: submerged } \\ \text { E: etched } & \text { M: machined } & \text { I: immersion } & \text { N-Sub: not submerged }\end{array}$

SP: sprayed MO: modified H: hydroxyapatite

* Significantly lower values than the subgroup used in brackets. $p<0.05$

** Significantly lower values than the subgroup used in brackets. $p<0.01$

Nuevos estudios deberán seguir varias líneas de investigación, como el mejor tratamiento de la superficie de óxido de circonio, la influencia de la carga, la contaminación microbiológica, las respuestas de los tejidos blandos ... Una descripción más detallada del tipo de modificación de la superficie aplicada a los implantes (por lo por lo menos en lo que respecta porosidad y granulometría) debería haber sido incluido en la metodología de los trabajos publicados de manera que la comparabilidad de los estudios puede ser mejorada y puntos de vista de la investigación para los colaboradores mejorada. Sin embargo, hay que reconocer que utilizando sólo la base de datos PubMed para la búsqueda bibliográfica puede no haberse captado toda la literatura disponible, aunque ciertamente si en su mayoría y los más relevantes. 


\title{
The role of topical simvastatin on bone regeneration:
}

\section{A systematic review}

\author{
Javier Montero ${ }^{1}$, Guillermo Manzano ${ }^{2}$, Alberto Albaladejo ${ }^{3}$
}

' DDS. PhD, Temured lecturer in Prosthodontics. Department of Surgery, Faculty of Medicine, University of Salamanca (USAL), Salamanca, Spain

${ }^{2}$ DDS, Postgraduate Student. Master in Dental Sciences. University of Salamanca (USAL), Salamanca, Spain

'DDS. PhD. Temured lecturer in Orthodontic5. Department of Surgery. Faculty of Medicine, University of Salamanca (USAL),

Salamanca, Spain

Carrespondence:

Clinisa Odoutalógina Facultad de Medictina

C/Abronso $X$ el Sabio SN.

Canpus Mignel de Uhawime.

C.P: 37007 , Salomana Spain

jenimonnguales

Moutero J, Manzeno G, Albaledejo A. The role of topical simvastatin on bone regenerztion: A systematic roviow. J Clin Exp Dent. 2014;6(3):e28690.

http://wwwmedicinsoral.com/odo/volumenes/v6i3/jcedv6i3pipdf

Rescived 10 1023s

Acceplet Gutasost

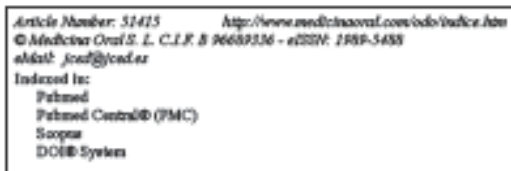

\begin{abstract}
Objectives: The aim of this systematic review was to summarize the results conceming the use of simvastatin for promoting bone regeneration and to discuss the level of scientific evidence supporting such findings.

Material and Methods: A Pubmed search using "Simvastatin"[Mesh] AND "Bone Regeneration"[Mesh] as Boolean operators was constrained to the last 10 years and only included papers written in English.

Results: Of the 41 relevant papers reviewed, most of them $(76.2 \%)$ have been published in the last 5 years, and most of them address animal studies $(66.6 \%)$ performed on rats or rabbits in extraoral regions. Only 4 randomized controlled trials (RCT5) assessed the role of topical simvastatin in periodontal patients.

Conclusions: A large part of the evidence concerning the role of topical simvastatin on bone regeneration comes from animal studies (mainly rats) focusing on extraoral bone defects. Only the use of subgingival simvastatin after
\end{abstract} root scaling has been properly supported by RCT.

Key words: Simvastatin, bone regeneration, topical administration, osteogenesis, osteoinduction.

\section{Introduction}

Since the popularization of dental implants, clinicians have found themselves in circumstances in which they are forced to place implants in areas where the quality, quantity and topography of bone substrate are clearly unfavorable. In addition, several regenerative strategies have been proposed with the aim of preserving the alveolar process after tooth extraction (1) or for angmenting bone support for dental inplants (2). Thus, the demand for effective biomaterials for bone augmentation procedures is currently increasing owing to the disadvantages of using autogenous bone graft material, such as limited bone availability, additional morbidity at the donor site, the impossibility of storage, and the need for general anesthesia for extraoral donor sites (3). In light of this, researchers are now searching for bone graft materials with improved osteogenic properties, with the advantages of autologous bone grafts [osteogenesis, osteoinduction and osteoconduction], but without their disadvantages [donor site morbidity, difficulty of storage and maintenance, unlimited availability, etc] 


\subsection{Efecto de la Simvastatina sobre la regeneración ósea}

La regeneración ósea requiere tres componentes esenciales: en primer lugar moléculas de señalización; en segundo lugar, un andamio que actúe como superficie osteoconductiva y que de soporte a la formación ósea producida por los osteoblastos; y por último, células responsables de la formación ósea (150). La estrategia que se intenta desarrollar con la combinación de simvastatina con los materiales aloplásticos disponibles en el mercado es producir, mediante estímulos externos, una estimulación de las células del organismo y provocar de esta forma una reparación local del tejido óseo de una forma óptima en el menor tiempo posible $(66,82,151)$.

En la reparación de los defectos craneales, las células osteogénicas proliferan y migran principalmente desde la dura madre y los bordes del defecto en los grupos tratados en los estadíos iniciales de la cicatrización ósea (82). Durante la regeneración ósea, las células mesenquimales juegan un papel importante ya que son a partir de las cuales se diferencian las células osteogénicas. Los almacenes de estas células mesenquimales son la médula ósea, tejido de granulación, el periostio, el endostio y los tejidos blandos circundantes (82). Varios estudios han demostrado que el proceso de regeneración ósea craneal es regulado inicialmente por citoquinas y células precursoras que provienen de la dura madre $(82,85)$.

Las proteínas morfogenéticas óseas (BMP: Bone Morphogenetic Proteins) son capaces de inducir la diferenciación de células madre mesenquimales a osteoblastos, acelerando sustancialmente la regeneración de un defecto óseo, pero la dificultad de su síntesis, almacenamiento, manipulación y coste dificultan enormemente su aplicación clínica $(73,74,152)$. Por ello se plantea el uso de otras sustancias que induzcan la formación endógena de BMPs, entre las que destaca la simvastatina. 


\subsubsection{Fundamentos bioquímicos de la acción de la simvastatina tópica sobre el tejido} óseo

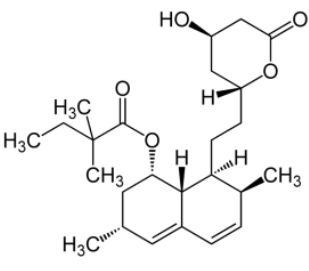

Figura 5. Estructura química de la simvastatina

La simvastatina $\left(\mathrm{C}_{25} \mathrm{H}_{38} \mathrm{O}_{5}\right)$ es una modificación química de la lovastatina, que consiste en el reemplazo en la cadena lateral del grupo 2-metil-butiril de la lovastatina por un grupo 2,2 dimetil-butiril (Figura 5) (153). La simvastatina es un fármaco inactivo, que tras la administración oral es convertida a su forma activa mediante la acción de la enzima intracelular citocromo P450 en el hígado. La simvastatina no es bien absorbida, y menos de un $5 \%$ de la dosis oral pasa a circulación sistémica (124). Las concentraciones de simvastatina en médula ósea provenientes de su administración sistémica no han sido bien establecidas todavía, pero los osteoblastos y los osteoclastos podrían estar expuestos a muy bajas concentraciones de estatina con pautas orales de administración (124).

Es uno de los fármacos más comúnmente prescritos para el tratamiento de la hipercolesterolemia, debido a que inhibe la vía del mevalonato anulando la acción de la enzima 3-hidroxi-3metil-glutaril Coenzima A reductasa (HMG-CoA reductasa) impidiendo la síntesis de colesterol (154). La HMG-CoA reductasa convierte HMG-CoA a mevalonato y es la enzima determinante en la síntesis de colesterol. Una inhibición competitiva de esta enzima por la acción farmacológica de las estatinas desciende la biosíntesis intracelular del colesterol, la cual se lleva a cabo por un aumento de la transcripción lo que lleva al aumento de la producción microsomal de la HMG-CoA reductasa y receptores de superficie para lipoproteína de baja densidad (LDL) (154). Debido a la regulación positiva del HMG-CoA reductasa, la síntesis de colesterol desciende ligeramente, pero la estimulación de las LDL reduce los niveles de colesterol en plasma (154).

Además de los efectos hipolipemiantes, recientemente se han estudiado efectos pleiotrópicos, como son la inhibición de crecimiento tumoral y metástasis, promoción de la angiogénesis, descenso del péptido $\beta$-amieloide, supresión de linfocitos $T$, etc (155). En particular, uno de los efectos que más puede influir en el campo de la odontoestomatología es la capacidad de las estatinas de promover la diferenciación 
osteoblástica, provocada por la estimulación de la producción de la BMP-2 (155). También se ha estudiado la posibilidad de que las estatinas aumenten el factor de crecimiento endotelial vascular, favoreciendo también así la formación ósea. Sin embargo, existe controversia en el potencial de las estatinas en la regeneración ósea, ya que a ciertas dosis puede provocar inflamación local sin efectos visibles en cuanto a mejora de formación de hueso (155).

Pero además de esta función principal de regulación de los niveles de colesterol en sangre, se ha observado que las estatinas promueven la actividad osteoblástica e inhiben la actividad osteoclástica y tienen un efecto favorecedor de la angiogénesis. Se han planteado varios mecanismos de acción que pueden explicar estos efectos (155).

- Efectos sobre la actividad de los osteoblastos: actúan aumentando los niveles de BMP's $(152,156)$. La evaluación de la expresión de la BMP-2 es la forma más indicada para investigar la capacidad de curación ósea y regeneración. Las proteínas morfogenéticas óseas (BMPs) son factores de inducción ósea que actúan sobre las células mesenquimales inmaduras, incluidos los osteoblastos, promoviendo la osteogénesis (156). Existen diferentes hipótesis sobre cómo la simvastatina produce este aumento en la expresión de BMP's (157):

1. Las estatinas, y la simvastatina en particular promueven la diferenciación osteoblástica mediante la vía Ras/Smad/erk/BMP-2) (Figura 6) (158). La simvastatina ha demostrado que invierte los efectos supresivos del factor de necrosis tumoral e impide la inhibición de BMP-2 mediada por la fosforilación 1,5 y 8 de Smad (158). Los osteoblastos y los adipocitos de la médula tienen un origen mesenquimal común y se ha visto que los agentes adipogénicos suprimen la diferenciación osteoblástica. 


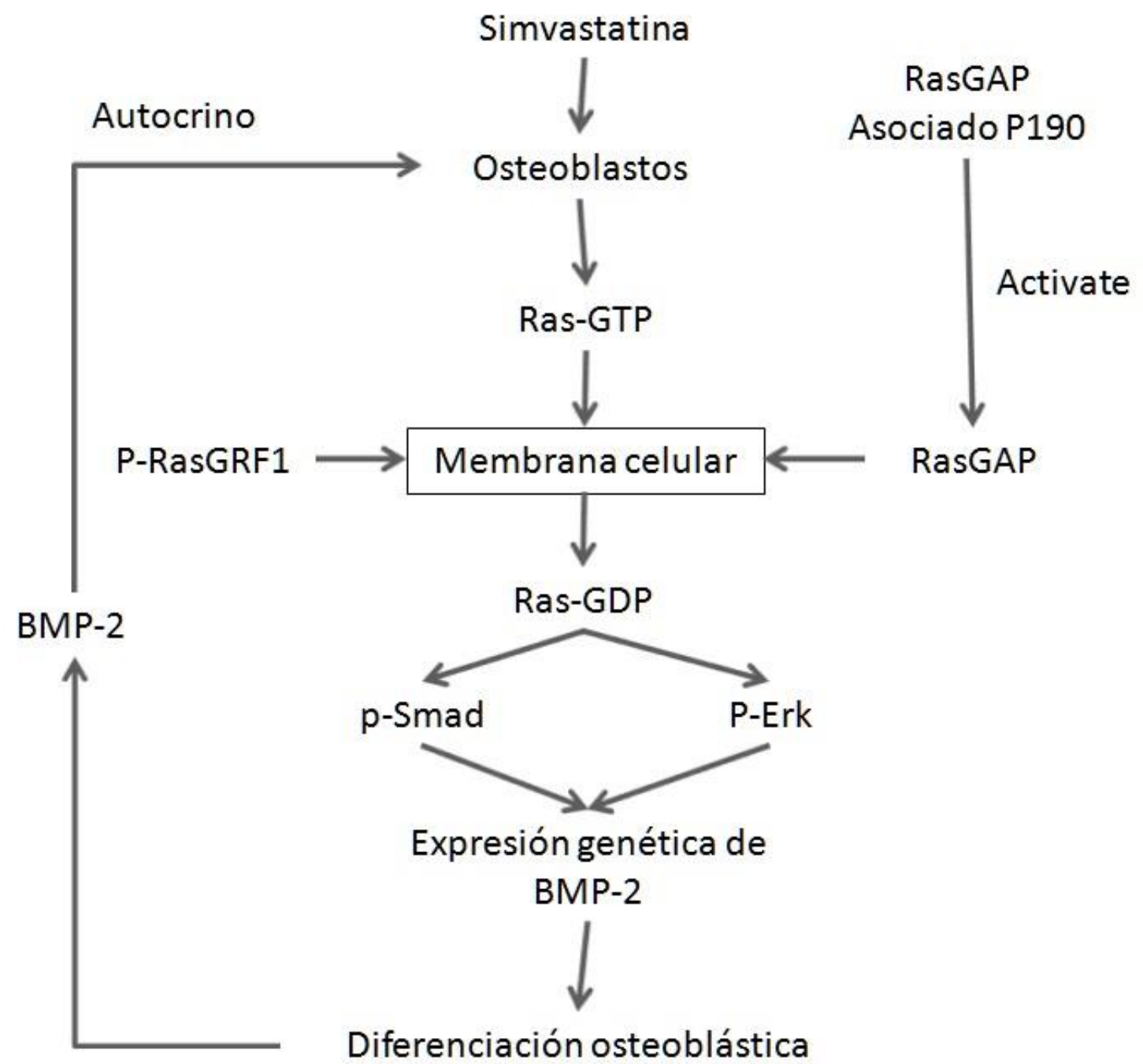

Figura 6.Esquema acción de la simvastatina sobre la vía de señalización Ras/Smad/erk/BMP-2

2. La simvastatina estimula la BMP la cual induce la diferenciación de osteoblastos mediante el antagonismo de TNF $\alpha$ con Ras/Rho/mitogen protein kinasa activada y aumentando la señalización de la BMP-Smad $(158,159)$. Desciende la disponibilidad de compuestos intermedios lipídicos isoprenoides como el Farmesil difosfato (FPP) y el geranil-geranil difosfato (GGPP), que son productos finales de la vía del mevalonato diferentes al colesterol y que juegan un papel importante en la prenilación de algunas pequeñas GTPasas (tamaño 20$25 \mathrm{KDa}$ ) como Ras y Rho, las cuales son importantes para el mantenimiento de la integridad celular, el citoesqueleto y el tráfico de vesículas. Las estatinas dificultan la prenilación de las pequeñas GTPasas inhibiendo el FPP y el GGPP, 
provocando por ello que la síntesis de BMP-2 o la expresión de la osteocalcina aumenten (159). Sus efectos en cuanto a formación ósea están asociados con el aumento de la expresión del ARNm de la BMP-2 y con el aumento de la expresión del factor de crecimiento endotelial vascular los cuales son factores importantes en la diferenciación osteoblástica y la neoformación ósea (159).

La activación de Ras y la consecuente activación de la vía MAPK o Akt es necesaria para que la expresión de BMP-2 inducida por estatinas produzca una diferenciación de las células mesenquimales progenitoras de osteoblastos. La forma activa de Ras es una cadena GTP y es sensible a su localización (159). La actividad de Ras puede ser regulada mediante 3 vías:

- Modificaciones postraslacionales que facilitan el anclaje a la membrana y su localización intracelular.

- Activación mediante enzimas factor intercambiador del nucleótido de guanina (GEF) que causan que se disocie el GDP de la GTPasa, permitiendo su asociación con un nuevo GTP.

- Inactivación mediante proteínas activadoras de GTPasa (GAP: GTPActivated Protein) estimulando la actividad de GTPasas intrínsecas.

- Efectos sobre la actividad de osteoclastos: los mecanismos de acción de las estatinas sobre la actividad osteoclástica más importantes reflejados en la literatura son:

1. Las estatinas parecen reducir la reabsorción ósea disminuyendo la expresión de la enzima osteoclástica catepsina $\mathrm{K}$ a través de la depresión RANKL, impidiendo la fusión de precursores osteoclásticos y rompiendo el anillo de actina de los osteoclastos lo cual provoca un descenso marcado del número de osteoclastos activos $(155,159)$. El ligando de receptor activador para el factor nuclear $\mathrm{k} B$, más conocido como RANKL (Receptor Activator for Nuclear Factor $\kappa$ B Ligand), es una importante molécula del metabolismo óseo que se encuentra en la superficie de la membrana de los osteoblastos, de las células del estroma y de los linfocitos T. Éstos últimos son los únicos en los que se ha 
demostrado la capacidad de secretarla. Su principal función es la activación de los osteoclastos $(155,159)$.

2. El descenso en el número de osteoclastos se justifica mediante estudios histológicos que vieron una baja actividad de la fosfatasa ácida tartrato resistente 5b, indicando baja actividad osteoclástica (155).

3. La prenilación de algunos tipos de pequeñas guanosin trifosfatasas (GTPasas) son también importantes en este proceso debido a que estas GTPasas preniladas activan los osteoclastos e inhiben la síntesis de BMP-2. Las estatinas inhiben esta prenilación y como resultado se puede obtener un aumento de masa ósea sistémicamente $(152,155)$.

4. Inhibición de las GTPasas de la membrana de los osteoclastos lo que conlleva la pérdida de su capacidad de transporte intracelular (155).

- Mecanismos favorecedores de la angiogénesis: la necesidad de vasos sanguíneos es un requisito fundamental para el correcto crecimiento y remodelación de la sustancia ósea $(160,161)$.

1. La simvastatina estimula el factor de crecimiento endotelial vascular (VEGF) de forma dosis dependiente y algunos autores defienden que se puede promover la diferenciación de los osteoblastos y la formación ósea inicial mediante la estimulación de VEGF en tejido óseo $(85,124,162)$.

- Otros efectos favorecedores para la regeneración ósea: la simvastatina aumenta la actividad de la fosfatasa alcalina y la mineralización e incrementa la expresión de la sialoproteína ósea, osteocalcina y el colágeno tipo I. También se han observado efectos antiinflamatorios por el descenso que causa de la producción de IL6 e IL-8 $(157,162)$.

Como consecuencia, las estatinas juegan un papel importante de forma directa participando tanto en la activación osteoblástica como en la inhibición de osteoclastos y de forma indirecta estimulando la neovascularización mediante el aumento de VEGF, lo que se deriva en un incremento de masa ósea. 


\subsubsection{Dosis de simvastatina.}

Para que la simvastatina administrada sistémicamente por vía oral tenga efectos significativos a nivel óseo, las concentraciones deben ser extremadamente altas, debido a su degradación hepática. Se estima que sólo un $5 \%$ del total de la simvastatina administrada vía oral pasa a la circulación general (124). En ratas los autores consideran que una dosis de $10 \mathrm{mg} / \mathrm{kg} /$ día la cual es equivalente a una dosis en humanos de $70 \mathrm{mg} /$ día, teniendo en cuenta que el metabolismo de las ratas es 10 veces más rápido que el de humanos (124). Por esto hay que ser precavidos a la hora de ajustar las dosis de los experimentos animales antes de plantear su uso en humanos, ya que no es una fórmula matemática infalible, simplemente estas relaciones suponen una guía a la hora de realizar la extrapolación $(124,151)$. Existe evidencia de que una alta concentración de simvastatina sistémica puede inducir un fallo hepático, enfermedad de Kidney, rabdomiolisis, mialgia y otros efectos secundarios $(124,151)$. Por ello los estudios utilizan su aplicación de forma tópica, bien en inyección subcutánea con una pauta de aplicaciones repetidas durante un periodo de seguimiento o aplicación intraoperatoria en el defecto óseo en combinación con diferentes biomateriales. La simvastatina posee propiedades antiinflamatorias, pero estas propiedades se ven alteradas también a altas dosis, provocando paradójicamente inflamación e incluso un descenso de la tasa de neoformación ósea $(1,66,82,83,86)$.

Mundy y colaboradores (79) observaron un aumento de volumen óseo en ratas ovarictomizadas con una dosis administrada sistémicamente de $5-10 \mathrm{mg} / \mathrm{kg}$ durante 35 días. Otros estudios animales indican que una alta dosis de simvastatina sistémica (20mg/kg/día) incrementa la formación ósea, mientras que una dosis menor $(1 \mathrm{mg} / \mathrm{kg} /$ día) disminuye la formación ósea e incluso favorece la reabsorción (163).

En cuanto a la aplicación tópica de simvastatina, la dosis evaluada depende además de la forma de administración del fármaco y del carrier. En la literatura hay múltiples vías de administración tópica de simvastatina en un defecto óseo. Stein en su estudio de 2005 (86) aplica simvastatina a diferentes dosis y encuentra signos clínicos de inflamación que podían ser reducidos disminuyendo la dosis de simvastatina. Stein y colaboradores demuestran que una dosis de $0.1 \mathrm{mg}$ de simvastatina produce una inflamación mínima medida mediante la observación clínica y el infiltrado inflamatorio, 
pero que aportaba poco crecimiento óseo en comparación con el grupo control, sugiriendo como dosis óptima de simvastatina $0.5 \mathrm{mg}(86)$ la cual es utilizada por otros autores con resultados satisfactorios (164). En cambio, para Nyan y colaboradores la dosis óptima es de $0.1 \mathrm{mg}$ ya que es la que significativamente produce una formación ósea mayor con menor inflamación $(1,66,82,83)$. Estas variaciones pueden deberse a diferencias entre los modelos experimentales y el biomaterial utilizado como carrier de la simvastatina. Stein y colaboradores (86) aplican simvastatina en el periostio en zonas mandibulares intactas mientras que Nyan y colaboradores $(1,82,83)$ lo hacen en un defecto óseo en calota. Como vehículo de la simvastatina, Stein (86) utiliza gel de metilcelulosa mientras que Nyan $(1,82,83)$ y Rojbani $(66)$ utilizan fosfatos tricálcicos o hidroxiapatita. Esta es una de las justificaciones que nos hacen plantearnos evaluar con los mismos carriers y en el mismo modelo de experimentación ambas dosis de simvastatina de 0.1 y $0.5 \mathrm{mg}$.

La administración tópica de bajas dosis de simvastatina $(0.5 \mathrm{mg} / 30 \mu \mathrm{l}-0.2 \mathrm{mg} / \mu \mathrm{l})$ son efectivas para recuperar tejidos periodontales implicados en destrucción de hueso alveolar. Ha sido estudiado que la formación de nueva cortical ósea aumenta cuando se aplica simvastatina subperióstica. (165)

Sin embargo otros autores como Lima y colaboradores (166) evalúan la influencia de dosis de simvastatina de $2.2 \mathrm{mg} / 50 \mu \mathrm{l}$ y $0.5 \mathrm{mg} / 50 \mu \mathrm{l}$ en combinación con matriz ósea bovina desmineralizada obteniendo resultados que indican que no sólo la simvastatina no produce una mejora en el proceso de osteogénesis sino que lo dificultan y enlentece.

Las dosis deben ser escogidas con precaución considerando los beneficios y los riesgos. Todos los autores consultados en la literatura coinciden en que son necesarios más estudios para confirmar la dosis óptima para lograr los efectos terapéuticos perseguidos.

\subsubsection{Influencia del carrier.}

La principal limitación para el uso clínico de las estatinas para regeneración ósea es la ausencia de un carrier efectivo que permita su correcta aplicación y garantice su 
posterior liberación en las concentraciones efectivas que permitan mejorar el proceso de regeneración ósea (124).

El uso satisfactorio de la simvastatina como promotor de formación ósea in vivo depende de la concentración local del fármaco, por lo que también se reflejan en la literatura continuos esfuerzos encaminados a establecer un adecuado medio de liberación de la simvastatina. Las propiedades que debería poseer un carrier ideal son favorecer que el agente terapéutico llegue al sitio de aplicación y pueda ser retenido en ese sitio para ir liberándose a un ritmo adecuado, posibilitando la menor dosis posible, permitiendo que se pierda la menor cantidad posible en su trayecto desde su administración hasta el sitio de aplicación (124). Además debería proveer de un andamiaje para que permitiera la llegada de las moléculas precursoras, la infiltración celular y la neoformación vascular, actuando como sustrato para el crecimiento y la diferenciación celular (167). Además el carrier ideal debería ayudar a definir la forma del nuevo hueso resultante y tener una tasa de reabsorción igual a la de creación de hueso autólogo para ir de esta forma favoreciendo el recambio y la maduración del hueso neoformado y no interferir en dicho proceso, lo cual podría provocar la aparición de tejido fibroso o la encapsulación fibrosa de las partículas no degradadas del carrier utilizado (124). Por último el carrier debe ser biocompatible y no generar reacciones ni de inmunidad ni inflamatorias, al igual que los productos que puedan derivarse durante su reabsorción. Carriers hidrofóbicos pueden producir respuestas inflamatorias mayores $(66,82)$.

Existen en la literatura varios autores que han utilizado diferentes carriers en la aplicación local de la simvastatina en diferentes modelos animales. La esponja de gelatina es biocompatible, biorreabsorbible y se adapta fácilmente a la forma del defecto debido a su estructura de esponja (156). Un defecto de $3 \mathrm{~mm}$ de diámetro en la región del ángulo mandibular de ratas Wistar fueron rellenadas con un injerto consistente en una esponja de gelatina cargada con simvastatina y se obtuvo un $240 \%$ más de nuevo hueso que en el grupo control (156). Un copolímero de ácido poliláctico/poliglicólico cargado con $1 \mathrm{mg}$ de simvastatina implantado en alveolos postextracción en incisivos mandibulares y la aplicación local de simvastatina en la zona parece prevenir el hueso alveolar residual promoviendo la neoformación ósea en del 
alveolo (162). Defectos de tamaño crítico realizados en la calota de ratas Wistar fueron tratados con sulfato cálcico aislado (control) o con sulfato cálcico en combinación con 1 mg de simvastatina. Dicha combinación se mostró efectiva. El mismo diseño del experimento se realizó con $\alpha$-TCP obteniendo también unos resultados satisfactorios en la combinación del biomaterial con simvastatina en comparación con el biomaterial aislado $(1,82,83)$. Estudios sobre la liberación de proteínas por parte de materiales de fosfato cálcico plantean que el proceso se realiza de una forma bifásica: una liberación inicial rápida seguida de una liberación más lenta y constante. Estos mecanismos de liberación son los que hacen que en un primer momento los niveles de simvastatina en los estadíos iniciales produzcan una estimulación celular que provoca síntesis de BMP-2 (152), con la subsecuente estimulación de la migración y diferenciación de células mesenquimales a osteoblastos. Este proceso está en consonancia con los resultados observados en algunos estudios de aceleración de la regeneración ósea en los primeros días, tras los que se va produciendo una liberación sostenida de la simvastatina a medida que el material de fosfato cálcico se va reabsorbiendo $(1,67,152,159)$. Nyan y colaboradores [1] añaden, que la dosis de $0.1 \mathrm{mg}$, que defienden como adecuada, hace que la tasa de reabsorción del material de fosfato tricálcico sea óptima, ya que dosis mayores de 0.25 o 0.50 muestran un aumento de la reacción inflamatoria en la zona, la cual dificulta el proceso de regeneración y la correcta degradación de las partículas de biomaterial y su reemplazo por hueso [1]. La implementación de simvastatina en la superficie de implantes de titanio parece acelerar la osteogénesis alrededor de los mismos (160).

De nuevo todos los autores coinciden en que son necesarios más estudios para tratar de encontrar el carrier adecuado que sirva como andamiaje capaz de liberar gradualmente de una forma óptima la simvastatina y a su vez se degrade de forma similar a la velocidad de neoformación de hueso autólogo y que constituya una superficie osteoconductiva donde dicha formación ósea pueda llevarse a cabo. 


\section{Risk Factors in Early Implant Failure: A Meta-Analysis}

Guilermo Marzano, DDS, * Javier Montero, DDS, PhD, † Javier Marth-Valejo, PhD, $\neq$ Massimo Del Fabbro, BSc, PhD, $\$$ Manuel Bravo, MD, PhD, $\|$ and Tiziano Testori, MD, DDS1

$\mathrm{U}$ nsuccessful implant surgery can be characterized by the mobility of the implant, continwous radiolucency around the implant, peri-implantitis with suppuration, or subjective complaints from the patient. ${ }^{1}$ However, no specific criteria for unsuccessful dental implants have been defined. ${ }^{2}$ The inability of tissue to establish and/or maintain osseointegration is thought to cause implant failures. ${ }^{3}$ Implant failures have been frequently associated with factors such as poor bone quality, insufficient bone volume, inadequate primary implant stability, and overload. ${ }^{4}$

Implant failures can be subdivided into early or late failures, depending on when they occur, that is, before abutment connection (early) or after implant loading (late). This subdivision is neeessary because the etiology of these 2 kinds of failures is often different." Early failure of an implant results from an inability to establish an intimate

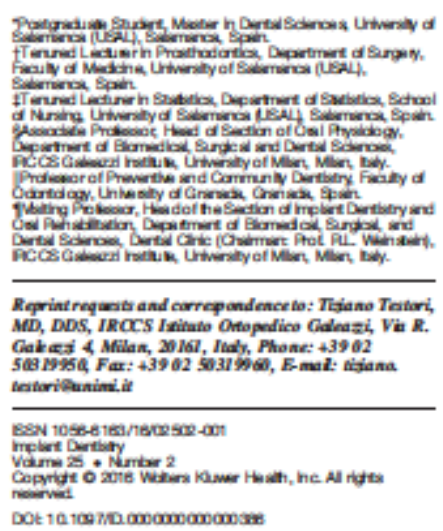

Background: Clinicians should be able to weigh the role of the main risk factors associated with early implant failure.

Purpose: The aim of this metaanalysis was to assess the influence of different patient-related and implant-related risk factors on the occurrence of early implant failure

Materials and Methods: In July, 2014 the main electronic databases were searched for studies reporting on early failures. Relevant papers were selected by 2 independent authors using predefined selection criteria. Three authors independently scored the induded studies for quality assessment. The estimated odds ratios of the main risk factors from the selected papers were subjected to meta-analysis.

Results: Nine studies were included. A total of 18,171 implants were meta-analyzed, of which 10,921 were analyzed for smoking. 15,260 for implant diameter, 16,075 for implant length and 16,711 for implant location (maxilla vs mandible). The main significant risk factors for early implant failures were the smoking habit (odds ratio [OR], 1.7; $95 \%$ confidence interval [CI], $1.3,2.3)$, implants shorter than 10 $m m(O R, 1.6 ; 95 \% C I, 1.2,2.2)$ and implants placed in the maxilla $(O R$ 1.3; $95 \%$ CI 1.0, 1.6).

Conclusions: Clinicians should be aware of the increased risk of early failure in the presence of smokers, implants with reduced length, and implant-supported maxillary rehabilitation. (Implant Dent 2016;25:1-9)

Key Words: dental implant, early failures, systematic review, risk as sessment bone-to-implant contact. ${ }^{6}$ This means that bone healing after implant insertion is impaired or jeopardized. The mechanismsthat nomally lead to wound heat ing by means of bone apposition fail, and instead fibrous scartissue is formed around the implant.' This can lead to epithelial downgrowth, the so-called saucerization or marsupialization of the implant, which results in mobility or even implant loss. ${ }^{8}$ Early failures are characterized by minimal bone loss, ${ }^{3}$ and most of them occur very soon; so, knowledge of the potential risk factors of early failure is of paramount importance for clinicians." Clinical studies have identified the foll-owing factors: implant feature (width, length, surface, thread design. shape, etc), the quality and quantity of the bone site, surgery-related factors (flap/flapless, submerged/nonsubmerged positioning, insertion torque [related to bone density], bone standard drilling protocoVadapted drilling in low-density bone, Piezosurgery/conventional drilling, etc), use of grafted bone, and systemic factors such as genctic predisposition, smoking, and metabolic disorders, ${ }^{210}$ 


\subsection{Factores de riesgo que participan en el fracaso temprano en}

\section{implantología.}

En este estudio de metanálisis se han identificado factores de riesgo significativos que pueden participar en el proceso de fracaso temprano en implantología. Sin embargo, aunque se han encontrado resultados significativos y homogéneos, es necesario poner de manifiesto que dichos resultados no son concluyentes debido al pequeño número de estudios disponibles para el análisis, y a la influencia que uno de los estudios (Alsaadi et. al (101)) tiene en la mayoría de los cálculos.

En nuestro estudio, nos hemos centrado en los factores de riesgo más ampliamente estudiados con el objetivo de poder obtener un conjunto de datos mayor para nuestro análisis. La mitad de los factores de riesgo evaluados están relacionados con el paciente (hábitos tabáquicos y morfología ósea) y la otra mitad están relacionados con las características del implante (longitud y diámetro). Sin embargo, somos conscientes de la existencia de otros factores de riesgo locales y sistémicos que deberán abordarse en futuros estudios. Los factores de riesgo locales que se podrían destacar son la existencia de una historia previa de periodontitis/periimplantitis, alteraciones de la inmunidad, cantidad de encía queratinizada, técnicas de fresado para preparación del lecho implantario, estado endodóntico de dientes vecinos, procedimientos de regeneración simultáneos a la colocación de implantes, etc. También podemos encontrar factores de riesgos generales que algunos estudios han destacado como por ejemplo pacientes sometidos a radioterapia y/o quimioterapia, enfermedad de Crohn u osteoporosis (96).

Los 9 estudios incluidos en el metanálisis consideran el fracaso temprano como cualquier implante fracasado antes de aplicarle carga y expresan correctamente los factores de riesgo asociados al paciente y aquellos relacionados con el implante. La calidad de estos estudios estaba por encima de 5 en todos los parámetros (Tabla 3).

\begin{tabular}{|l|l|l|l|l|l|l|}
\hline Estudio & $\begin{array}{l}\text { Tamaño } \\
\text { muestral }\end{array}$ & $\begin{array}{l}\text { Diseño del } \\
\text { estudio }\end{array}$ & Seguimiento & Resultados & $\begin{array}{l}\text { Calidad } \\
\text { análisis } \\
\text { estadístico* }\end{array}$ & $\begin{array}{l}\text { Evaluación } \\
\text { Global* }\end{array}$ \\
\hline $\begin{array}{l}\text { Alsaadi et al, } \\
2007 \text { (8) }\end{array}$ & +++ & +++ & & +++ & 8 & 7,7 \\
\cline { 2 - 7 } & & & & & & \\
\hline
\end{tabular}




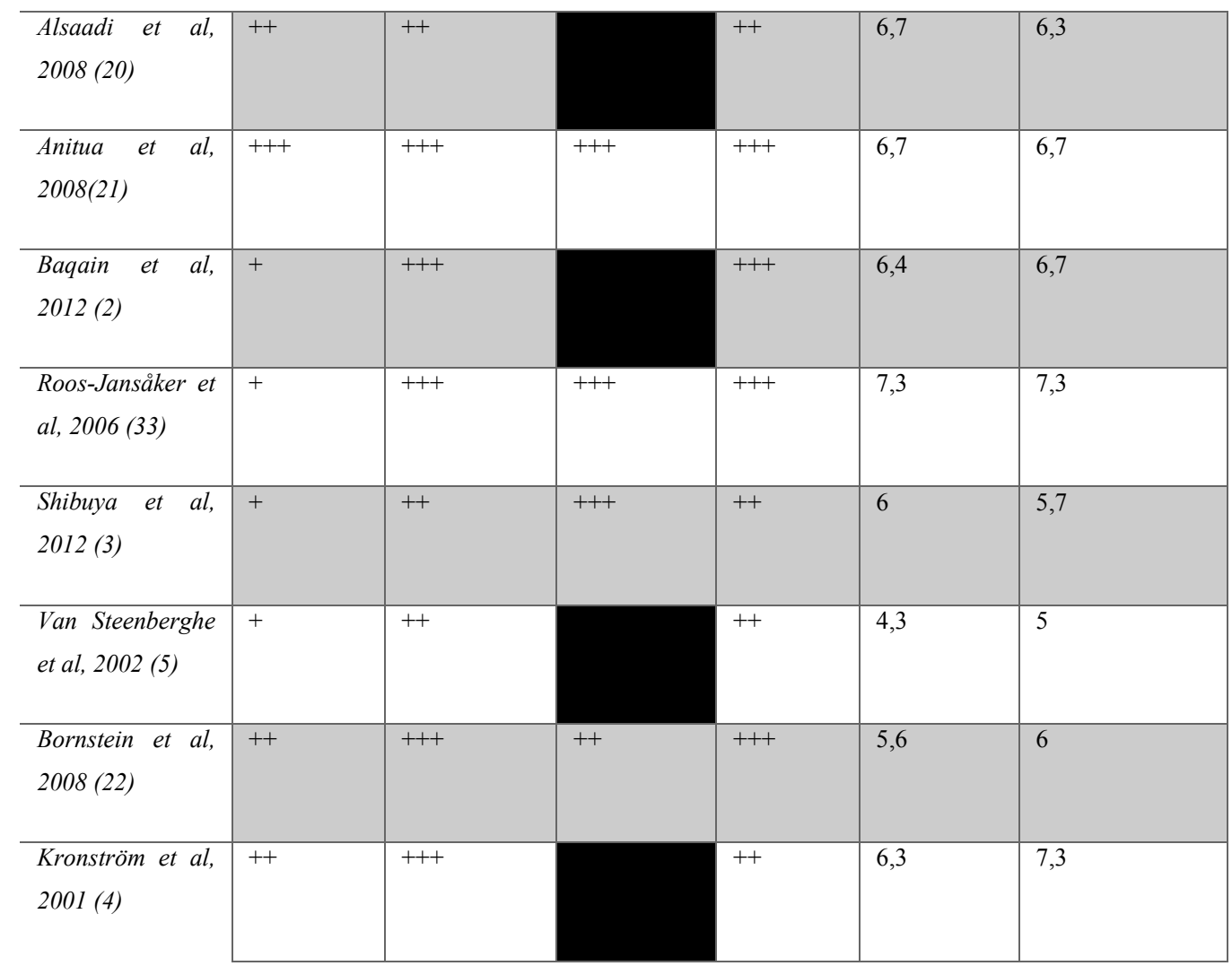

Tabla 3. Resumen de la valoración de los jueces de los artículos seleccionados para el estudio de meta-analítico.

- Selección de las variables de estudio: Los 9 estudios incluidos en el metanálisis nos permiten evaluar el riesgo de 2 factores relaticos al implante que pueden incidir en el fracaso temprano de los mismos: la longitud del implante (analizado en 6 de los estudios) y su diámetro (analizado en 4 de los estudios). Respecto a los factores de riesgo relaticos al paciente se evaluaron los hábitos tabáquicos ( 6 estudios) y la localización anatómica del implante ( 6 estudios). Para estas variables, consideramos de forma preliminar que existe mayor riesgo de fracaso temprano de aquellos implantes colocados en fumadores (variable fumar), implantes de diámetro inferior a $4 \mathrm{~mm}$ (variable anchura), implantes de longitud inferior a $10 \mathrm{~mm}$ (variable longitud) y los implantes colocados en el maxilar superior (variable localización) (Tabla 4). La unidad de medida fue el implante (en lugar del paciente) porque así los presentan los artículos analizados. 


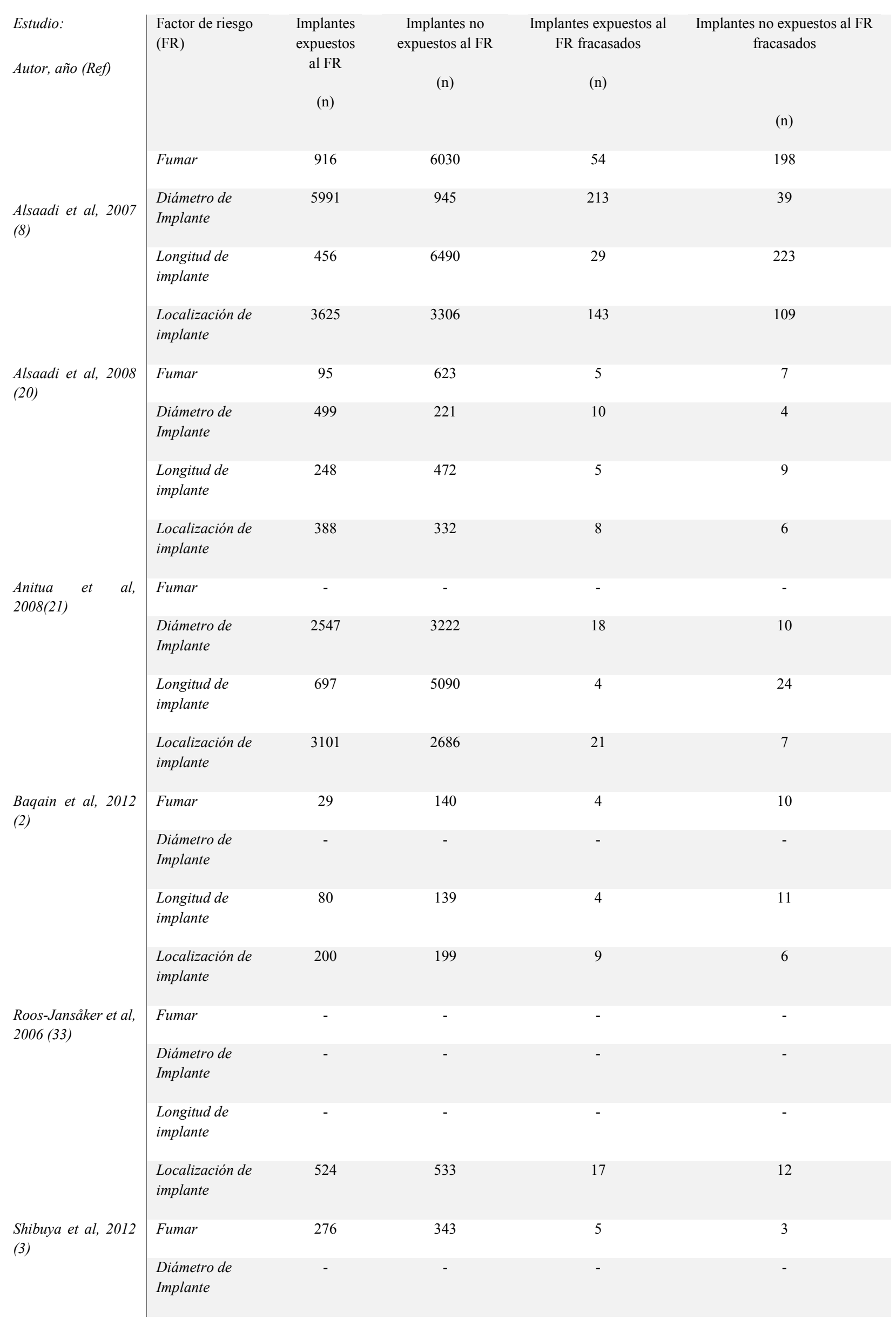




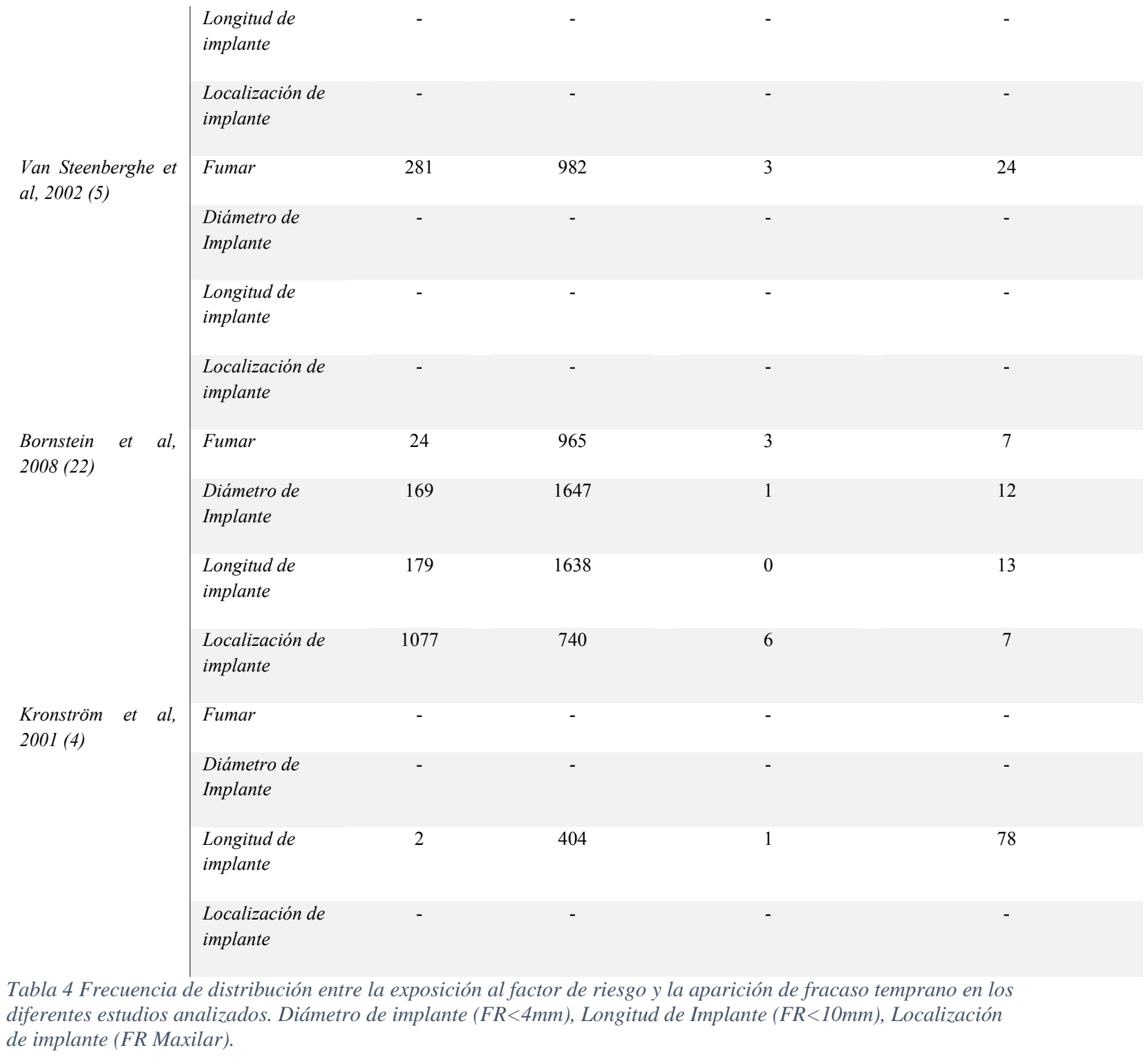

Una gran variedad de factores locales y sistémicos pueden interferir en el proceso normal de cicatrización ósea alrededor de los implantes dentales inmediatamente tras su inserción. La cicatrización de los tejidos circundantes comienza con el coágulo sanguíneo formado entre la superficie implantaria y el hueso que lo hospeda y, dependiendo del entorno y de la inmovilidad relativa de la interfase hueso-implante, las células mesenquimales pluripotenciales se diferenciarán bien en fibroblastos o en osteoblastos, formando respectivamente un tejido cicatricial (provocando la no osteointegración del implante y por tanto su fracaso) o nuevo hueso (101). El establecimiento de condiciones pobres de vascularización o de baja concentración de oxígeno en la zona pueden llevar a la diferenciación de las células mesenquimales pluripotenciales hacia una estirpe condrogénica (101). El estrés mecánico al que están sometidos los tejidos puede tener su influencia sobre la diferenciación celular, pudiendo llegar a alterar la expresión genética de las células y su actividad (101), lo que explicaría por qué 
micromovimientos de una magnitud excesiva durante la fase de osteointegración del implante pueden afectar al sellado del hueso entorno al implante, formándose en ese caso una cicatriz de estirpe fibrosa $(168,169)$. El papel de factores endógenos en los procesos de diferenciación celular está menos documentada (101).

\subsubsection{Factores de riesgo relacionados con el paciente}

En pacientes sanos, las tasas de éxito de implantes dentales oscilan entre el $90 \%$ y el $95 \%$ con un seguimiento de 10 años (2), y aunque muchos factores de diseño juegan un papel importante en el éxito del implante, los estudios clínicos demuestran que las condiciones de salud del paciente y la calidad ósea son también factores determinantes en la osteointegración y en la posterior supervivencia del implante dental (170).

En general, los factores de riesgo sistémicos pueden aumentar el riesgo de fracaso del tratamiento o de aparición de complicaciones, pero existen muy pocas contraindicaciones absolutas definidas en la literatura relacionadas con el tratamiento con implantes dentales $(170,171)$. Las condiciones que aumentan el riesgo de ocurrencia del fracaso implantológico incluyen fumar (vasoconstricción, hipoxia celular, sustancias químicas y condiciones físicas que pueden alterar la osteointegración), enfermedades endocrinas, osteoporosis (reducción de la densidad ósea alveolar y la masa debido a la alteración del metabolismo óseo), alteraciones inmunológicas, procesos inflamatorios, factores microbianos, enfermedades cardiovasculares, alteraciones en el metabolismo sanguíneo, quimioterapia y/o radioterapia, etc $(170,171)$. Sin embargo, se ha sugerido que el grado de control de la enfermedad puede ser más importante que la naturaleza de la propia enfermedad sistémica, haciéndose imprescindible la evaluación cuidadosa del paciente antes de iniciar el tratamiento con implantes dentales (171).

Está ampliamente aceptado que factores como el género o la edad no afectan directamente a la aparición de fracasos en implantología (96), pero debido a la distribución desigual de los datos y grupos de edad en los diversos estudios publicados nos impidieron incluir estos factores en el metanálisis para constatar que este concepto está apoyado realmente por una evidencia científica sólida. Sin embargo, en cuanto al hábito tabáquico, se desprende del análisis que se trata de un factor significativamente predictor de fracasos tempranos en implantología. Hay que tener en cuenta que los efectos del consumo de tabaco inhalado pueden dividirse en 2 fases: la fase volátil y la fase de partículas. La fase volátil o gaseosa, constituida por el $95 \%$ del humo del cigarrillo, está formada por aproximadamente unos 500 componentes diferentes entre los que se incluyen nitrógeno, monóxido de carbono y dióxido de carbono. Entre los cerca de 3500 
componentes químicos liberados en la fase de partículas se encuentran la nicotina, nornicotina, anatabina, y anabisina (172). La nicotina ha mostrado capacidad de aumento del proceso de agregación plaquetaria, disminución de niveles de prostaciclina microvascular y la inhibición de la función de los fibroblastos, eritrocitos y macrófagos $(101,173,174)$. El monóxido de carbono se une a la hemoglobina mucho más fácilmente que el oxígeno, desplazando al oxígeno de dicha molécula disminuyendo de esta forma la concentración de oxígeno en los tejidos (175). Por todo ello, fumar altera la dinámica de cicatrización tanto de tejidos blandos como del hueso (176).

En la literatura existe una amplia evidencia de que fumar interfiere en el pronóstico de los implantes dentales de una forma directamente proporcional dosis-dependiente (177), y los resultados de este metanálisis concluyen que fumar incrementa significativamente el riesgo de fracaso temprano en implantología entre 1.3 a 2.3 veces, en consonancia con otras revisiones sistemáticas y metanálisis (178).

Sin embargo, Sverzut et al. (179) sugieren que el tabaco no puede ser considerado un factor de riesgo por si solo en fracasos tempranos. A pesar de esta afirmación, estos autores mantienen que existe evidencia suficiente para sugerir que existe un efecto dosis-dependiente del tabaco sobre el proceso de osteointegración (101) y puede que obtuvieran los resultados anteriormente comentados debido a que no se tuvo en cuenta en su estudio el número de cigarrillos/día que fumaban los diferentes pacientes. La ausencia de resultados significativos para pacientes fumadores en otros estudios, como puede ser el realizado por Anitua et al. (180) o el estudio de Roos-Jansåkeret al. (181), pueden estar relacionados con el pequeño número de individuos con pérdidas de implantes dentro de la muestra analizada, lo cual reduce el poder estadístico del análisis. Otros estudios han reportado un efecto deletéreo del consumo de tabaco inhalado en la pérdida de implantes $(177,182-185)$. Wilson and Nunn (183) reportaron un incremento del riesgo de fracaso de los implantes colocados en pacientes fumadores de al menos 2.5 veces superior si los comparamos con los no fumadores, y Wallace (185) describe un ratio de fracaso del $16.6 \%$ en paciente fumadores comparado con el $6.9 \%$ en no fumadores.

En un gran estudio clínico se analizaron un total de 2,066 implantes colocados en 310 pacientes, y se vio que fumar resultó ser el factor principal de fracaso de implantes en el momento de la segunda fase quirúrgica (186).

Por otra parte, en relación al estudio del tipo de hueso y de acuerdo con los resultados de nuestro meta-análisis, estimamos que implantes colocados en el maxilar tienen un riesgo ligeramente superior de desencadenar un fracaso de forma temprana que los colocados en 
mandíbula, siendo esta diferencia significativa $(O R=1.27)$. Este hallazgo concuerda con la literatura existente. Anitua et al. (180) consideraron que colocar implantes en el maxilar no es un factor de riesgo para su fracaso per se, sin embargo, los ratios de supervivencia en maxilar son significativamente menores que en mandíbula. Sin embargo, estos resultados desfavorables fueron explicados como consecuencias de una mayor dificultad debido a la anatomía en los casos maxilares en dicho estudio. De hecho, el número de implantes colocados mediante el protocolo en 2 fases (1139 en maxilar versus 190 en mandíbula) y la necesidad de aplicar técnicas especiales adicionales (904 en maxilar versus 354 en mandíbula) pueden apoyar dicha lectura (180). Siguiendo la misma línea de resultados, Moy et al. (187) evaluaron 4680 implantes en 1140 pacientes y los resultados que obtuvieron fueron de una incidencia 2 veces mayor de fracasos en el hueso maxilar comparado con la mandíbula. Otros estudios analizados muestran resultados similares, sugiriendo un ratio mayor de fracaso de implantes insertados en el hueso maxilar $(188,189)$.

\subsubsection{Factores relativos al implante}

En relación con los factores de riesgo para el fracaso temprano en implantología relacionados con las características del implante que han sido analizados en este metanálisis (longitud y diámetro del implante), en un artículo de revisión Renouard \& Nisand (17) reportaron que parecía existir una tendencia al incremento del ratio de fracaso en implantes de menor longitud, con mayor diámetro y con superficie maquinada. Sin embargo, Alsaadi et al (101) afirman que el aumento del riesgo de fracaso en implantes cortos y de mayor diámetro puede estar asociado con la técnica durante la preparación del lecho, existencia de un hueso de pobre densidad, influencia de características de diseño del implante, y el hecho de que este tipo de implantes sean utilizados como "rescate" en zonas con condiciones anatómicas comprometidas, con una pobre calidad y cantidad ósea. En contraste, un estudio reciente muestra que la mayor parte de los fracasos tempranos se produce en implantes cortos y estrechos (16). De forma similar, Baqain et al. (91) encontraron que los fracasos eran más comunes en implantes estrechos (<3.5 $\mathrm{mm}$ de diámetro) pero no estaban relacionados con implantes cortos ( $<10 \mathrm{~mm}$ de longitud), los cuales tenían unos valores ligeramente más altos de fracaso pero sin ser estadísticamente significativos. Los resultados de nuestro metanálisis apuntan en la dirección opuesta, es decir, los implantes estrechos parecen tener un ratio de fracasos similar a los implantes anchos, pero sin embargo los implantes de menos de $10 \mathrm{~mm}$ de longitud tienen un riesgo de fracaso temprano significativamente mayor (13). De acuerdo con el metanálisis realizado, la mayor controversia fue observada en la influencia que tiene el diámetro del implante sobre la aparición de fracaso temprano, con un $p$-valor $=0.16$ del test $Q$, en comparación a la influencia de la longitud, con un 
$p$-valor $=0.68$ del test $Q$. Debe tenerse en cuenta, que debido a la diferente agrupación de los implantes en los diferentes estudios, tuvieron que ser tomados como implantes estrechos aquellos de un diámetro menor a $4 \mathrm{~mm}$ en lugar de aquellos con diámetro inferior a $3.5 \mathrm{~mm}$ como es habitual, para poder permitir el estudio meta-analítico (13).

En cuanto al estudio de la longitud del implante como factor de riesgo para el fracaso temprano en implantología, nuestros resultados están en consonancia con numerosos estudios, en los cuales se afirma la asociación entre implantes cortos y el riesgo de fracaso (13). Misch et al. (15) observaron un ratio de éxito menor (85.3\%) para implantes de menos de $10 \mathrm{~mm}$ de longitud. Olate et al. (16) llegaron a la conclusión de que existía una relación significativa entre el fracaso temprano e implantes cortos $(6-9 \mathrm{~mm})$.

Cabe destacar que los implantes cortos y estrechos son colocados en áreas en las que la disponibilidad ósea es limitada o incluso insuficiente, lo cual puede comprometer la supervivencia clínica del implante, lo cual se ve incrementado por la menor superficie de contacto entre hueso e implante (BIC). Sin embargo, debido a que no es posible analizar los datos directamente del paciente y que los OR originalmente no se ajustan de la mima forma entre los diferentes estudios, no es posible realizar un meta-análisis del efecto de ambas variables a la vez. De la misma forma, sería recomendable analizar la influencia de la calidad ósea relacionada con las características del implante colocado, principalmente en casos en la que ésta fuera deficiente, aunque raramente se evalúa esta variable en los artículos analizados. La calidad ósea se clasifica clásicamente en 4 categorías (Lekholm \& Zarb, 1985), dependiendo del grado de corticalización que presente (96). Los mayores porcentajes de fracasos tempranos se producen en huesos tipo cuatro (cortical ósea muy fina combinada con un hueso medular poco mineralizado con grandes espacios trabeculares) $(96,190,191)$. De hecho, debido a sus bajas propiedades biomecánicas, es difícil habitualmente lograr una adecuada estabilidad primaria de los implantes, lo cual es indispensable para el establecimiento de un nivel adecuado de BIC (168).

\section{Limitaciones del estudio}

La principal limitación de este estudio se deriva del hecho de que no ha sido posible incluir un número mayor de artículos publicados en el meta-análisis. Un gran número de estudios fueron descartados debido a la ausencia de distribuciones de datos adecuadas que permitieran realizar un estudio de tipo metanalítico, aunque su metodología y diseño fueran adecuados. Además, 
podrían haberse utilizado otras bases de datos biomédicas, como Embase y Cochrane Library para una revisión más exhaustiva.

Entendemos que futuras investigaciones deberían centrarse en el efecto de la carga inmediata como factor de riesgo sobre el fracaso de los implantes dentales, debido al aumento de estudios sobre este tema y la relevancia de que los resultados podrían tener sobre dicha situación clínica para el profesional y para los pacientes. Sin embargo, la carga diferida sigue siendo el protocolo más utilizado por los clínicos, por lo que la información expuesta en este artículo debería ayudar a la mayoría de los clínicos a apoyar su estrategia de tratamiento basada en la evidencia científica actualmente existente para mejorar el pronóstico en implantología. 


\title{
Clinical evaluation of the incidence of prosthetic complications in implant crowns constructed with UCLA castable abutments. A cohort follow-up study
}

\author{
Javier Montero ${ }^{a}$, Guillermo Manzano ${ }^{b}$, David Beltrán ${ }^{b}$, Christopher D. Lynch ${ }^{c}$, \\ María-Jesús Suárez-García ${ }^{d}$, Raquel Castillo-Oyagüe ${ }^{d, *}$ \\ "Prosthodantics, Depar tment of Surgey, Faculty of Medicine, Univer sity of Salamanca (USAL), C/Alfonso X el Sabio, s/n, \\ Campus de Unamuna, E-37007 Salamanca, Spain \\ "Department of Surgery, Faculty of Mediaine, University of Salamanca (USAL), C/Alfonso X d Sabio, s/n, \\ Campus de Unamung, E-37007 Salamanca, Spain

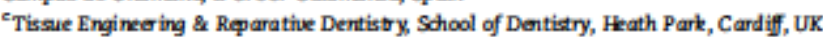 \\ ${ }^{d}$ Prosthodantics, Department of Bucoffacial Prostheses, Faculty of Dentistry, Compluterse University of Madrid (UCM), \\ Pza. Ramón y Cajal, s/n, E-290so Madrid, Spain
}

\section{A RTICIE INFO}

\section{Article history:}

Received 25 May 2012

Received in revised form

31 August 2012

Accepted 3 September 2012

\section{Keywords:}

Dental implants

UCLA astable abutments

Cobalt-chromium

Implant-supported crowns

Screw loosening

Ceramic fracture
A BSTR ACT

Objoctive: To evahuate the incidence of prosthetic cormplications in implant-retained crowns made with UCL.A castable abutments and to identify possible risk factors with a view to estahlishing recammendations to help predict the success of such restara tians. Methods: A cohart follow-up study was carried out in 71 partially denta te potients rehabilitated with 93 implant-retained single crowns. Data regarding socio-demographic bockground, a natamical fea tures implant", and prosthesis-rela ted variables wererecorded. The incidence rate ( $\%$ ), relative risk (RR) and odds ratio (OR) were applied for predictive risk factors. ANOVA and Student t-tests were used to compare quantitative variables the chisquare test was used to compare proportions and also a logistic regression analysis was performed. The statistical significance was set at $a=0.05$.

Results: Two implants $(27 \times)$ were lost during the first year of function. The indidence of prosthetic complications in the observed mean period $(26.2 \pm 15.4$ manths) was 11.9\%, consisting of screw loosening $(10.8 \%)$ and ceramic fracture $(1.1 \%)$. A higher tendency for prosthetic complications was noticed in posterior mandibular crowns restaring saddles langer than $10 \mathrm{~mm}$ with mesiodistal cantilevers longer than $6 \mathrm{~mm}$, having natural antagonists, after lang-term use ( $>20$ months), with initial torque values superiar than $30 \mathrm{Ncm}$. Concluvions: Screw bosening is the most frequent complication in implant retained crowns fabricated with UCLA abutments cast in cobalt-dhramium. Nevertheless, the cannection usually remains stable after retightening the screws. A high survival rate was recarded, and these prostheses may be a suitable treatment option.

Clinical significance Based on the study findings the risk of prosthetic complications is expected to increase when lang-apan posteriar edentulous areas are rehabilitated with single implant-supported crowns The antagonist occhusal plane should be restored to prevent torsianal farces and overlooding. Implant systerns with initial brque vahues less than $30 \mathrm{Ncm}$ should be selected.

(1) 2012 Elsevier Ltd. All rights reserved.

\footnotetext{
- Comeponding author. Tel: 434 607367903; fix +34913942029.

E-mail addres: raquelcastiloGodon ucm es (R. Castillo-Oyagüe). 0300-5712/5 - see front matter of 2012 Elsevier Ltd All rights reserved. http://deddoiorg/10.1016/j.jdent 2012.09.001
} 


\subsection{Evaluación clínica de la incidencia de complicaciones protéticas en coronas implanto-soportadas realizadas sobre}

\section{pilares tipo UCLA.}

Actualmente, existen una amplia variedad de opciones terapéuticas para la reposición de dientes perdidos de forma fija. El rango abarca desde puentes de resina cementados o prótesis parciales fijas (FPDs: Fixed Partial Dentures), hasta la rehabilitación mediante prótesis sobre implantes osteointegrados. Sin embargo, para tomar la decisión de tratamiento, es importante conocer los ratios de supervivencia, el comportamiento biológico y las complicaciones técnicas, no sólo para los implantes sino también de las diferentes restauraciones protésicas (192). En este estudio, el periodo de seguimiento medio ha sido de 26.2 meses, analizando las complicaciones protéticas que aparecen en coronas implanto-retenidas con el objetivo de establecer recomendaciones clínicas que ayuden a reducir estos problemas en futuros pacientes (104).

Las coronas sobre implantes muestran unos altos ratios de supervivencia, pero con una prevalencia de complicaciones técnicas reseñable (111), lo cual es una preocupación tanto para clínicos como para pacientes.

En este estudio, se han utilizado procedimientos estandarizados de laboratorio para la fabricación de las restauraciones además de revisiones clínicas dobles realizadas por un mismo operador (DB), con el fin de obtener una alta fiabilidad en los resultados. En cambio, como limitaciones del estudio realizado, podemos destacar la imposibilidad de realizar medidas de la magnitud de las fuerzas oclusales en cada caso y el hecho de que los pacientes seleccionados para este estudio procedieran de un mismo centro Universitario. Además, las variables evaluadas no fueron asignadas de forma aleatoria, por lo que no puede establecerse una relación de causa-efecto (104). Por tanto, los factores de riesgo estudiados están basados en la distribución de las complicaciones protéticas que tienen relación con dichas variables.

El principal hallazgo de esta investigación fue que el aflojamiento del tornillo se mostró como la complicación protética más frecuente con una incidencia de un 10,8\% (Tabla 5) durante un periodo medio de $26.2 \pm 15.4$ meses (104), lo cual es superior a los resultados de estudios previos similares presentes en la literatura con periodos de seguimiento de entre 5-10 años (112-114). Esto puede ser debido a diferencias en el tipo de aditamento utilizado, al sistema de implantes o al torque inicial empleado. 


\section{POSICIÓN EN LA ARCADA}

\begin{tabular}{lccccc}
\hline & Incisivo n (\%) & Canino n $(\%)$ & Premolar n (\%) & Molar n (\%) & Total \\
\hline Maxilar & $10(10.7)$ & $1(1.1)$ & $21(22.6)$ & $15(16.1)$ & $47(50.5)$ \\
\hline Mandíbula & $1(1.1)$ & $1(1.1)$ & $2(2.1)$ & $42(45.2)$ & $46(49.5)$ \\
\hline Total & $11(11.8)$ & $2(2.2)$ & $23(24.7)$ & $57(61.3)$ & $93(100)$ \\
\hline
\end{tabular}

MARCA DE IMPLANTE Y TORQUE INICIAL $(\mathrm{Media} \pm S D=29.5 \pm 5.7 \mathrm{Ncm})$

\begin{tabular}{|c|c|c|}
\hline & $\mathbf{N}$ & $\%$ \\
\hline Biomet $3 \mathrm{i}^{\mathrm{a}}(20 \mathrm{Ncm})$ & 22 & 23.6 \\
\hline $\operatorname{Defcon}^{\mathrm{b}}(35 \mathrm{Ncm})$ & 9 & 9.7 \\
\hline Microdent ${ }^{\mathrm{c}}(32 \mathrm{Ncm})$ & 12 & 13.0 \\
\hline Mozograu $^{\mathrm{d}}(30 \mathrm{Ncm})$ & 30 & 32.3 \\
\hline Nobel Biocare $(35 \mathrm{Ncm})$ & 20 & 21.5 \\
\hline
\end{tabular}

PLATAFORMA DEL IMPLANTE (DIÁMETRO)

\begin{tabular}{|c|c|c|}
\hline Estrecho & 9 & 9.7 \\
\hline Estándar (4.1 mm) & 76 & 81.7 \\
\hline Ancho & 8 & 8.6 \\
\hline \multicolumn{3}{|c|}{ LONGITUD DE IMPLANTE } \\
\hline$<13 \mathrm{~mm}$ & 59 & 63.4 \\
\hline$\geq 13 \mathrm{~mm}$ & 34 & 36.6 \\
\hline \multicolumn{3}{|c|}{ TIPO DE RETENCIÓN } \\
\hline Atornillado & 84 & 90.3 \\
\hline Cementado & 9 & 9.7 \\
\hline \multicolumn{3}{|c|}{ COMPLICACIONES EN CORONAS SOBRE IMPLANTES } \\
\hline Aflojamiento de tornillo & 10 & 10.8 \\
\hline Fracaso en la & 2 & 2.2 \\
\hline osteointegración del implante & & \\
\hline
\end{tabular}




\begin{tabular}{lcc}
\hline Fractura de la cerámica & 1 & 1.1 \\
\hline Ausencia de problemas & 80 & 86.0 \\
\hline
\end{tabular}

${ }^{a}$ Osseotite. Biomet 3i, Palm Beach Gardens, FL, USA; ${ }^{b}$ Defcon TSA. Impladent, Barcelona, Spain; ${ }^{c}$ MK. Microdent SL, Barcelona, Spain; ${ }^{d} M G$ Osseous. Mozograu SL, Valladolid, Spain; ${ }^{e} M K$ III. Nobel Biocare AB, Göteborg, Sweden.

Tabla 5 Localización de las restauraciones, tipo deimplante y causas de las complicaciones protéticas en las restauraciones analizadas $(n=93)$

Sin embargo, todos los aditamentos que sufrieron aflojamiento se mostraron estables tras ser atornillados al torque recomendado por el fabricante, con una sola excepción que tuvo que ser re-atornillado en 2 ocasiones. Los resultados obtenidos en nuestro estudio están en concordancia conla revisión sistemática realizada por Jung et al. (111) en la cual la incidencia acumulada de aflojamiento de tornillo fue del $12.7 \%$ tras 5 años de seguimiento, doblando la incidencia de estudios previos(112,114).

El uso de aditamentos calcinables tipo UCLA, puede haber contribuido a la alta frecuencia de complicaciones protéticas registrada en este estudio, ya que su procedimiento de calcinado es muy sensible a la técnica y puede producirse una alteración en la adaptación entre las interfases implante-aditamento. Los pilares tipo UCLA con base mecanizada en oro y base pre-mecanizada parecen tener un menor número de complicaciones protéticas que los totalmente calcinables (193). Para colar los pilares UCLA se utiliza una aleación de Cr-Co debido a su alta resistencia a la fractura, adecuado módulo elástico, dureza, resistencia a la corrosión y bajo precio lo cual los convierte en una buena alternativa para realizar tanto prótesis atornilladas sobre implantes como pilares customizados para coronas cementadas $(107,193)$. Sin embargo, hacen falta estudios de éxito a largo plazo de restauraciones implantosoportadas fabricadas con el método anteriormente descrito.

Otro posible factor que puede explicar la alta incidencia del aflojamiento de tornillo reside en el uso de titanio en todo tipo de restauraciones. Se ha reportado una mayor estabilidad del atornillado utilizando tornillos de oro o en aquellos de titanio en los que su superficie ha sido tratada, ya que pueden alcanzar unos valores mayores de precarga a cualquier torque (194).

De acuerdo con las conclusiones de otros autores $(105,108)$ el aflojamiento de tornillo ocurre principalmente en el sector posterior mandibular (Tabla 6). Además de la influencia del tamaño de las restauraciones de los molares, las fuerzas de masticación que se producen en los sectores posteriores de ambas arcadas son entre tres y cinco veces más intensas que las que se producen a la altura de los sectores anteriores (195). En nuestro estudio, aproximadamente el $80 \%$ de las restauraciones analizadas estuvieron localizadas en sectores molares y premolares (Tabla 6) lo cual podría justificar la alta incidencia de aflojamiento de tornillo reportada (Tabla 5). 


\begin{tabular}{|c|c|c|c|c|c|}
\hline & \multirow{2}{*}{$\begin{array}{c}\text { Incidencia } \\
(\%)\end{array}$} & \multirow{2}{*}{$\begin{array}{c}\text { Chi- } \\
\text { cuadrado } \\
\text { test } \\
\text { p-value }\end{array}$} & \multirow{2}{*}{$\mathbf{R} \mathbf{R}$} & \multicolumn{2}{|c|}{ Intervalo de confianza $95 \%$ para $R R$} \\
\hline & & & & Inferior & Superior \\
\hline \multicolumn{6}{|c|}{ FACTORES PROSTODÓNCICOS } \\
\hline \multicolumn{6}{|l|}{ Localización } \\
\hline Posterior & 13.8 & \multirow{2}{*}{0.15} & 1.2 & 1.1 & 1.3 \\
\hline Anterior & 0.0 & & NS & NS & NS \\
\hline \multicolumn{6}{|l|}{ Arcada } \\
\hline Maxilar & 8.5 & \multirow{2}{*}{0.31} & 0.6 & 0.3 & 1.3 \\
\hline Mandibular & 15.2 & & 1.5 & 1.0 & 2.3 \\
\hline \multicolumn{6}{|c|}{ Longitud de la brecha edéntula } \\
\hline$>10 \mathrm{~mm}$ & 18.2 & \multirow{2}{*}{0.07} & 1.7 & 1.1 & 2.6 \\
\hline$\leq 10 \mathrm{~mm}$ & 6.1 & & 0.5 & 0.2 & 1.3 \\
\hline \multicolumn{6}{|c|}{ Cantiléver mesio-distal } \\
\hline$>6 \mathrm{~mm}$ & 15.9 & \multirow{2}{*}{0.25} & 1.4 & 0.9 & 2.3 \\
\hline$\leq 6 \mathrm{~mm}$ & 8.2 & & 0.7 & 0.3 & 1.5 \\
\hline \multicolumn{6}{|l|}{ Tipo de antagonista } \\
\hline Natural & 14.3 & \multirow{2}{*}{0.20} & 1.2 & 1.0 & 1.6 \\
\hline Prótesis & 4.3 & & 0.3 & 0.1 & 2.3 \\
\hline \multicolumn{6}{|l|}{ Tiempo de función } \\
\hline$>20$ meses & 18.2 & \multirow{2}{*}{0.07} & 1.7 & 1.1 & 2.6 \\
\hline$\leq 20$ meses & 6.1 & & 0.5 & 0.2 & 1.3 \\
\hline \multicolumn{6}{|l|}{ Torque inicial } \\
\hline$>30 \mathrm{Ncm}$ & 14.6 & \multirow{2}{*}{0.46} & 1.3 & 0.7 & 2.3 \\
\hline$\leq 30 \mathrm{Ncm}$ & 9.6 & & 0.8 & 0.4 & 1.6 \\
\hline \multicolumn{6}{|c|}{ FACTORES RELACIONADOS CON EL PACIENTE } \\
\hline Hábitos tabáquicos & & & & & \\
\hline
\end{tabular}




\begin{tabular}{|c|c|c|c|c|c|}
\hline Fumadores & 14.5 & \multirow{2}{*}{0.26} & 1.3 & 0.9 & 1.8 \\
\hline No fumadores & 6.5 & & 0.5 & 0.1 & 1.9 \\
\hline \multicolumn{6}{|l|}{ Edad } \\
\hline$>45$ años & 17.1 & \multirow{2}{*}{0.16} & 1.5 & 0.9 & 2.6 \\
\hline$\leq 45$ años & 7.7 & & 0.6 & 0.3 & 1.4 \\
\hline
\end{tabular}

Tabla 6 Factores de riesgo para la aparición de complicaciones protéticas en restauraciones unitarias implantosoportadas. $(n=93)$.

No solamente el factor de la localización anatómica de la restauración puede tener influencia a la hora de justificar el aumento del riesgo de aflojamiento de tornillo que se ha encontrado en este estudio: la longitud de la brecha edéntula restaurada mediante una restauración soportada por un implante unitario (>10 mm), el tipo de antagonista, la precarga inicial o el valor del torque inicial influencian significativamente el riesgo de aflojamiento de acuerdo a un modelo de regresión logística multivariante (104). Estos hallazgos están en concordancia con los encontrados en la literatura $(105,108,112,196)$. La edad del paciente y el tiempo de función se muestran como factores no significativos dentro del modelo de regresión múltiple, aunque los valores se expresan en la dirección correcta de acuerdo con otros estudios (118,121,197-201) por lo que los pacientes de mayor edad y las restauraciones con un tiempo de función más largo, tienen un ratio mayor de aparición de aflojamiento de tornillo (Tabla 6).

Un sector edéntulo que va a ser restaurado mediante una restauración soportada mediante un solo implante y una corona con una longitud mesio-distal grande teniendo zonas de cantiléver, constituyen situaciones en las que el riesgo de que se produzca aflojamiento del tornillo está aumentado (Tabla 6) (104). La influencia negativa de los cantiléver en el éxito a largo plazo de las restauraciones es un hecho documentado en la literatura $(105,196,197)$. Cuando fuerzas de compresión se producen cerca de la cresta marginal de la corona fuera de la proyección axial del eje implantario, se producen fuerzas de torsión que aumentan el riesgo de aflojamiento del tornillo y fractura del mismo.

Bakaeen et al. (105) llegaron a la conclusión de que el riesgo de aflojamiento de tornillo puede minimizarse reduciendo el tamaño de la cara oclusal de los molares tanto en sentido vestíbulopalatino/lingual y mesio-distal con el objetivo de minimizar dichas fuerzas de torsión. Teniendo en cuenta que cuanto mayor sea la distancia de la fuerza ejercida al eje del implante, mayor será el momento de torsión y las fuerzas de palanca $(105,196,197)$ son preferibles plataformas de implantes estándar o anchas (standard or Wide platform) en comparación con aquellos implantes de plataforma estrecha (narrow platform) siempre que sea posible, con el objetivo de 
reducir dichos cantilévers. Sin embargo, este aspecto no estuvo entre los aspectos a analizar en este estudio (104).

Un factor que sé mostró significativo en nuestro estudio fue el hecho de que el antagonista de la restauración que sufrió aflojamiento de tornillo fuera dentición natural (Tabla 6). Cuando un diente se encuentra en infraoclusión, algunas veces erupciona hasta conseguir un contacto oclusal con su antagonista (202). Este proceso fisiológico no se produce cuando el antagonista es una prótesis implanto-retenida, una prótesis fija sobre dientes naturales o una prótesis removible $(201,202)$. Además, la mayoría de los dientes naturales no están posicionados en una relación intercuspal óptima, teniendo tendencia siempre a una migración e inclinación hacia mesial. Este fenómeno genera fuerzas oblicuas y torsionales que pueden causar sobrecargas sobre las restauraciones. Por el contrario, cuando el antagonista es una prótesis, el plano oclusal y demás variables oclusales deberían ser las ideales, optimizando de esta forma la distribución de las fuerzas. Los resultados del presente estudio están en concordancia con aquellos expuestos en la bibliografía en relación a factores biomecánicos $(201,202)$.

Además, en el presente estudio se ha puesto de manifiesto que un torque de atornillado inicial alto aumenta la incidencia de complicaciones (Tabla 6) (104). Este hallazgo debe tomarse con cautela, ya que este factor está estrechamente relacionado con la marca de implante sobre el cual está realizada la restauración, ya que el torque inicial se estableció siguiendo las indicaciones del fabricante (Tabla 5) por lo que no puede ser tomada como una variable independiente. Otra posible explicación para esta contradicción aparente, puede radicar en el fenómeno de asentamiento (settling effect) (203). Un alto torque puede conllevar una erosión de las superficies en contacto, alterando sus micro-rugosidades causando una pérdida de la precarga. Se estima que el fenómeno de asentamiento es responsable de una pérdida de la precarga que oscila entre el $2 \%$ y el $10 \%(109,119)$. Algunos autores recomiendan apretar de nuevo el tornillo 10 minutos después de la primera vez para compensar esa pérdida debida al asentamiento $(109,120)$

Solamente en una prótesis atornillada se produjo fractura de la cerámica (Tabla 5) (104). El recubrimiento cerámico utilizado tenía una estructura de leucita (SLS) que la hace particularmente resistente al estrés y a la propagación de las fracturas (204). Además, aunque la unión del metal con la cerámica es predecible en ambos tipos de conexiones implanto protésicas, las coronas atornilladas son más propensas a sufrir microfisuras (cerca del acceso del tornillo) en comparación con las prótesis cemento retenidas (205). 
La resina acrílica tiene una mayor resilencia que la cerámica como material de recubrimiento y, por lo tanto, presenta ratios de fractura inferiores (206) lo cual está en concordancia con los datos aportados por este estudio (104).

Por lo tanto, basándonos en los hallazgos de este estudio, se puede esperar que el riesgo de complicaciones protéticas se incremente en brechas edéntulas de sectores posteriores largas (>10 mm) que son rehabilitadas mediante coronas unitarias implanto-soportadas. El plano oclusal del antagonista y su superficie oclusal deben ser restaurados con el objetivo de prevenir fuerzas torsionales y sobrecargas. Además, parece ser recomendable elegir aquellos sistemas de implantes que recomienden un torque inicial menor a $30 \mathrm{Ncm}$ (104). A pesar de las complicaciones encontradas en este estudio, los altos ratios de supervivencia obtenidos en este estudio (los cuales son similares a los encontrados en la literatura en estudios multicéntricos prospectivos para restauraciones unitarias implantosoportadas $(108,117))$ nos llevan a la conclusión que esta modalidad de tratamiento con aditamentos de tipo UCLA se muestra adecuada para el uso clínico rutinario (104).

Además, la durabilidad de estas restauraciones sobre implantes dependerá de otros factores que deben ser analizados en futuros ensayos clínicos, como son la técnica quirúrgica, el diseño del implante, las características de la superficie implantaria, la correlación entre el patrón oclusal y los fracasos entre los diferentes materiales para restauraciones así como la presencia de bruxismo o apretamiento y su influencia. También debe ser estudiada la influencia que tiene la experiencia del operador en el éxito a largo plazo de las coronas implanto-soportadas (104). 
6. RECOMENDACIONES CLÍNICAS 
Teniendo en cuenta la metodología de este trabajo de Tesis Doctoral y los objetivos expuestos en el apartado correspondiente, tras la exposición de los trabajos publicados y la discusión de sus hallazgos, podemos extraer una serie de recomendaciones clínicas de cada uno de los estudios, sin perder de vista que el espíritu de este trabajo ha sido poder arrojar algo de claridad en la medida de lo posible sobre ciertos aspectos de la práctica clínica diaria en implantología dental, por todo ello enumeramos las siguientes recomendaciones siguiendo el mismo orden de las fases del tratamiento que han sido expuestas:

- Nuevos materiales para la fabricación de implantes como el zirconio parecen mostrarse prometedores ya que en estudios animales han mostrado tasas de osteointegración similares a los implantes de titanio aportando nuevas ventajas como por ejemplo la mejora en la estética debido a su color.

- Respecto a la fase de cicatrización y regeneración ósea, el papel que pueden jugar moléculas exógenas en la aceleración del proceso en combinación con biomateriales está siendo un tema ampliamente estudiado. La simvastatina parece ser una molécula prometedora en este aspecto, aunque no existe suficiente evidencia científica al respecto. La mayor parte de la evidencia con respecto al papel de la simvastatina tópica sobre la regeneración ósea, proviene de estudios en animales, centrándose en defectos óseos extraorales. Sin embargo 4 ensayos clínicos aleatorizados bien diseñados han reportado resultados clínicos significativamente mejores cuando un gel fluido de simvastatina [1,2 $\mathrm{mg} / 0,1 \mathrm{ml}]$ se inyectó en los sitios previamente tratados con raspado y alisado radicular en pacientes periodontales. Ninguna otra aplicación ha sido adecuadamente evaluada en humanos, por lo que queda un largo camino para que este tipo de técnicas y combinaciones puedan llegar a implementarse en la práctica clínica habitual.

- En cuanto al estudio de los factores de riesgo que pueden favorecer la aparición de fracasos tempranos de los implantes dentales, provocando por tanto su pérdida prematura, el estudio meta-analítico muestra como factores de riesgo significativos: el consumo de tabaco inhalado, implantes de longitud inferior a $10 \mathrm{~mm}$ e implantes colocados en el maxilar. Por ello se recomienda extremar las precauciones cuando confluyen cualquiera de estos factores de riesgo e intentar manejarlos y minimizar su influencia en la medida de lo posible.

- Durante la fase protésica, la cual por definición es la fase final de un tratamiento de restauración sobre implantes, la complicación que se presenta con mayor frecuencia es el aflojamiento del tornillo. Centrándonos en restauraciones unitarias realizadas sobre 
pilares UCLA, esta complicación ocurre de manera más frecuente en las siguientes situaciones: brechas edéntulas de una longitud mayor a $10 \mathrm{~mm}$, coronas con cantiléver de más de $6 \mathrm{~mm}$, cuando el antagonista es un diente natural, o cuando tenemos un torque inicial de apriete del tornillo alto. Por ello durante el diseño y colocación de este tipo de restauraciones, debemos tener en cuenta estos factores de riesgo para evitar el aflojamiento del tornillo, que aun pudiéndose considerar una complicación menor puede conllevar aparejado otras complicaciones adicionales de mayor importancia como fracturas del tornillo, de la propia prótesis, etc, además del consumo del tiempo de sillón y el disconfor que conlleva al paciente. 
7. CONCLUSIONES 
Tras los objetivos planteados y el trabajo realizado siguiendo la metodología expuesta en la sección correspondiente, y posteriormente el análisis de los resultados obtenidos de cada uno de los estudios realizados, se proceden a enunciar las siguientes conclusiones:

1. El zirconio como material para la fabricación de implantes tiene unos niveles de osteointegración similares a las que presentan los implantes de titanio en modelos animales.

2. La Simvastatina parece ser una sustancia prometedora aplicada de forma tópica en combinación con biomateriales para acelerar los procesos de regeneración ósea en modelo animal.

3. Los principales factores de riesgo para el fracaso temprano en implantología son: tabaquismo (OR=1.7; 95\%; Cl: 1.3-2.3), implantes de longitud <10mm (OR=1.6; 95\%; $\mathrm{Cl}: 1.2-2.2$ ) e implantes colocados en el maxilar (OR=1.3; 95\%; $\mathrm{Cl}: 1.0-1.6)$

4. El aflojamiento de tornillos es la complicación más frecuente en coronas unitarias realizadas sobre pilares UCLA siendo los principales factores de riesgo: brechas edéntulas de longitud mesio-distal superior a $10 \mathrm{~mm}$ restauradas con una corona unitaria, áreas de cantiléver superiores a $6 \mathrm{~mm}$, torques iniciales de apretamiento del tornillo alto y dentición natural antagonista. 
8. BIBLIOGRAFÍA 
1. Nyan M, Sato D, Kihara H, Machida T, Ohya K, Kasugai S. Effects of the combination with alpha-tricalcium phosphate and simvastatin on bone regeneration. Clin Oral Implants Res. 2009;20(3):280-7.

2. Gaviria L, Salcido JP, Guda T, Ong JL. Current trends in dental implants. J Korean Assoc Oral Maxillofac Surg. 2014;40(2):50-60.

3. Brånemark PI, Adell R, Breine U, Hansson BO, Lindström J, Ohlsson A. Intra-osseous anchorage of dental prostheses. I. Experimental studies. Scand J Plast Reconstr Surg. 1969;3(2):81-100.

4. Brånemark $\mathrm{PI}$, Hansson $\mathrm{BO}$, Adell $\mathrm{R}$, Breine $\mathrm{U}$, Lindström J, Hallén $\mathrm{O}$, et al. Osseointegrated implants in the treatment of the edentulous jaw. Experience from a 10-year period. Scand J Plast Reconstr Surg Suppl. 1977;16:1-132.

5. Brånemark PI, Adell R, Albrektsson T, Lekholm U, Lundkvist S, Rockler B. Osseointegrated titanium fixtures in the treatment of edentulousness. Biomaterials. 1983;4(1):25-8.

6. Manzano G, Herrero LR, Montero J. Comparison of clinical performance of zirconia implants and titanium implants in animal models: a systematic review. Int J Oral Maxillofac Implants. 2014;29(2):311-20.

7. Coelho PG, Granjeiro JM, Romanos GE, Suzuki M, Silva NRF, Cardaropoli G, et al. Basic research methods and current trends of dental implant surfaces. J Biomed Mater Res Part B Appl Biomater. 2009;88(2):579-96.

8. Aljateeli M, Wang H-L. Implant microdesigns and their impact on osseointegration. Implant Dent. 2013;22(2):127-32.

9. Stanford CM. Surface modifications of dental implants. Aust Dent J. 2008;53 Suppl 1:S26-33.

10. Binon PP. Implants and components: entering the new millennium. Int J Oral Maxillofac Implants. 2000;15(1):76-94.

11. Finger IM, Castellon $\mathrm{P}$, Block $\mathrm{M}$, Elian N. The evolution of external and internal implant/abutment connections. Pract Proced Aesthet Dent. 2003;15(8):625-32.

12. Triplett RG, Frohberg U, Sykaras N, Woody RD. Implant materials, design, and surface topographies: their influence on osseointegration of dental implants. J Long Term Eff Med Implants. 2003;13(6):485-501.

13. Manzano G, Montero J, Martín-Vallejo J, Del Fabbro M, Bravo M, Testori T. Risk Factors in Early Implant Failure: A Meta-Analysis. Implant Dent. 2016;25(2):272-80.

14. Grant B-TN, Pancko FX, Kraut RA. Outcomes of placing short dental implants in the posterior mandible: a retrospective study of 124 cases. J Oral Maxillofac Surg. 2009;67(4):7137. 
15. Misch CE, Steignga J, Barboza E, Misch-Dietsh F, Cianciola L, Kazor C. Short dental implants in posterior partial edentulism: a multicenter retrospective 6-year case series study. J Periodontol. 2006;77(8):1340-7.

16. Olate S, Lyrio MCN, de Moraes M, Mazzonetto R, Moreira RWF. Influence of diameter and length of implant on early dental implant failure. J Oral Maxillofac Surg. 2010;68(2):414-9.

17. Renouard F, Nisand D. Impact of implant length and diameter on survival rates. Clin Oral Implants Res. 2006;17 Suppl 2:35-51.

18. Lee J-H, Frias V, Lee K-W, Wright RF. Effect of implant size and shape on implant success rates: a literature review. J Prosthet Dent. 2005;94(4):377-81.

19. Koka S, Razzoog ME, Bloem TJ, Syed S. Microbial colonization of dental implants in partially edentulous subjects. J Prosthet Dent. 1993;70(2):141-4.

20. Lee J, Sieweke JH, Rodriguez NA, Schüpbach $P$, Lindström $H$, Susin C, et al. Evaluation of nano-technology-modified zirconia oral implants: a study in rabbits. J Clin Periodontol. 2009;36(7):610-7.

21. Le Guéhennec L, Soueidan A, Layrolle $P$, Amouriq $Y$. Surface treatments of titanium dental implants for rapid osseointegration. Dent Mater. 2007;23(7):844-54.

22. Schliephake H, Rublack J, Aeckerle N, Förster A, Schwenzer B, Reichert J, et al. In vivo effect of immobilisation of bone morphogenic protein 2 on titanium implants through nanoanchored oligonucleotides. Eur Cell Mater. 2015;30:28-40; discussion 40.

23. Mehrali M, Shirazi FS, Mehrali M, Metselaar HSC, Kadri NAB, Osman NAA. Dental implants from functionally graded materials. J Biomed Mater Res A. 2013;101(10):3046-57.

24. Hall JE, Guyton AC. Guyton\& Hall Compendio de fisiología médica. Elsevier España; 2007. $748 \mathrm{p.}$

25. Friedenstein AJ. Precursor cells of mechanocytes. Int Rev Cytol. 1976;47:327-59.

26. Davies JE. Bone Engineering. Em Squared; 2000. 656 p.

27. Yamaguchi A, Komori T, Suda T. Regulation of osteoblast differentiation mediated by bone morphogenetic proteins, hedgehogs, and Cbfa1. Endocr Rev. 2000;21(4):393-411.

28. Zarb GA, Lekholm U, Albrektsson TO. Aging, osteoporosis, and dental implants. Quintessence Pub. Co; 2002. 280 p.

29. Komori T, Yagi H, Nomura S, Yamaguchi A, Sasaki K, Deguchi K, et al. Targeted disruption of Cbfa1 results in a complete lack of bone formation owing to maturational arrest of osteoblasts. Cell. 1997;89(5):755-64.

30. Ducy P, Zhang R, Geoffroy V, Ridall AL, Karsenty G. Osf2/Cbfa1: a transcriptional activator of osteoblast differentiation. Cell. 1997;89(5):747-54. 
31. Hoshi K, Komori T, Ozawa H. Morphological characterization of skeletal cells in Cbfa1deficient mice. Bone. 1999;25(6):639-51.

32. Bilezikian JP, Raisz LG, Martin TJ. Principles of Bone Biology. Academic Press; 2008. 1024 p.

33. Civitelli R, Beyer EC, Warlow PM, Robertson AJ, Geist ST, Steinberg TH. Connexin43 mediates direct intercellular communication in human osteoblastic cell networks. J Clin Invest. 1993;91(5):1888-96.

34. Simonet WS, Lacey DL, Dunstan CR, Kelley M, Chang MS, Lüthy R, et al. Osteoprotegerin: a novel secreted protein involved in the regulation of bone density. Cell. 1997;89(2):309-19.

35. Fernández-Tresguerres-Hernández-Gil I, Alobera-Gracia MA, del-Canto-Pingarrón M, Blanco-Jerez L. Physiological bases of bone regeneration I. Histology and physiology of bone tissue. Med Oral Patol Oral Cir Bucal. 2006;11(1):E47-51.

36. HAM AW. Some histophysiological problems peculiar to calcified tissues. J Bone Joint Surg Am. 1952;24-A-3:701-28.

37. Lanyon LE. Osteocytes, strain detection, bone modeling and remodeling. Calcif Tissue Int. 1993;53 Suppl 1:S102-6; discussion S106-7.

38. Mundy GR. Cytokines and growth factors in the regulation of bone remodeling. J Bone Miner Res. 1993;8 Suppl 2:S505-10.

39. Morote J, Planas J. Pérdida de masa ósea en pacientes con cáncer de próstata sometidos a deprivación androgénica. Actas Urológicas Españolas. 2011;35(4):232-9.

40. Lacey DL, Timms E, Tan HL, Kelley MJ, Dunstan CR, Burgess T, et al. Osteoprotegerin ligand is a cytokine that regulates osteoclast differentiation and activation. Cell. 1998;93(2):16576.

41. Young MF. Bone matrix proteins: more than markers. Calcif Tissue Int. 2003;72(1):2-4.

42. Canalis E, McCarthy TL, Centrella M. The role of growth factors in skeletal remodeling. Endocrinol Metab Clin North Am. 1989;18(4):903-18.

43. Parfitt AM. The coupling of bone formation to bone resorption: a critical analysis of the concept and of its relevance to the pathogenesis of osteoporosis. Metab Bone Dis Relat Res. 1982;4(1):1-6.

44. Compston JE. Sex steroids and bone. Physiol Rev. 2001;81(1):419-47.

45. Lind M, Deleuran B, Thestrup-Pedersen K, Søballe K, Eriksen EF, Bünger C. Chemotaxis of human osteoblasts. Effects of osteotropic growth factors. APMIS. 1995;103(2):140-6.

46. Fernández-Tresguerres-Hernández-Gil I, Alobera-Gracia MA, del-Canto-Pingarrón M, Blanco-Jerez L. Physiological bases of bone regeneration II. The remodeling process. Med Oral Patol Oral Cir Bucal. 2006;11(2):E151-7. 
47. Cohick WS, Clemmons DR. The insulin-like growth factors. Annu Rev Physiol. 1993;55:131-53.

48. Hill PA, Reynolds JJ, Meikle MC. Osteoblasts mediate insulin-like growth factor-I and -II stimulation of osteoclast formation and function. Endocrinology. 1995;136(1):124-31.

49. Mohan S, Baylink DJ. Bone growth factors. Clin Orthop Relat Res. 1991;(263):30-48.

50. Baylink DJ, Finkelman RD, Mohan S. Growth factors to stimulate bone formation. J Bone Miner Res. 1993;8 Suppl 2:S565-72.

51. Horowitz M. Matrix proteins versus cytokines in the regulation of osteoblast function and bone formation. Calcif Tissue Int. 2003;72(1):5-7.

52. Canalis E, Economides AN, Gazzerro E. Bone morphogenetic proteins, their antagonists, and the skeleton. Endocr Rev. 2003;24(2):218-35.

53. Nash TJ, Howlett CR, Martin C, Steele J, Johnson KA, Hicklin DJ. Effect of platelet-derived growth factor on tibial osteotomies in rabbits. Bone. 1994;15(2):203-8.

54. Marie PJ. Fibroblast growth factor signaling controlling osteoblast differentiation. Gene. 2003;316:23-32.

55. Roodman GD, Kurihara N, Ohsaki Y, Kukita A, Hosking D, Demulder A, et al. Interleukin 6. A potential autocrine/paracrine factor in Paget's disease of bone. J Clin Invest. 1992;89(1):4652.

56. Kawaguchi H, Pilbeam CC, Harrison JR, Raisz LG. The role of prostaglandins in the regulation of bone metabolism. Clin Orthop Relat Res. 1995;(313):36-46.

57. Offenbacher S, Heasman PA, Collins JG. Modulation of host PGE2 secretion as a determinant of periodontal disease expression. J Periodontol. 1993;64(5 Suppl):432-44.

58. Jódar Gimeno E, Muñoz-Torres $M$, Escobar-Jiménez F, Quesada Charneco $M$, Luna del Castillo JD, Oleà N. Identification of metabolic bone disease in patients with endogenous hyperthyroidism: role of biological markers of bone turnover. Calcif Tissue Int. 1997;61(5):3706.

59. Raisz LG. Bone cell biology: new approaches and unanswered questions. J Bone Miner Res. 1993;8 Suppl 2:S457-65.

60. Hofbauer LC, Khosla S, Dunstan CR, Lacey DL, Spelsberg TC, Riggs BL. Estrogen stimulates gene expression and protein production of osteoprotegerin in human osteoblastic cells. Endocrinology. 1999;140(9):4367-70.

61. Manolagas SC. Birth and death of bone cells: basic regulatory mechanisms and implications for the pathogenesis and treatment of osteoporosis. Endocr Rev. 2000;21(2):11537. 
62. Harvey S, Hull KL. Growth hormone. A paracrine growth factor? Endocrine. 1997;7(3):267-79.

63. Grant SF, Ralston SH. Genes and osteoporosis. Trends Endocrinol Metab. 1997;8(6):2326.

64. Pocock NA, Eisman JA, Hopper JL, Yeates MG, Sambrook PN, Eberl S. Genetic determinants of bone mass in adults. A twin study. J Clin Invest. 1987;80(3):706-10.

65. Morey ER, Baylink DJ. Inhibition of bone formation during space flight. Science. 1978;201(4361):1138-41.

66. Rojbani $H$, Nyan $M$, Ohya K, Kasugai S. Evaluation of the osteoconductivity of $\alpha$ tricalcium phosphate, $\beta$-tricalcium phosphate, and hydroxyapatite combined with or without simvastatin in rat calvarial defect. J Biomed Mater Res A. 2011;98(4):488-98.

67. Kihara $H$, Shiota $M$, Yamashita $Y$, Kasugai S. Biodegradation process of alpha-TCP particles and new bone formation in a rabbit cranial defect model. J Biomed Mater Res Part B Appl Biomater. 2006;79(2):284-91.

68. Brugnami F, Caiazzo A, Leone C. Local intraoral autologous bone harvesting for dental implant treatment: alternative sources and criteria of choice. Keio J Med. 2009;58(1):24-8.

69. Swan MC, Goodacre TEE. Morbidity at the iliac crest donor site following bone grafting of the cleft alveolus. Br J Oral Maxillofac Surg. 2006;44(2):129-33.

70. Younger EM, Chapman MW. Morbidity at bone graft donor sites. J Orthop Trauma. 1989;3(3):192-5.

71. Urist MR. Bone: formation by autoinduction. Science. 1965;150(3698):893-9.

72. Urist MR, Strates BS. The Classic: Bone Morphogenetic Protein. Clin Orthop Relat Res. 2009;467(12):3051-62.

73. Boyne PJ, Salina S, Nakamura A, Audia F, Shabahang S. Bone regeneration using rhBMP2 induction in hemimandibulectomy type defects of elderly sub-human primates. Cell Tissue Bank. 2006;7(1):1-10.

74. Duan Z, Zheng Q, Guo X, Li C, Wu B, Wu W. Repair of rabbit femoral defects with a novel BMP2-derived oligopeptide P24. J Huazhong Univ Sci Technol Med Sci. 2008;28(4):426-30.

75. Figueiredo M, Henriques J, Martins G, Guerra F, Judas F, Figueiredo H. Physicochemical characterization of biomaterials commonly used in dentistry as bone substitutes--comparison with human bone. J Biomed Mater Res Part B Appl Biomater. 2010;92(2):409-19.

76. Kamitakahara M, Ohtsuki C, Miyazaki T. Review paper: behavior of ceramic biomaterials derived from tricalcium phosphate in physiological condition. J Biomater Appl. 2008;23(3):197212. 
77. Moy PK, Lundgren S, Holmes RE. Maxillary sinus augmentation: histomorphometric analysis of graft materials for maxillary sinus floor augmentation. J Oral Maxillofac Surg. 1993;51(8):857-62.

78. Yuan H, Yang Z, De Bruij JD, De Groot K, Zhang X. Material-dependent bone induction by calcium phosphate ceramics: a 2.5-year study in dog. Biomaterials. 2001;22(19):2617-23.

79. Mundy G, Garrett R, Harris S, Chan J, Chen D, Rossini G, et al. Stimulation of bone formation in vitro and in rodents by statins. Science. 1999;286(5446):1946-9.

80. Zhang M, Li X, Qiao Y, Nie S, Ma C. Does treatment with statins have the potential of enhancing vascular calcification? Chin Med J. 2008;121(5):473-4.

81. Hatano H, Maruo A, Bolander ME, Sarkar G. Statin stimulates bone morphogenetic protein-2, aggrecan, and type 2 collagen gene expression and proteoglycan synthesis in rat chondrocytes. J Orthop Sci. 2003;8(6):842-8.

82. Nyan M, Miyahara T, Noritake K, Hao J, Rodriguez R, Kuroda S, et al. Molecular and tissue responses in the healing of rat calvarial defects after local application of simvastatin combined with alpha tricalcium phosphate. J Biomed Mater Res Part B Appl Biomater. 2010;93(1):65-73.

83. Nyan $M$, Sato $D$, Oda $M$, Machida $T$, Kobayashi $H$, Nakamura $T$, et al. Bone formation with the combination of simvastatin and calcium sulfate in critical-sized rat calvarial defect. J Pharmacol Sci. 2007;104(4):384-6.

84. Skoglund B, Aspenberg P. Locally applied Simvastatin improves fracture healing in mice. BMC Musculoskelet Disord. 2007;8:98.

85. Sonobe M, Hattori K, Tomita N, Yoshikawa T, Aoki H, Takakura Y, et al. Stimulatory effects of statins on bone marrow-derived mesenchymal stem cells. Study of a new therapeutic agent for fracture. Biomed Mater Eng. 2005;15(4):261-7.

86. Stein D, Lee Y, Schmid MJ, Killpack B, Genrich MA, Narayana N, et al. Local simvastatin effects on mandibular bone growth and inflammation. J Periodontol. 2005;76(11):1861-70.

87. Giannoudis PV, Dinopoulos H, Tsiridis E. Bone substitutes: An update. Injury. 2005;36(3, Supplement):S20-7.

88. Jensen SS, Broggini N, Hjørting-Hansen E, Schenk R, Buser D. Bone healing and graft resorption of autograft, anorganic bovine bone and $\beta$-tricalcium phosphate. A histologic and histomorphometric study in the mandibles of minipigs. Clinical Oral Implants Research. 2006;17(3):237-43.

89. Figueiredo M, Henriques J, Martins G, Guerra F, Judas F, Figueiredo H. Physicochemical characterization of biomaterials commonly used in dentistry as bone substitutes--comparison with human bone. J Biomed Mater Res Part B Appl Biomater. 2010;92(2):409-19.

90. Albrektsson T, Lekholm U. Osseointegration: current state of the art. Dent Clin North Am. 1989;33(4):537-54. 
91. Baqain ZH, Moqbel WY, Sawair FA. Early dental implant failure: risk factors. Br J Oral Maxillofac Surg. 2012;50(3):239-43.

92. Shibuya Y, Takata N, Takeuchi J, Tsuji K, Ishida S, Kobayashi M, et al. Analysis of the 619 Brånemark System TiUnite implants: a retrospective study. Kobe J Med Sci. 2012;58(1):E19-28.

93. Kronström M, Svenson B, Hellman M, Persson GR. Early implant failures in patients treated with Brånemark System titanium dental implants: a retrospective study. Int J Oral Maxillofac Implants. 2001;16(2):201-7.

94. Albrektsson T, Zarb G, Worthington P, Eriksson AR. The long-term efficacy of currently used dental implants: a review and proposed criteria of success. Int J Oral Maxillofac Implants. 1986;1(1):11-25.

95. Misch CE, Perel ML, Wang H-L, Sammartino G, Galindo-Moreno P, Trisi P, et al. Implant success, survival, and failure: the International Congress of Oral Implantologists (ICOI) Pisa Consensus Conference. Implant Dent. 2008;17(1):5-15.

96. van Steenberghe D, Jacobs R, Desnyder M, Maffei G, Quirynen M. The relative impact of local and endogenous patient-related factors on implant failure up to the abutment stage. Clin Oral Implants Res. 2002;13(6):617-22.

97. Esposito M, Hirsch JM, Lekholm U, Thomsen P. Biological factors contributing to failures of osseointegrated oral implants. (I). Success criteria and epidemiology. Eur J Oral Sci. 1998;106(1):527-51.

98. Esposito M, Hirsch JM, Lekholm U, Thomsen P. Biological factors contributing to failures of osseointegrated oral implants. (II). Etiopathogenesis. Eur J Oral Sci. 1998;106(3):721-64.

99. Esposito M, Thomsen P, Ericson LE, Lekholm U. Histopathologic observations on early oral implant failures. Int J Oral Maxillofac Implants. 1999;14(6):798-810.

100. Koldsland OC, Scheie AA, Aass AM. Prevalence of implant loss and the influence of associated factors. J Periodontol. 2009;80(7):1069-75.

101. Alsaadi G, Quirynen M, Komárek A, van Steenberghe D. Impact of local and systemic factors on the incidence of oral implant failures, up to abutment connection. J Clin Periodontol. 2007;34(7):610-7.

102. Chrcanovic BR, Albrektsson T, Wennerberg A. Reasons for failures of oral implants. J Oral Rehabil. 2014;41(6):443-76.

103. Kronström M, Svensson B, Erickson E, Houston L, Braham P, Persson GR. Humoral immunity host factors in subjects with failing or successful titanium dental implants. J Clin Periodontol. 2000;27(12):875-82.

104. Montero J, Manzano G, Beltrán D, Lynch CD, Suárez-García M-J, Castillo-Oyagüe R. Clinical evaluation of the incidence of prosthetic complications in implant crowns constructed with UCLA castable abutments. A cohort follow-up study. J Dent. 2012;40(12):1081-9. 
105. Bakaeen LG, Winkler S, Neff PA. The effect of implant diameter, restoration design, and occlusal table variations on screw loosening of posterior single-tooth implant restorations. J Oral Implantol. 2001;27(2):63-72.

106. Hebel KS, Gajjar RC. Cement-retained versus screw-retained implant restorations: achieving optimal occlusion and esthetics in implant dentistry. J Prosthet Dent. 1997;77(1):2835.

107. Lewis S, Beumer J 3rd, Hornburg W, Moy P. The «UCLA» abutment. Int J Oral Maxillofac Implants. 1988;3(3):183-9.

108. Bianco G, Di Raimondo R, Luongo G, Paoleschi C, Piccoli P, Piccoli C, et al. Osseointegrated implant for single-tooth replacement: a retrospective multicenter study on routine use in private practice. Clin Implant Dent Relat Res. 2000;2(3):152-8.

109. Dixon DL, Breeding LC, Sadler JP, McKay ML. Comparison of screw loosening, rotation, and deflection among three implant designs. J Prosthet Dent. 1995;74(3):270-8.

110. Haas R, Mensdorff-Pouilly N, Mailath G, Watzek G. Brånemark single tooth implants: a preliminary report of 76 implants. J Prosthet Dent. 1995;73(3):274-9.

111. Jung RE, Pjetursson BE, Glauser R, Zembic A, Zwahlen M, Lang NP. A systematic review of the 5-year survival and complication rates of implant-supported single crowns. Clin Oral Implants Res. 2008;19(2):119-30.

112. KreissI ME, Gerds T, Muche R, Heydecke G, Strub JR. Technical complications of implantsupported fixed partial dentures in partially edentulous cases after an average observation period of 5 years. Clin Oral Implants Res. 2007;18(6):720-6.

113. Simon RL. Single implant-supported molar and premolar crowns: a ten-year retrospective clinical report. J Prosthet Dent. 2003;90(6):517-21.

114. Krennmair G, Seemann R, Schmidinger S, Ewers R, Piehslinger E. Clinical outcome of root-shaped dental implants of various diameters: 5-year results. Int J Oral Maxillofac Implants. 2010;25(2):357-66.

115. Brägger U, Hirt-Steiner S, Schnell N, Schmidlin K, Salvi GE, Pjetursson B, et al. Complication and failure rates of fixed dental prostheses in patients treated for periodontal disease. Clin Oral Implants Res. 2011;22(1):70-7.

116. Khraisat A, Abu-Hammad O, Dar-Odeh N, Al-Kayed AM. Abutment screw loosening and bending resistance of external hexagon implant system after lateral cyclic loading. Clin Implant Dent Relat Res. 2004;6(3):157-64.

117. Scheller H, Urgell JP, Kultje C, Klineberg I, Goldberg PV, Stevenson-Moore P, et al. A 5year multicenter study on implant-supported single crown restorations. Int J Oral Maxillofac Implants. 1998;13(2):212-8.

118. Siamos G, Winkler S, Boberick KG. Relationship between implant preload and screw loosening on implant-supported prostheses. J Oral Implantol. 2002;28(2):67-73. 
119. Gratton DG, Aquilino SA, Stanford CM. Micromotion and dynamic fatigue properties of the dental implant-abutment interface. J Prosthet Dent. 2001;85(1):47-52.

120. Breeding LC, Dixon DL, Nelson EW, Tietge JD. Torque required to loosen single-tooth implant abutment screws before and after simulated function. Int J Prosthodont. 1993;6(5):4359.

121. Byrne D, Jacobs S, O'Connell B, Houston F, Claffey N. Preloads generated with repeated tightening in three types of screws used in dental implant assemblies. J Prosthodont. 2006;15(3):164-71.

122. Jörnéus L, Jemt T, Carlsson L. Loads and designs of screw joints for single crowns supported by osseointegrated implants. Int J Oral Maxillofac Implants. 1992;7(3):353-9.

123. Hong $P$, Boyd D, Beyea SD, Bezuhly $M$. Enhancement of bone consolidation in mandibular distraction osteogenesis: a contemporary review of experimental studies involving adjuvant therapies. J Plast Reconstr Aesthet Surg. julio de 2013;66(7):883-95.

124. Park J-B. The use of simvastatin in bone regeneration. Med Oral Patol Oral Cir Bucal. 2009;14(9):e485-8.

125. Boissel JP, Blanchard J, Panak E, Peyrieux JC, Sacks H. Considerations for the metaanalysis of randomized clinical trials. Summary of a panel discussion. Control Clin Trials. 1989;10(3):254-81.

126. Galbraith RF. The radial plot: Graphical assessment of spread in ages. International Journal of Radiation Applications and Instrumentation Part D Nuclear Tracks and Radiation Measurements. 1990;17(3):207-14.

127. Higgins JPT, Thompson SG. Quantifying heterogeneity in a meta-analysis. Stat Med. 2002;21(11):1539-58.

128. Depprich R, Zipprich H, Ommerborn M, Naujoks C, Wiesmann H-P, Kiattavorncharoen S, et al. Osseointegration of zirconia implants compared with titanium: an in vivo study. Head Face Med. 2008;4:30.

129. Gahlert M, Röhling S, Wieland M, Sprecher CM, Kniha H, Milz S. Osseointegration of zirconia and titanium dental implants: a histological and histomorphometrical study in the maxilla of pigs. Clin Oral Implants Res. 2009;20(11):1247-53.

130. Stadlinger B, Hennig M, Eckelt U, Kuhlisch E, Mai R. Comparison of zirconia and titanium implants after a short healing period. A pilot study in minipigs. Int J Oral Maxillofac Surg. 2010;39(6):585-92.

131. Sennerby L, Dasmah A, Larsson B, Iverhed M. Bone tissue responses to surface-modified zirconia implants: A histomorphometric and removal torque study in the rabbit. Clin Implant Dent Relat Res. 2005;7 Suppl 1:S13-20. 
132. Koch FP, Weng D, Krämer S, Biesterfeld S, Jahn-Eimermacher A, Wagner W. Osseointegration of one-piece zirconia implants compared with a titanium implant of identical design: a histomorphometric study in the dog. Clin Oral Implants Res. 2010;21(3):350-6.

133. Kohal RJ, Wolkewitz M, Hinze M, Han J-S, Bächle M, Butz F. Biomechanical and histological behavior of zirconia implants: an experiment in the rat. Clin Oral Implants Res. 2009;20(4):333-9.

134. Hoffmann O, Angelov N, Gallez F, Jung RE, Weber FE. The zirconia implant-bone interface: a preliminary histologic evaluation in rabbits. Int J Oral Maxillofac Implants. 2008;23(4):691-5.

135. Rocchietta I, Fontana F, Addis A, Schupbach P, Simion M. Surface-modified zirconia implants: tissue response in rabbits. Clin Oral Implants Res. 2009;20(8):844-50.

136. Kohal RJ, Weng D, Bächle M, Strub JR. Loaded custom-made zirconia and titanium implants show similar osseointegration: an animal experiment. J Periodontol. 2004;75(9):12628.

137. Depprich R, Zipprich H, Ommerborn M, Mahn E, Lammers L, Handschel J, et al. Osseointegration of zirconia implants: an SEM observation of the bone-implant interface. Head Face Med. 2008;4:25.

138. Schliephake H, Hefti T, Schlottig F, Gédet P, Staedt H. Mechanical anchorage and periimplant bone formation of surface-modified zirconia in minipigs. J Clin Periodontol. 2010;37(9):818-28.

139. Ferguson SJ, Langhoff JD, Voelter K, von Rechenberg B, Scharnweber D, Bierbaum S, et al. Biomechanical comparison of different surface modifications for dental implants. Int J Oral Maxillofac Implants. 2008;23(6):1037-46.

140. Langhoff JD, Voelter K, Scharnweber D, Schnabelrauch M, Schlottig F, Hefti T, et al. Comparison of chemically and pharmaceutically modified titanium and zirconia implant surfaces in dentistry: a study in sheep. Int J Oral Maxillofac Surg. 2008;37(12):1125-32.

141. Buser D, Schenk RK, Steinemann S, Fiorellini JP, Fox CH, Stich H. Influence of surface characteristics on bone integration of titanium implants. A histomorphometric study in miniature pigs. J Biomed Mater Res. 1991;25(7):889-902.

142. Wennerberg A, Albrektsson T, Andersson B, Krol JJ. A histomorphometric and removal torque study of screw-shaped titanium implants with three different surface topographies. Clin Oral Implants Res. 1995;6(1):24-30.

143. Wennerberg A, Albrektsson T, Lausmaa J. Torque and histomorphometric evaluation of c.p. titanium screws blasted with 25- and 75-microns-sized particles of Al2O3. J Biomed Mater Res. 1996;30(2):251-60. 
144. Wennerberg A, Hallgren C, Johansson C, Danelli S. A histomorphometric evaluation of screw-shaped implants each prepared with two surface roughnesses. Clin Oral Implants Res. 1998;9(1):11-9.

145. Gotfredsen K, Berglundh T, Lindhe J. Anchorage of titanium implants with different surface characteristics: an experimental study in rabbits. Clin Implant Dent Relat Res. 2000;2(3):120-8.

146. Gahlert M, Gudehus T, Eichhorn S, Steinhauser E, Kniha H, Erhardt W. Biomechanical and histomorphometric comparison between zirconia implants with varying surface textures and a titanium implant in the maxilla of miniature pigs. Clin Oral Implants Res. 2007;18(5):6628.

147. Gahlert M, Röhling S, Wieland M, Eichhorn S, Küchenhoff H, Kniha H. A comparison study of the osseointegration of zirconia and titanium dental implants. A biomechanical evaluation in the maxilla of pigs. Clin Implant Dent Relat Res. 2010;12(4):297-305.

148. Shin D, Blanchard SB, Ito M, Chu T-MG. Peripheral quantitative computer tomographic, histomorphometric, and removal torque analyses of two different non-coated implants in a rabbit model. Clin Oral Implants Res. 2011;22(3):242-50.

149. Hoffmann O, Angelov N, Zafiropoulos G-G, Andreana S. Osseointegration of zirconia implants with different surface characteristics: an evaluation in rabbits. Int J Oral Maxillofac Implants. 2012;27(2):352-8.

150. Fernández-Tresguerres-Hernández-Gil I, Alobera-Gracia MA, del-Canto-Pingarrón M, Blanco-Jerez L. Physiological bases of bone regeneration II. The remodeling process. Med Oral Patol Oral Cir Bucal. 2006;11(2):E151-7.

151. Montero J, Manzano G, Albaladejo A. The role of topical simvastatin on bone regeneration: A systematic review. J Clin Exp Dent. 2014;6(3):e286-90.

152. Alam S, Ueki K, Nakagawa K, Marukawa K, Hashiba Y, Yamamoto E, et al. Statin-induced bone morphogenetic protein (BMP) 2 expression during bone regeneration: an immunohistochemical study. Oral Surg Oral Med Oral Pathol Oral Radiol Endod. 2009;107(1):229.

153. Fernández PL. Velázquez. Farmacología Básica y Clínica. Ed. Médica Panamericana; 2008. $1404 \mathrm{p}$.

154. Anbinder AL, Junqueira JC, Mancini MNG, Balducci I, Rocha RF da, Carvalho YR. Influence of simvastatin on bone regeneration of tibial defects and blood cholesterol level in rats. Braz Dent J. 2006;17(4):267-73.

155. Ayukawa Y, Yasukawa E, Moriyama Y, Ogino Y, Wada H, Atsuta I, et al. Local application of statin promotes bone repair through the suppression of osteoclasts and the enhancement of osteoblasts at bone-healing sites in rats. Oral Surg Oral Med Oral Pathol Oral Radiol Endod. 2009;107(3):336-42. 
156. Ozeç I. Re: Statin-induced bone morphogenetic protein (BMP) 2 expression during bone regeneration: an immunohistochemical study. Oral Surg Oral Med Oral Pathol Oral Radiol Endod. 2009;107(5):605-6.

157. Mukozawa A, Ueki K, Marukawa K, Okabe K, Moroi A, Nakagawa K. Bone healing of critical-sized nasal defects in rabbits by statins in two different carriers. Clin Oral Implants Res. 2011;22(11):1327-35.

158. Chen P-Y, Sun J-S, Tsuang Y-H, Chen M-H, Weng P-W, Lin F-H. Simvastatin promotes osteoblast viability and differentiation via Ras/Smad/Erk/BMP-2 signaling pathway. Nutr Res. 2010;30(3):191-9.

159. Maciel-Oliveira N, Bradaschia-Correa V, Arana-Chavez VE. Early alveolar bone regeneration in rats after topical administration of simvastatin. Oral Surg Oral Med Oral Pathol Oral Radiol Endod. 2011;112(2):170-9.

160. Ayukawa Y, Okamura A, Koyano K. Simvastatin promotes osteogenesis around titanium implants. Clin Oral Implants Res. 2004;15(3):346-50.

161. Grasser WA, Baumann AP, Petras SF, Harwood HJ Jr, Devalaraja R, Renkiewicz R, et al. Regulation of osteoclast differentiation by statins. J Musculoskelet Neuronal Interact. 2003;3(1):53-62.

162. Wu Z, Liu C, Zang G, Sun H. The effect of simvastatin on remodelling of the alveolar bone following tooth extraction. Int J Oral Maxillofac Surg. 2008;37(2):170-6.

163. Mundy G, Garrett R, Harris S, Chan J, Chen D, Rossini G, et al. Stimulation of bone formation in vitro and in rodents by statins. Science. 1999;286(5446):1946-9.

164. Ozeç I, Kiliç E, Gümüş C, Göze F. Effect of local simvastatin application on mandibular defects. J Craniofac Surg. 2007;18(3):546-50.

165. Seto H, Ohba H, Tokunaga K, Hama H, Horibe M, Nagata T. Topical administration of simvastatin recovers alveolar bone loss in rats. J Periodont Res. 2008;43(3):261-7.

166. Lima CEV de C, Calixto JC, Anbinder AL. Influence of the association between simvastatin and demineralized bovine bone matrix on bone repair in rats. Braz Oral Res. 2011;25(1):42-8.

167. Tanigo T, Takaoka R, Tabata Y. Sustained release of water-insoluble simvastatin from biodegradable hydrogel augments bone regeneration. J Control Release. 2010;143(2):201-6.

168. Ivanoff CJ, Sennerby L, Lekholm U. Influence of initial implant mobility on the integration of titanium implants. An experimental study in rabbits. Clin Oral Implants Res. 1996;7(2):120-7.

169. Szmukler-Moncler S, Piattelli A, Favero GA, Dubruille JH. Considerations preliminary to the application of early and immediate loading protocols in dental implantology. Clin Oral Implants Res. 2000;11(1):12-25.

170. Diz P, Scully C, Sanz M. Dental implants in the medically compromised patient. J Dent. 2013;41(3):195-206. 
171. Scully C, Hobkirk J, Dios PD. Dental endosseous implants in the medically compromised patient. J Oral Rehabil. 2007;34(8):590-9.

172. Hoffmann D, Hoffmann I. The changing cigarette, 1950-1995. J Toxicol Environ Health. 1997;50(4):307-64.

173. Jorgensen LN, Kallehave F, Christensen E, Siana JE, Gottrup F. Less collagen production in smokers. Surgery. 1998;123(4):450-5.

174. Zevin S, Gourlay SG, Benowitz NL. Clinical pharmacology of nicotine. Clin Dermatol. 1998;16(5):557-64.

175. Leow YH, Maibach HI. Cigarette smoking, cutaneous vasculature, and tissue oxygen. Clin Dermatol. 1998;16(5):579-84.

176. Porter SE, Hanley EN. The musculoskeletal effects of smoking. J Am Acad Orthop Surg. 2001;9(1):9-17.

177. Bain CA. Smoking and implant failure--benefits of a smoking cessation protocol. Int J Oral Maxillofac Implants. 1996;11(6):756-9.

178. Strietzel FP, Reichart PA, Kale A, Kulkarni M, Wegner B, Küchler I. Smoking interferes with the prognosis of dental implant treatment: a systematic review and meta-analysis. J Clin Periodontol. 2007;34(6):523-44.

179. Sverzut AT, Stabile GAV, de Moraes M, Mazzonetto R, Moreira RWF. The influence of tobacco on early dental implant failure. J Oral Maxillofac Surg. 2008;66(5):1004-9.

180. Anitua E, Orive G, Aguirre JJ, Ardanza B, Andía I. 5-year clinical experience with BTI dental implants: risk factors for implant failure. J Clin Periodontol. 2008;35(8):724-32.

181. Roos-Jansåker AM, Lindahl C, Renvert H, Renvert S. Nine- to fourteen-year follow-up of implant treatment. Part I: implant loss and associations to various factors. J Clin Periodontol. 2006;33(4):283-9.

182. Bain CA, Moy PK. The association between the failure of dental implants and cigarette smoking. Int J Oral Maxillofac Implants. 1993;8(6):609-15.

183. Wilson TG, Nunn M. The relationship between the interleukin-1 periodontal genotype and implant loss. Initial data. J Periodontol. 1999;70(7):724-9.

184. Lambert PM, Morris HF, Ochi S. The influence of smoking on 3-year clinical success of osseointegrated dental implants. Ann Periodontol. 2000;5(1):79-89.

185. Wallace RH. The relationship between cigarette smoking and dental implant failure. Eur J Prosthodont Restor Dent. 2000;8(3):103-6.

186. Gorman LM, Lambert PM, Morris HF, Ochi S, Winkler S. The effect of smoking on implant survival at second-stage surgery: DICRG Interim Report No. 5. Dental Implant CLinical Research Group. Implant Dent. 1994;3(3):165-8. 
187. Moy PK, Medina D, Shetty V, Aghaloo TL. Dental implant failure rates and associated risk factors. Int J Oral Maxillofac Implants. 2005;20(4):569-77.

188. Eckert SE, Choi Y-G, Sánchez AR, Koka S. Comparison of dental implant systems: quality of clinical evidence and prediction of 5-year survival. Int J Oral Maxillofac Implants. 2005;20(3):406-15.

189. Davarpanah M, Martinez H, Etienne D, Zabalegui I, Mattout P, Chiche F, et al. A prospective multicenter evaluation of 1,583 $3 \mathrm{i}$ implants: 1- to 5-year data. Int J Oral Maxillofac Implants. 2002;17(6):820-8.

190. Friberg B, Jemt T, Lekholm U. Early failures in 4,641 consecutively placed Brånemark dental implants: a study from stage 1 surgery to the connection of completed prostheses. Int J Oral Maxillofac Implants. 1991;6(2):142-6.

191. Jaffin RA, Berman CL. The excessive loss of Branemark fixtures in type IV bone: a 5-year analysis. J Periodontol. 1991;62(1):2-4.

192. Papaspyridakos P, Chen C-J, Chuang S-K, Weber H-P, Gallucci GO. A systematic review of biologic and technical complications with fixed implant rehabilitations for edentulous patients. Int J Oral Maxillofac Implants. 2012;27(1):102-10.

193. Vigolo P, Majzoub Z, Cordioli G. Measurement of the dimensions and abutment rotational freedom of gold-machined 3i UCLA-type abutments in the as-received condition, after casting with a noble metal alloy and porcelain firing. J Prosthet Dent. 2000;84(5):548-53.

194. Stüker RA, Teixeira ER, Beck JCP, da Costa NP. Preload and torque removal evaluation of three different abutment screws for single standing implant restorations. J Appl Oral Sci. 2008;16(1):55-8.

195. Johnsen SE, Svensson KG, Trulsson M. Forces applied by anterior and posterior teeth and roles of periodontal afferents during hold-and-split tasks in human subjects. Exp Brain Res. 2007;178(1):126-34.

196. Sato Y, Shindoi N, Hosokawa R, Tsuga K, Akagawa Y. Biomechanical effects of double or wide implants for single molar replacement in the posterior mandibular region. J Oral Rehabil. 2000;27(10):842-5.

197. Aboyoussef $\mathrm{H}$, Weiner S, Ehrenberg D. Effect of an antirotation resistance form on screw loosening for single implant-supported crowns. J Prosthet Dent. 2000;83(4):450-5.

198. Weiss El, Kozak D, Gross MD. Effect of repeated closures on opening torque values in seven abutment-implant systems. J Prosthet Dent. 2000;84(2):194-9.

199. Khraisat A, Hashimoto A, Nomura S, Miyakawa O. Effect of lateral cyclic loading on abutment screw loosening of an external hexagon implant system. J Prosthet Dent. 2004;91(4):326-34.

200. Tsuge T, Hagiwara Y. Influence of lateral-oblique cyclic loading on abutment screw loosening of internal and external hexagon implants. Dent Mater J. 2009;28(4):373-81. 
201. Petridis HP, Tsiggos N, Michail A, Kafantaris SN, Hatzikyriakos A, Kafantaris NM. Threedimensional positional changes of teeth adjacent to posterior edentulous spaces in relation to age at time of tooth loss and elapsed time. Eur J Prosthodont Restor Dent. 2010;18(2):78-83.

202. Craddock HL, Youngson CC, Manogue M, Blance A. Occlusal changes following posterior tooth loss in adults. Part 1: a study of clinical parameters associated with the extent and type of supraeruption in unopposed posterior teeth. J Prosthodont. 2007;16(6):485-94.

203. Winkler S, Ring K, Ring JD, Boberick KG. Implant screw mechanics and the settling effect: overview. J Oral Implantol. 2003;29(5):242-5.

204. Seghi RR, Denry IL, Rosenstiel SF. Relative fracture toughness and hardness of new dental ceramics. J Prosthet Dent. 1995;74(2):145-50.

205. Zarone F, Sorrentino R, Traini T, Di lorio D, Caputi S. Fracture resistance of implantsupported screw- versus cement-retained porcelain fused to metal single crowns: SEM fractographic analysis. Dent Mater. 2007;23(3):296-301.

206. Bassit R, Lindström H, Rangert B. In vivo registration of force development with ceramic and acrylic resin occlusal materials on implant-supported prostheses. Int J Oral Maxillofac Implants. 2002;17(1):17-23. 

9. GLOSARIO

DE

TÉRMINOS 
1

1,25(OH)2 vitamina D3 35

$\boldsymbol{A}$

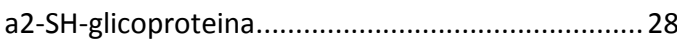

acido $\gamma$-carboxi-glutámico ......................................... 27

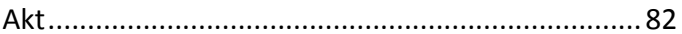

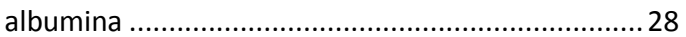

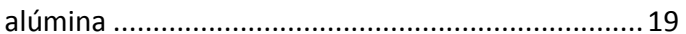

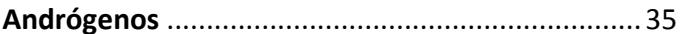

anhidrasa carbónica II ............................................. 25

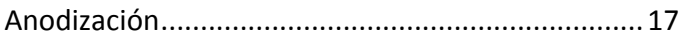

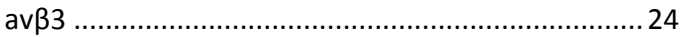

B

BIC (Bone Implant Contact)........................ 14, 43, 70

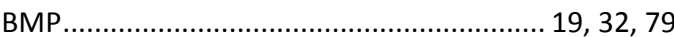

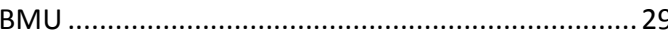

C

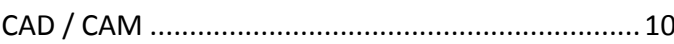

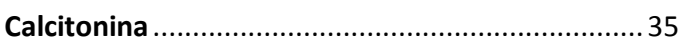

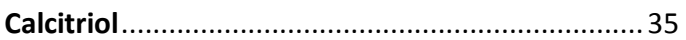

células C ....................................................... 35

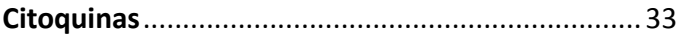

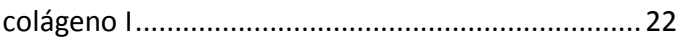

core-binding factor $a-1$............................................. 21

$\boldsymbol{E}$

efecto de asentamiento ......................................... 49

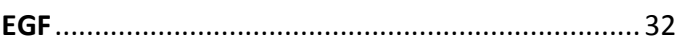

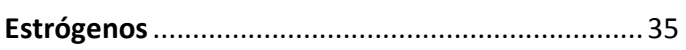

$\boldsymbol{F}$

factor estimulante de las colonias de macrófagos.. 25

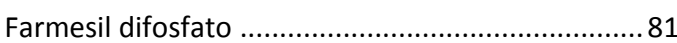

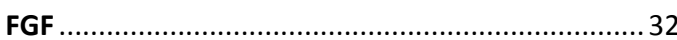

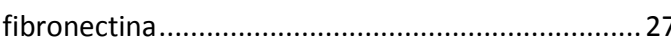

fosfatasa ácida tartrato resistente ........................... 24 fosfatasa alcalina

22,27

$\bar{G}$

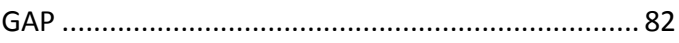

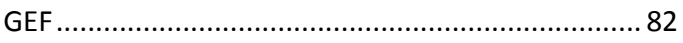

geranil-geranil difosfato......................................... 81

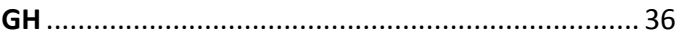

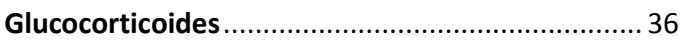

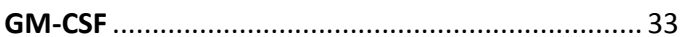

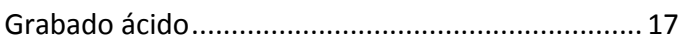

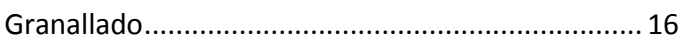

$\boldsymbol{H}$

Hedgehog ............................................................. 21

hidroxiapatita ...................................................... 43

HMG-CoA reductasa .................................................. 79

I

IGF

31

IGF-I...................................................... 30, 35, 36

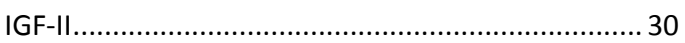

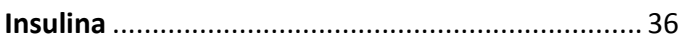

Interleuquina 1 .................................................... 33

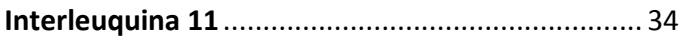

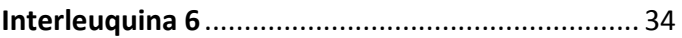

$L$

láser

18

$M$

MAPK

N

Nanotecnología 18 


\section{O}

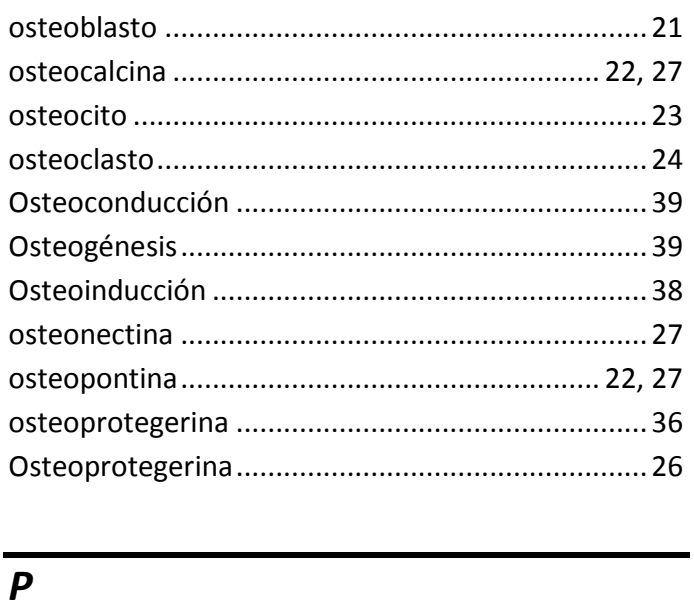

parathormona ..................................................... 35

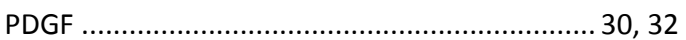

pequeñas GTPasas ................................................ 81

precarga .............................................................. 48

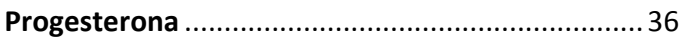

Prostaglandinas ..................................................... 34

Proteínas de la matriz ............................................... 33

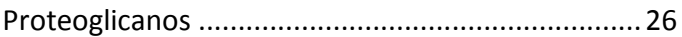

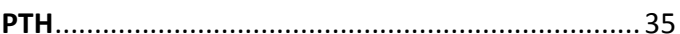

Pulverización de plasma........................................... 16

$\boldsymbol{R}$

RANK

. .26

RANKL

$26,35,82,83$

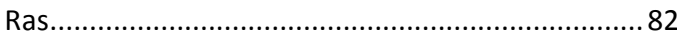

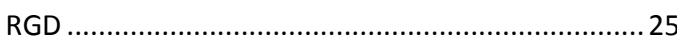

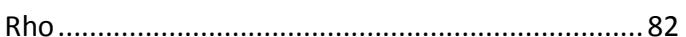

RTQ (Removal Torque) ........................................... 70

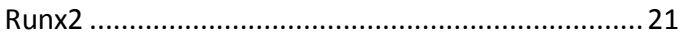

$S$

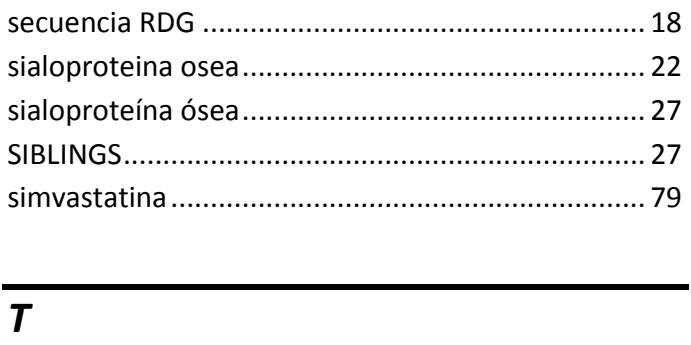

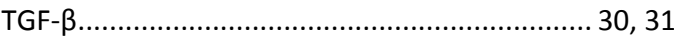

Ti-6Al-4V ................................................. 12

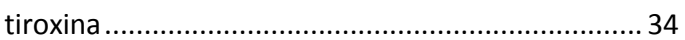

TNF ............................................................... 33

triyodotironina ................................................. 34

trombospondina ............................................... 27

$\boldsymbol{U}$

UCLA...................................................... 103

(Universal Castable Long Abutment).................. 46

Unidades Formadoras de Colonias de Granulocitos y

Macrofagos ...................................................... 24

V

VEGF.

32,83

vía Ras/Smad/erk/BMP-2 .............................. 80

vitronectina.................................................... 27

$\boldsymbol{\alpha}$

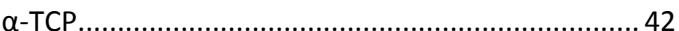

B

$\beta-$ TCP. 42 